\title{
Automatic Signature Verification: The State of the Art
}

\author{
Donato Impedovo and Giuseppe Pirlo, Member, IEEE
}

\begin{abstract}
In recent years, along with the extraordinary diffusion of the Internet and a growing need for personal verification in many daily applications, automatic signature verification is being considered with renewed interest. This paper presents the state of the art in automatic signature verification. It addresses the most valuable results obtained so far and highlights the most profitable directions of research to date. It includes a comprehensive bibliography of more than 300 selected references as an aid for researchers working in the field.
\end{abstract}

Index Terms-Biometry, personal verification, signature verification, system security.

\section{INTRODUCTION}

$\mathbf{T}$ HE SECURITY requirements of the today's society have placed biometrics at the center of a large debate, as it is becoming a key aspect in a multitude of applications [19], [262], [370]. The term biometrics refers to individual recognition based on a person's distinguishing characteristics. While other techniques use the possession of a token (i.e., badge, ID card, etc.) or the knowledge of something (i.e., a password, key phase, etc.) to perform personal recognition, biometric techniques offer the potential to use the inherent characteristics of the person to be recognized to perform this task. Thus, biometric attributes do not suffer from the disadvantages of either the token-based approaches, whose attributes can be lost or stolen, and knowledge-based approaches, whose attributes can be forgotten [137], [325].

A biometric system can either verify or identify. In verification mode, it authenticates the person's identity on the basis of his/her claimed identity. Instead, in identification mode, it establishes the person's identity (among those enrolled in a database) without the subjects having to claim their identity [139], [325]. Depending on the personal traits considered, two types of biometrics can be defined: physiological or behavioral. The former are based on the measurement of biological traits of users, like, for instance, fingerprint, face, hand geometry, retina, and iris. The latter consider behavioral traits of users, such as voice or handwritten signature [19], [139], [322], [325], [370].

The assessment of biometrics is a multifaceted problem [139], [326], [336]. For instance, a biometric trait should be universal,

Manuscript received March 2, 2007; revised August 3, 2007 and November 7, 2007. This paper was recommended by Associate Editor M. Last.

D. Impedovo is with the Dipartimento di Elettrotecnica ed Elettronica, Politecnico di Bari, Bari 70126, Italy and also with the Centro "Rete Puglia,” Università degli Studi di Bari, Bari 70124, Italy (e-mail: impedovo@ deemail.poliba.it).

G. Pirlo is with the Dipartimento di Informatica, Università degli Studi di Bari, Bari 70126, Italy and also with the Centro "Rete Puglia," Università degli Studi di Bari, Bari 70124, Italy (e-mail: pirlo@di.uniba.it).

Color versions of one or more of the figures in this paper are available online at http://ieeexplore.ieee.org.

Digital Object Identifier 10.1109/TSMCC.2008.923866

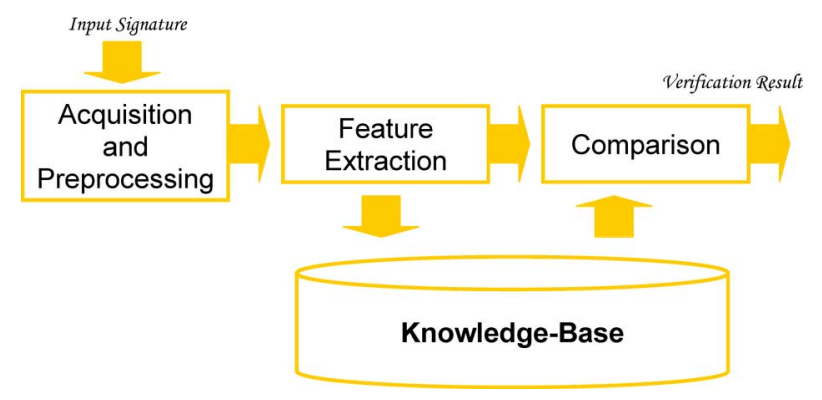

Fig. 1. Process of signature verification.

i.e., each person should possess the trait; unique, i.e., no two persons should share the same trait; permanent, i.e., the trait should neither change nor be alterable; collectable, i.e., the trait can be obtained easily. In addition, biometric system design should also address other desirable features such as accuracy, cost and speed effectiveness, acceptability by the users, and so on [127], [322].

Although a wide set of biometrics has been considered so far, it is worth noting that no trait is able to completely satisfy all the desirable characteristics required for a biometric system [137]. Thus, the assessment of a biometric trait is strongly dependent on the specific application since it involves not only technical issues but also social and cultural aspects [137], [322], [325].

Handwritten signatures occupy a very special place in this wide set of biometric traits [78], [81], [165], [248], [258]. This is mainly due to the fact that handwritten signatures have long been established as the most widespread means of personal verification. Signatures are generally recognized as a legal means of verifying an individual's identity by administrative and financial institutions [225], [336]. Moreover, verification by signature analysis requires no invasive measurements and people are familiar with the use of signatures in their daily life [259].

Unfortunately, a handwritten signature is the result of a complex process depending on the psychophysical state of the signer and the conditions under which the signature apposition process occurs. Therefore, although complex theories have been proposed to model the psychophysical mechanisms underlying handwriting [253]-[256] and the ink-depository processes [62], [99], [100], [101], signature verification still remains an open challenge since a signature is judged to be genuine or a forgery only on the basis of a few reference specimens [250]. Fig. 1 sketches the three main phases of automatic signature verification: data acquisition and preprocessing, feature extraction, and classification. During enrolment phase, the input signatures are processed and their personal features are extracted and stored into the knowledge base. During the classification phase, personal features extracted from an inputted signature are compared 
against the information in the knowledge base, in order to judge the authenticity of the inputted signature.

Automatic signature verification involves aspects from disciplines ranging from human anatomy to engineering, from neuroscience to computer science and system science [196]. Because of this fact, in recent years, studies on signature verification have attracted researchers from different fields, working for universities and companies, which are interested in not only the scientific challenges but also the valuable applications this field offers [229]. Comprehensive survey papers reported the progress in the field of automatic signature verification until 1993 [165], [258], [291]. In 1994, a special issue and a book collecting the most relevant research activities were published [251]. Successively, various papers have summarized the increasing research efforts in the field [52], [58], [224], [248], [280] also with respect to the more general area of handwriting analysis and processing [259].

In conjunction with the recent and extraordinary growth of the Internet, automatic signature verification is being considered with new interest. The creation of specific laws and regulations, which have been approved in many countries [173], [336], and the attention that several national associations and international institutes have given to the standardization of signature data interchange formats [10], [135], [136] are evidence of the renewed attention in this field. The aim of these efforts is to facilitate the integration of signature verification technologies into other standard equipment to form complete solutions for a wide range of commercial applications such as banking, insurance, health care, ID security, document management, e-commerce, and retail point-of-sale (POS) [78], [259], [320].

This paper presents the state of the art in automatic signature verification, with specific attention to the most recent advancements. Following an introduction of the phases of the signature verification process, the main contributions of research activities in recent years are described and the most promising trends are discussed. Specifically, Section II presents the main aspects related to data acquisition and preprocessing and Section III discusses the feature extraction phase. Section IV describes research activities concerning the classification phase while Section $\mathrm{V}$ summarizes the performance of systems for automatic signature verification reported in the literature. A brief discussion on the applications of automatic signature verification and the most promising research directions are reported in Section VI, along with the conclusions of this paper. A bibliography of more than 300 references is also provided for the more interested reader. It includes the most relevant papers recently published as well as some older papers, which can help give a comprehensive outline of developments in this field of research.

\section{DAtA ACQUisition AND PREPROCESSING}

On the basis of the data acquisition method, two categories of systems for handwritten signature verification can be identified: static (offline) systems and dynamic (online) systems [132]. Static systems use offline acquisition devices that perform data acquisition after the writing process has been completed. In this case, the signature is represented as a gray level image $\{S(x, y)\}_{0<x<X, 0<y<Y}$, where $S(x, y)$ denotes the gray level at the position $(x, y)$ of the image. Instead, dynamic systems use online acquisition devices that generate electronic

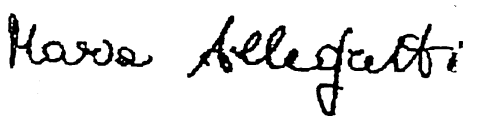

(a)

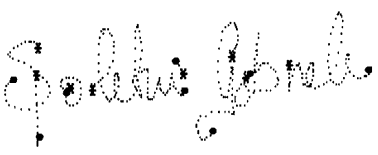

(b)

Fig. 2. Static/dynamic signatures. (a) Static signature. (b) Dynamic signature (“*”: pen-down; "•": pen-up).

signals representative of the signature during the writing process. In this case, the signature is represented as a sequence $\{S(n)\}_{n=0,1, N}$, where $S(n)$ is the signal value sampled at time $n \Delta t$ of the signing process $(0 \leq n \leq n), \Delta t$ being the sampling period. Therefore, the offline case involves the treatment of the spatioluminance of a signature image [see Fig. 2(a)], whereas the online case concerns the treatment of a spatiotemporal representation of the signature [see Fig. 2(b)].

The most traditional online acquisition devices are digitizing tablets [115]. Of course, the use of digitizing tablets is far from being natural and many attempts have been made to produce electronic pens that are more acceptable to users while being easy to integrate into current systems [121], [300], [314]. Electronic pens with touch-sensitive screens and digital-ink technologies that avoid signer disorientation by providing immediate feedback to the writer are good examples of such efforts [5], [6]. Electronic pens are also capable of detecting position, velocity, acceleration, pressure, pen inclination, and writing forces, with the use of strain gauges [46], magnetoelastic sensors [374], shift of resonance frequency [237], and laser diodes [300]. Some input devices use ink pen, which is exactly like using a conventional pen on standard paper positioned on the tablet. In this case, the pen produces conventional handwriting using ink, while producing an exact electronic replica of the actual handwriting. The advantage is the possibility to record online and offline data at the same time and to allow very natural writing since an almost standard pen and paper are used [106], [239]. In general, the development of the digitizing devices, ranging from the traditional table-based tablets to the recent handy digitizer tablets [158], personal digital assistant (PDA) [266], and input devices for mobile computing [5], [6], [72], [74], [261], poses new problems concerning device interoperability, that is, the capability of a verification system to adapt to the data obtained from different devices. One example of this is mouse-based signature verification that has been the object of specific research due to its relevance in Internet-based transactions [173], [313]. Other approaches capture handwriting by computer vision techniques. For instance, a special stylus conveying a small charge-coupled device (CCD) camera that captures a series of snapshots of the writing has been recently proposed [219]. The system recovers the whole handwritten trace by analyzing the sequence of successive snapshots. The stylus is also provided with a stress sensor for detecting the pressure applied on the ballpoint and determining the pen-up/pen-down information. There are also alternative approaches that do not require the use of a special stylus, and instead exploit a video camera that is focused 
TABLE I

Segmentation TeChNiqueS

\begin{tabular}{|l|c|l|}
\hline \multicolumn{1}{c}{ Technique } \\
\hline Segmentation by Pen-down/Pen-up Signals & Online & $\begin{array}{l}\text { G. Dimauro et al. [54, 56], Herbst and Liu [121], R. Plamondon [252], C. Schmidt and K.-F. } \\
\text { Kraiss [298], Y. Xuhua et al. [352, 353, 354] }\end{array}$ \\
\hline Segmentation by Velocity Signal Analysis & Online & H.Y. Kwon et al. [162], R. Plamondon et al [260] \\
\hline Segmentation by Perceptually relevant points. & Online & $\begin{array}{l}\text { J.J. Brault and R. Plamondon [21], M.M.Shafiei and H.R. Rabiee [299], K.W. Yue and W.S. } \\
\text { Wijesoma [369] }\end{array}$ \\
\hline Segmentation by Dynamic Time Warping & Online & $\begin{array}{l}\text { L. Bovino et al. [18], S. Chen and S. N. Srihari [33], V. Di Lecce et al. [50], G. Dimauro et al. } \\
\text { [55], J. Lee et al. [166], W.-S. Lee et al. [172], T.H. Rhee et al. [275] }\end{array}$ \\
\hline Segmentation by Connected Components & Offline & G. Congedo et al. [41], G. Dimauro et al. [57, 59] \\
\hline Segmentation by Tree Structure Analysis & Offline & M. Ammar et al [8] \\
\hline Segmentation by Statistics of Directional Data & Offline & K. Huang and H.Yan [127], R. Sabourin and R.Plamondon [287, 289] \\
\hline
\end{tabular}

on the user while writing on a piece of paper with a normal pen [24], [210], [355]. In this way, handwriting is recovered from the spatiotemporal representation given by the sequence of images. This approach can be the simplest way for a user to interact with the computer by using handwriting, and its potential has been specifically demonstrated in the domain of automatic signature verification [207], [209], [211]. In addition, a handglove device for virtual reality applications has been used for online signature verification [317]. This device can provide data on both the dynamics of the pen motion during signing and the individual's hand shape.

In the preprocessing phase, the enhancement of the input data is generally based on techniques originating from standard signal processing algorithms [242].

When static signatures are considered, typical preprocessing algorithms concern signature extraction [59], [61], noise removal by median filters [15], [17], [126] and morphological operators [126], [263], signature size normalization [17], [263], binarization [126], thinning [17], [359], and smearing [126], [283]. In this field, an important issue is the treatment of static signature images on bank checks, since bank check processing still remains an open challenge for the scientific community [59]. In fact, bank check images are very complex because they generally contain a color pictorial background, several logos, and many preprinted guidelines. Thus, the treatment of signature images extracted from the bank check is very difficult and the development of signature verification systems with the accuracy required of banks and other financial institutions is an area of continued research [39], [59], [60], [61], [171], [236], [367]. For this purpose, specific hybrid systems have been developed, which combine online and offline information for handwritten signature verification. The online reference signature, acquired through a digitizing tablet, serves for the preprocessing of the corresponding scanned offline signature image. This kind of hybrid system is well suited for a banking environment where the presence of the customer is needed to open a new account, but is unnecessary during the verification of signatures on checks and other documents [375], [376].

Typical preprocessing algorithms for dynamic signature verification involve filtering, noise reduction, and smoothing. For this purpose, Fourier transform [146], [147], [379], mathematical morphology [115], and Gaussian functions [37], [138], [180] have been used. Signature normalization procedures using global reference systems (center of mass and principal axes of inertia) [131] and Fourier transform [7], [146], [147], [149], [203], [273] have been considered to standardize signatures in the domain of position, size, orientation, and time duration.

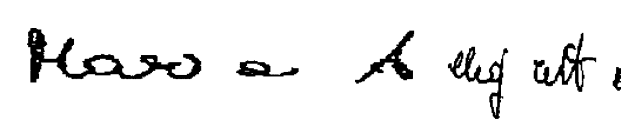

(a)

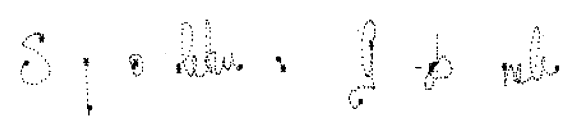

(b)

Fig. 3. Examples of signature segmentation. (a) Offline signature segmentation by connected components. (b) Online signature segmentation by components (“*”: pen-down; “•”: pen-up).

A crucial preprocessing step, that strongly influences all the successive phases of signature verification, is segmentation. Signature segmentation is a complex task since different signatures produced by the same writer can differ from each other due to local stretching, compression, omission or additional parts. Because of this, specific attention has been devoted to signature segmentation, and several techniques have been proposed. In general, some segmentation techniques derive from specific characteristics of handwritten signatures and reflect specific handwriting models [54], [56], [252], [260]. Other techniques provide segmentation results well suited for particular techniques used for signature verification [55], [172]. Table I reports some of the most relevant techniques for signature segmentation.

The simplest segmentation approaches for static signatures derive from structural descriptions. Some approaches perform structural analysis through the identification of connected components obtained by contour-following algorithms [41], [57], [59]. Fig. 3(a) shows the signature in Fig. 2(a) segmented into connected components. Other approaches describe a signature by a tree structure, obtained through the analysis of horizontal and vertical projection histograms, which identifies fundamental segments in the static image [8]. Offline signature segmentation by statistics of directional data has also been considered [287, 289]. This approach permits the extraction of textured regions that are characterized by local uniformity in the orientation of the gradient, evaluated with the Sobel operator.

Concerning dynamic signatures, some segmentation techniques have been derived directly from the acquired signals representative of the input signature. A widespread segmentation technique that uses pressure information is based on the consideration that the signature can be regarded as a sequence of writing units, delimited by abrupt interruptions [54], [56]; writing 


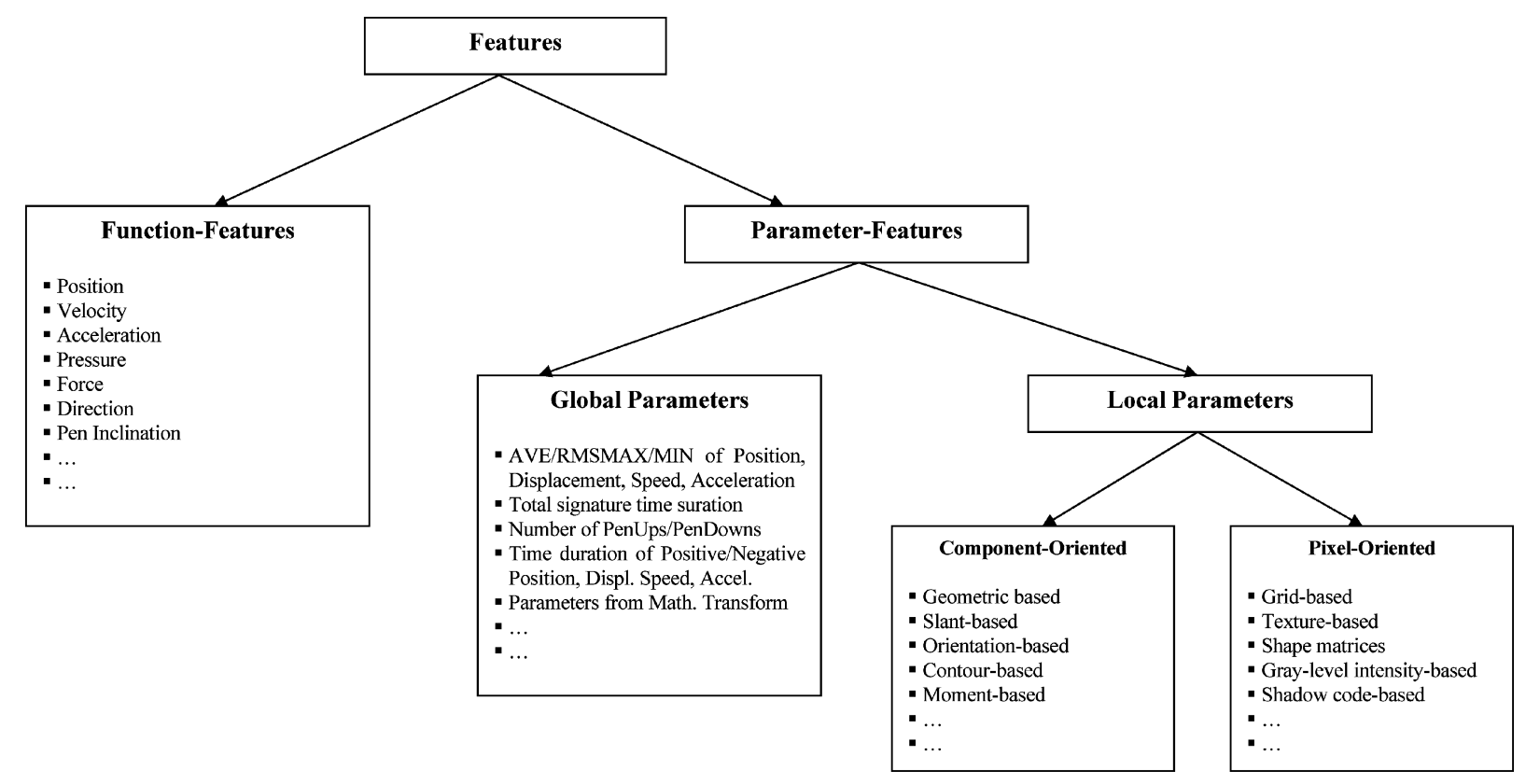

Fig. 4. Features categories.

units are the regular parts of the signature, while interruptions are the singularities of the signature. Thus, pen-up/pen-down signals are used to segment a signature into components, where each component is a piece of the written trace between a pendown and a pen-up movement [54], [56], [121], [252], [298]. Furthermore, only a finite set of components can be generated by each writer, as demonstrated by the experimental evidence that singularities can occur only in definite positions in the signature of an individual [56]. Fig. 3(b) shows the signature of Fig. 2(b) segmented into components. Other approaches exclusively use pen-up strokes for signature verification, since pen-up strokes can be memorized by the computer but are invisible to humans. Hence, possibility of imitating these strokes deliberately is low [352]-[354].

Other segmentation techniques use curvilinear and angular velocity signals [260]. In other cases, signature segmentation is performed by the analysis of the velocity signals, also using static features, when necessary [162].

A different segmentation technique is based on the detection of perceptually important points of a signature [21]. The importance of a point depends on the change of the writing angle between the selected point and the neighbor. A modified version of this technique considers the end points of pen-down strokes as significant splitting points [299]. Other approaches use perceptually important points for segmenting signatures while consider the evolutionary-distance measure, based on arc length distance, for segment association [369].

In order to allow the segmentation of two or more signatures into the same number of perfectly corresponding segments, dynamic time warping (DTW) has been widely used for signature segmentation [55], [166], [172], [275]. After the splitting of a first signature, according to uniform spatial criteria [172] or the position of geometric extremes [55], [166], DTW is applied to determine the corresponding set of points on other specimens. A model-guided segmentation technique has also been proposed [275]. This uses DTW to segment an input signature according to its correspondence with the reference model.

\section{FEATURE EXTRACTION}

As shown in Fig. 4, two types of features can be used for signature verification: functions or parameters. When function features are used, the signature is usually characterized in terms of a time function whose values constitute the feature set. When parameter features are used, the signature is characterized as a vector of elements, each one representative of the value of a feature. In general, function features allow better performance than parameters, but they usually require time-consuming procedures for matching [258]. Furthermore, parameters are generally classified into two main categories: global and local. Global parameters concern the whole signature; typical global parameters are total time duration of a signature, number of pen lifts, number of components, global orientation of the signature, coefficients obtained by mathematical transforms, etc. Local parameters concern features extracted from specific parts of the signature. Depending on the level of detail considered, local parameters can be divided into component-oriented parameters, which are extracted at the level of each component (i.e., height to width ratio of the stroke, relative positions of the strokes, stroke orientation, etc.), and pixel-oriented parameters, which are extracted at pixel level (i.e., grid-based information, pixel density, gray-level intensity, texture, etc.). It is worth noting that some parameters, which are generally considered to be global features, can also be applied locally, and vice versa. For instance, contour-based features can be extracted at global level (i.e., envelopes extracted at the level of the whole signature) or at local level (i.e., at the level of each connected component).

Table II presents some of the most common function features found in the literature. Position, velocity, and acceleration functions are widely used for online signature verification. Position 
TABLE II

FUNCTION FEATURES

\begin{tabular}{|c|c|c|}
\hline Functions & Category & References \\
\hline Position & Online / Offline & $\begin{array}{l}\text { G. Congedo et al. [40], J. Fierrez-Aguilar et al. [94], Y. Hongo et al. [122], Y. Kato et al. [150], Y. Komiya et al. } \\
\text { [159], S. Krawczyk and A. K. Jain [160], J. P. Leszcyska [177], Mizukami et al [199, 200], H. Morita et al. [205], } \\
\text { D.Muramatsu and T.Matsumoto [212, 213, 214], I. Nakanishi et al. [221, 222, 223], T. Ohishi et al. [233, 234, 235], } \\
\text { J. Ortega-Garcia et al. [238], J.D. Penagos at al [245], D. Sakamoto et al. [292, 293], Y. Sato and K. Kogure [296], } \\
\text { Q.-Z.Wu et al. [346] }\end{array}$ \\
\hline Velocity & Online & $\begin{array}{l}\text { A. I. Al-Shoshan [7], G. Congedo et al. [40], V. Di Lecce et al. [50, 51], M. Fuentes et al. [104], K. Huang and H. } \\
\text { Yan [129], A.K. Jain et al. [138], G.V. Kiran et al. [158], J. Ortega-Garcia et al. [238], J.D. Penagos at al [245], T. } \\
\text { Qu et al. [266, 267], C. Schmidt and K.-F. Kraiss [298], J. Sternby [312], Q.-Z.Wu et al. [346], K. Yu et al. [368], K. } \\
\text { Zhang et al. [372] }\end{array}$ \\
\hline Acceleration & Online & $\begin{array}{l}\text { G. Congedo et al. [40], N.M. Herbst and C.N.Liu [121], G.V. Kiran et al. [158], J.S.Lew [178, 179], J.D. Penagos } \\
\text { et al.[245], C. Schmidt and K.-F. Kraiss [298], A.F.Syukri et al. [313] }\end{array}$ \\
\hline Pressure & Online & $\begin{array}{l}\text { J. Fierrez-Aguilar et al. [94], Y. Hongo et al. [122], K. Huang and H. Yan [129], Y. Kato et al. [150], M. } \\
\text { Kawamoto et al. [151], Y. Komiya et al. [159], S. Krawczyk and A. K. Jain [160], H. Morita et al. [205], T. Ohishi } \\
\text { et al. [233, 234, 235], J. Ortega-Garcia et al. [238], J.D. Penagos at al [245], T. Qu et al. [266, 267], D. Sakamoto } \\
\text { et al. [292, 293], Y. Sato and K. Kogure [296], C. Schmidt and K.-F. Kraiss [298], J. Sternby [312], K. Tanabe } \\
\text { et al. [315], K. Yu et al. [368] }\end{array}$ \\
\hline Force & & H.D Crane and J.S. Ostrem [46], R. Martens and L. Claesen [187, 188, 189] \\
\hline $\begin{array}{l}\text { Direction of pen } \\
\text { movement }\end{array}$ & Online & $\begin{array}{l}\text { M. Fuentes et al. [104], J. J. Igarza et al. [130], I. Nakanishi et al. [222, 223], J. Ortega-Garcia et al. [239], I. } \\
\text { Yoshimura and M. Yoshimura [363], M. Yoshimura et al. [366] }\end{array}$ \\
\hline Pen inclination & Online & $\begin{array}{l}\text { J. J. Igarza et al. [130], Y. Kato et al. [150], M. Kawamoto et al. [151], Y. Komiya et al. [159], R. Martens and L. } \\
\text { Claesen [187, 188, 189], H. Morita at al. [205], T. Ohishi et al. [233, 234, 235], J. Ortega-Garcia et al. [238], D. } \\
\text { Sakamoto et al. [292, 293], J. Sternby [312], K. Yu et al. [368] }\end{array}$ \\
\hline
\end{tabular}

function is conveyed directly by the acquisition device whereas velocity and acceleration functions can be provided by both the acquisition device [121], [178] and numerically derived from position [40], [51], [346]. In recent years, pressure and force functions have been used frequently and specific devices have been developed to capture these functions directly during the signing process [46], [219], [235], [237], [300], [374]. In particular, pressure information, which can be registered with respect to various velocity bands, has been exploited for signature verification in order to take advantage of interfeature dependencies [154]. Furthermore, direction of pen movement [363], [366] and pen inclination [130], [151], [238] have also been successfully considered to improve the performance in online signature verification, whereas pen trajectory functions have been extracted from static signatures, in order to exploit the potential of dynamic information for offline signature verification as well [226]. Recent studies also demonstrate that signature verification can be successfully performed by means of "motif" series, which are characteristic subsequences extracted from function features [109].

In general, position, velocity, and pen inclination functions are considered among the most consistent features in online signature verification, when a distance-based consistency model is applied. This model starts from the consideration that the characteristics of a feature must also be estimated by using the distance measure associated to the feature itself [174].

Table III shows some parameter features that have been widely considered for automatic signature verification. Some parameters are specifically devoted to dynamic signature verification. This is the case of some global parameters that describe the signature apposition process, as the total signature time duration [146], [147], [170], [266], the pen-down time ratio [146], [147], [227], [335], and the number of pen lifts (pen-down, pen-up) [82], [166], [169], [170]. Other parameters are numerically derived from time functions representative of a signature, like, for instance, the average (AVE), the root mean square (rms), and the maximum (MAX) and minimum (MIN) values of position, displacement, speed, and acceleration [169], [170], [227]. In other cases, the parameters-that have been used for both dynamic and static signature verification-are determined as coefficients obtained from mathematical tools as Fourier [41], [54], [56], [57], [59], [194], [268], [345], [347], Hadamard [228], cosine [193], wavelet [49], [75], [76], [176], [189], [194], [195], [220], [274], [323], [332], [356], Radom [38], and fractal [127], [206] transforms.

Other parameters in Table III are more widely used for static signature verification, when dynamic information is not available. For example, typical local features extracted from a signature at the component level are geometric-based parameters, such as signature image area, signature height and width, length to width ratio, middle zone width to signature width radio, number of characteristic points (end points, cross-points, cusps, loops, etc.), and so on [8], [17], [290]. Other well-known parameters based on slant [8], [17], [59], [270], [301], orientation [290], contour [15], [26], [230], [231], [274], direction [66]-[68], [149], [282], [301], [350], and curvature [138], [145] have also been considered. Conversely, typical parameters extracted at pixel level are grid-based features. When grid-based parameters are used, the signature image is divided into rectangular regions and well-defined image characteristics, such as ink-distribution [17], [301] or normalized vector angle [185], are evaluated in each region. Grid features and global geometric features are used to build multiscale verification functions [263]-[265]. Texture features have also been extracted, based on the co-occurrence matrices of the signature image [17], shape matrices [283], and gray-level intensity features that provide useful pressure information [44], [126]. The extended shadow code has been considered as a feature vector to incorporate both local and global information into the verification decision [284]. A morphological shape descriptor used in signature verification is the pecstrum, which is computed by measuring the result of successive morphological openings of 
TABLE III

PARAMETER FEATURES

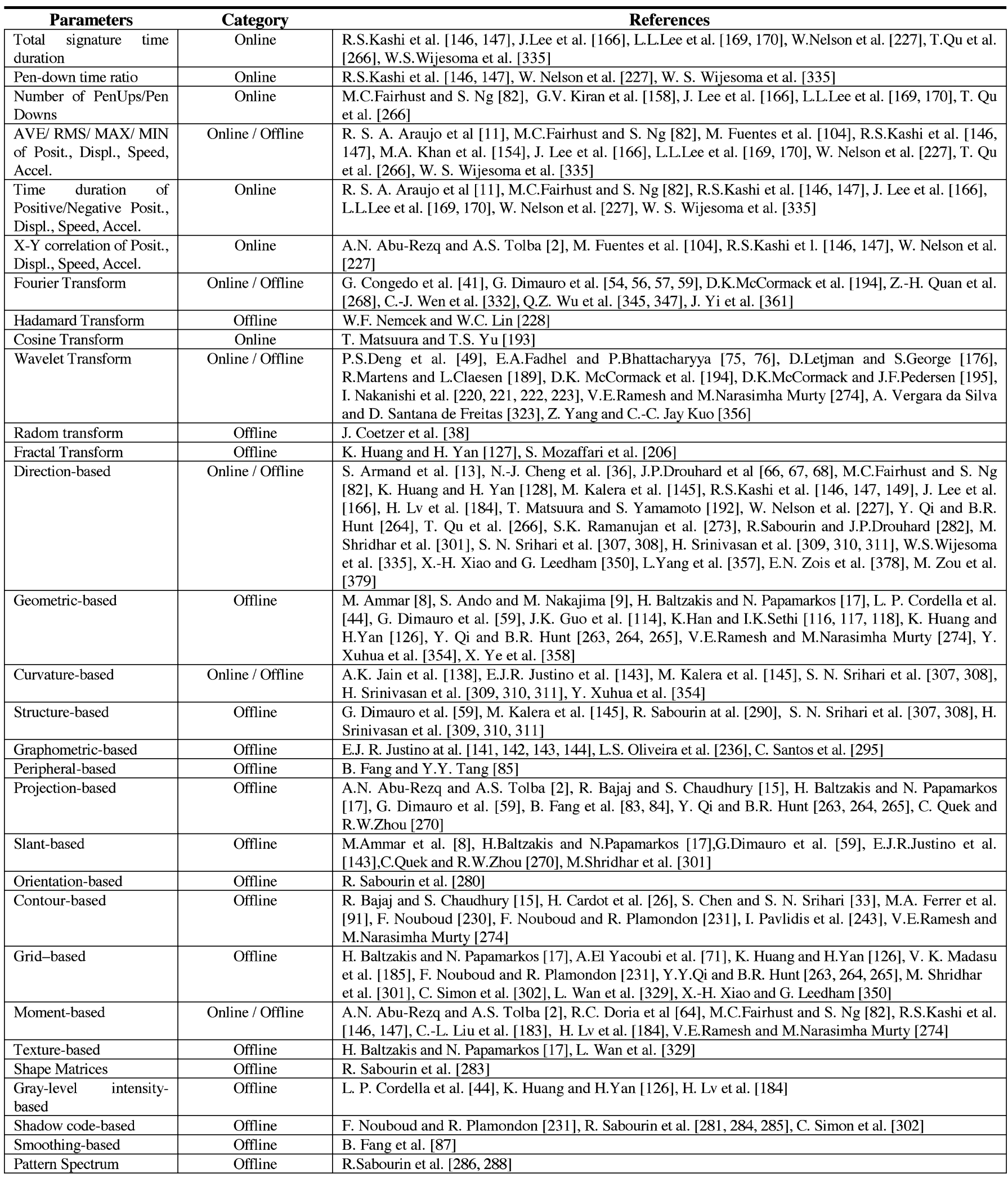




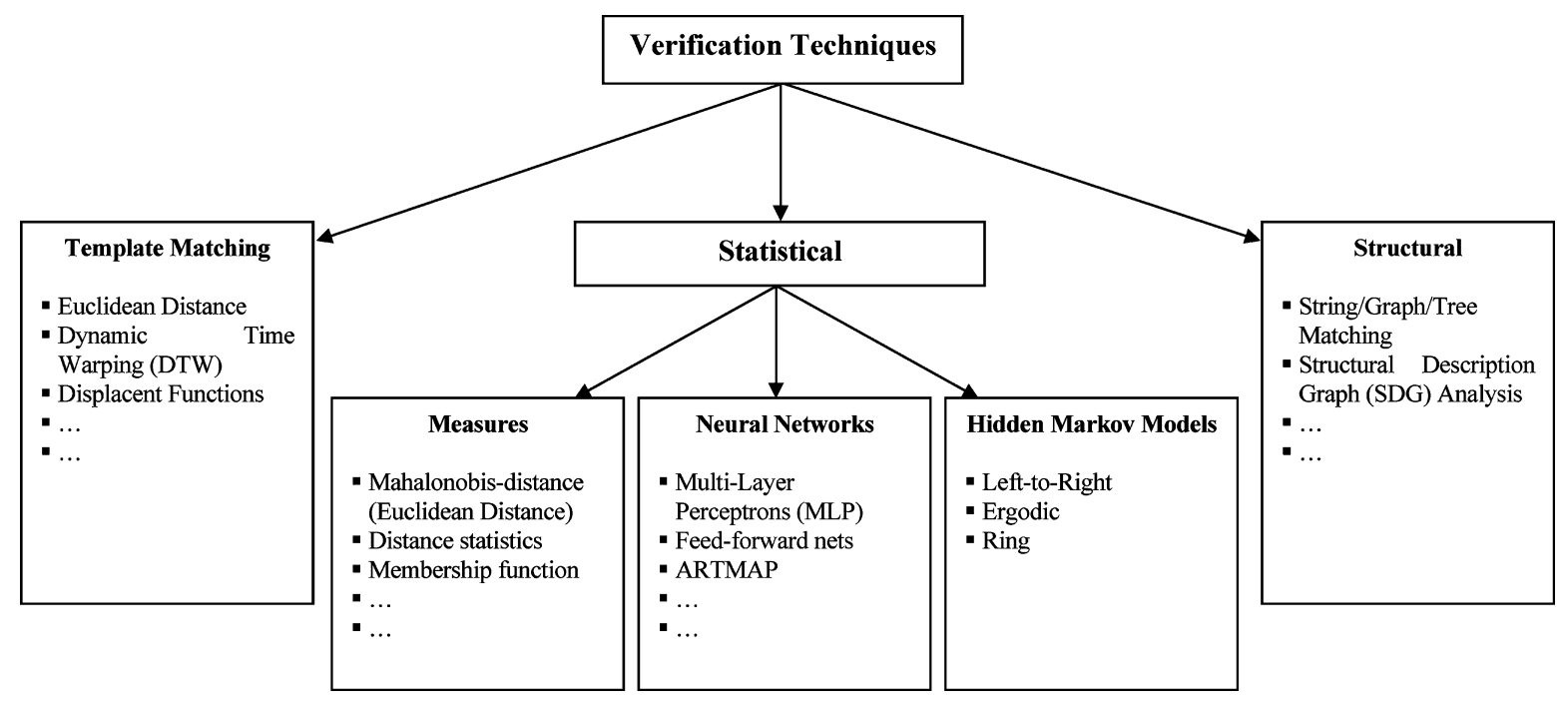

Fig. 5. Signature verification techniques.

the image, as the size of the structuring element increases [286]. The sequences of openings so obtained are called granulometries [288]. A smoothness index has been used for detecting skilled forgeries in offline signature verification. This technique was inspired by expert examiners who observed that well-forged signatures are generally less smooth on a detailed scale than the genuine ones [87]. According to an expert forensic approach [295], [304], graphometric-based parameters have also been considered, including static features (caliber, proportionality, etc.) and pseudodynamic features (apparent pressure, stroke curvature, and regularity) [141], [142], [144], [295]. Indeed, it is worth noting that research in automatic signature verification has been strongly influenced by the work of forensic document examiners, as discussed in some excellent papers [23], [99], [246], [305], [306]. For instance, starting from a static signature image, pseudodynamic features can be used to extract information on the dynamics of the underlying signing process. This is considered by forensic experts to be a fundamental aspect concerning the authorship of the sample in question [99], [101], [304]. In general, although not every feature analyzed by a forensic examiner can easily be represented as a parameter feature extracted by a computer program - and vice versa [246], [305], it is quite easy to find close relationships between many parameter features and some of the main features used by forensic experts [70], [99], [101], [236], [295], [303]-[305].

Whatever feature set is considered, the evidence that an individual's signature is unique has led many researchers to devote specific attention to the selection of the most suitable features for a signer. Indeed, signatures from different writers generally contain very few common characteristics, and thus, the use of a universally applied feature set is not effective. Feature selection in the domain of signature verification is also required because system efficiency, processing cost, and memory requirement are strictly dependent on the cardinality of the feature set [77], [80], [152], [276]. Therefore, the smaller the feature vector, the greater the number of individuals that can be enrolled in the system and the faster speeds that can be achieved in the verification process [77], [78]. In recent years, several techniques have been proposed for feature selection based on principal component analysis (PCA) and self-organizing feature maps [317], sequential forward search/sequential backward search (SFS/SBS) [80], inter-intra class distance radios (ICDRs) [82], and analysis of feature variability [227], [252]. Forgerybased feature analysis has also been proposed to select feature sets well suited for random and skilled forgery, respectively. This approach has been motivated by evidence that some features are best suited for distinguishing skilled forgeries from genuine signatures whereas other features are better at distinguishing random forgeries [275].

Other approaches use the same features set for each person and face the problem of personalized feature selection by assigning a different weight to each feature [157]. Neural networks (NNs) [168] and genetic algorithms (GAs) have been widely used for determining genetically optimized weighted parameters [274], as well as for selecting optimal functions [191], personalized parameters [334], [352]-[354], or signature strokes to be used for verification [325], [326].

\section{Classification}

In the verification process, the authenticity of the test signature is evaluated by matching its features against those stored in the knowledge base developed during the enrolment stage. This process produces a single response (Boolean value) that states the authenticity of the test signature. The verification process involves many critical aspects that ranges from the technique for signature matching to the strategy used for the development of the knowledge base.

Fig. 5 shows some of the most relevant approaches to signature verification, although blended solutions can be adopted in several cases. When template matching techniques are considered, a questioned sample is matched against templates of authentic/forgery signatures. In this case, the most common approaches use DTW for signature matching. When statistical approaches are used, distance-based classifiers can be considered. NNs have also been widely used for signature verification, due to their capabilities in learning and generalizing. More recently, special attention has been devoted to the use of hidden Markov 
models (HMMs) for both offline and online signature verification. Syntactic approaches are generally related to structural representations of signatures, which are described through their elementary elements (also called "primitives"), and compared through graph or three matching techniques.

The classification techniques most common in the literature are reported in Table IV. When functions are considered, the matching problem can be complicated by random variations, due to the writer's pauses or hesitations. These variations can create portions of signals, such as deletions, additions, and gaps, which complicate the problem of matching. DTW allows the compression or expansion of the time axis of two time sequences representative of the signatures to obtain the minimum of a given distance value [32], [177], [339], [363], [366], [373]. More precisely, let $T:\left(T_{1}, T_{2}, \ldots, T_{N_{T}}\right)$ and $R:\left(R_{1}, R_{2}, \ldots, R_{N_{R}}\right)$ be two online signatures, the DTW is used to determine the optimal warping function $W^{*}(T, R)$ minimizing a well-defined dissimilarity measure $D_{W(T, R)}=$ $\sum_{k=1}^{K} \mathrm{~d}\left(c_{k}\right)$, where $c_{k}=\left(i_{k}, j_{k}\right)\left(k, i_{k}, j_{k}\right.$ integers, $1 \leq k \leq$ $\left.K, 1 \leq i_{k} \leq N_{T}, 1 \leq j_{k} \leq N_{R}\right)$ and $\mathrm{d}\left(c_{k}\right)=\mathrm{d}\left(T_{i_{k}}, R_{j_{k}}\right)$ is a distance measure between the samples of $T$ and $R$. A detailed discussion on DTW, which was initially used in the field of speech processing, is beyond the aim of this paper and further information can be found in the literature [272].

In the field of automatic signature verification, although the superiority of DTW has not been proven with respect to other comparison techniques, such as regional correlation and skeletal tree matching [241], [249], DTW has been extensively used and continuous [207]-[209] and parallel [14] implementations have been investigated. In addition, several techniques for signature data reduction based on GAs [337], [338], PCA [155], [180], minor component analysis (MCA) [180], linear regression (LR) [175], polygonal approximation (PA) [337], [338], extreme points (EPs) [90], and random [337], [338] selection have been considered. Stroke-based DTW has also been investigated [339]. This process starts from the consideration that a comparison between the complete time sequences will not only result in higher computational load but also lead to a loss of the information related to the structural organization of the signatures. In order to avoid deformation of reference signatures when matched against test specimens, a well-suited form of asymmetric DTW was defined [186], [187], [189]. Other template matching approaches can use well-defined distortion measures [344], similarity measures [347], displacement functions [199], [200], relaxation matching [128], accumulated position and velocity distances based on split-and-merge mechanisms [346], fuzzy logic [185], and pattern matching [283], [318].

When parameters are used as features, statistical-based techniques are generally chosen. The most common approaches use Mahalanobis and Euclidean distances: Mahalanobis distance is used when the full covariance matrix is available for each signature class [85], [186], [188], [189], [268], [371]; Euclidean distance is considered when only the mean vector of the class is known [54], [56], [57], [273], [288], [295]. Membership functions [266] and other distance statistics [145], [310] have also been used.

NNs have been widely used for automatic signature verification for a long time, as [165] demonstrates. Table IV shows some of the NN models that have been used recently: Bayesian NNs [30], [351], multilayer perceptrons (MLPs) [7], [15], [17], [126], [167], [345], [350], time-delay NNs [22], [167], ARTMAP NNs [215]-[217], backpropagation neural networks (BPNs) [13], [15], [47], [66]-[68], self-organizing maps [1], [2], and radial basis functions (RBFs) [13], [109], [203], [232], [316]. Fuzzy NN, which combine the advantages of both NNs and fuzzy rule-based systems, has also been considered [102], [270], [353]. In order to improve effectiveness in using NNs, suitable transformed versions of signatures have been proposed and used for input [37]. A transform can reproduce a time-series pattern assuming a constant linear velocity to model the temporal characteristics of the signing process; another transform can map the signal onto a horizontal versus vertical velocity plane, where the variation of the velocities over time is represented as a visible shape. Instead, other approaches first modify the test signature to the template signature by dynamic programming (DP) matching, and then, use an NN to compare dynamic information along the matched points of the signatures [316]. Although NNs have demonstrated good capabilities in generalization [75], they require large amounts of learning data that are not always available [156]. To this purpose, the use of synthetically generated signatures has also been proposed [126].

Recently, intensive research has been devoted to HMMs. These models have found to be well suited for signature modeling since they are highly adaptable to personal variability [104], [190], [321], [357]. Strictly speaking, a HMM is a double stochastic approach in which one underlying yet unobservable process may be estimated through a set of processes that produce a sequence of observations. A comprehensive discussion on HMM is beyond the aim of this paper and can be found in the literature [271]. Concerning the field of signature verification, various HMM topologies have been considered so far, as Fig. 6 shows. Most approaches use the left-to-right HMM topology, since it is considered well suited for signature modeling [71], [91], [130], [146], [321], [333], [379]. Ergodic topology has also been considered for both online and offline signatures verification [269], [333]. Furthermore, in order to guarantee invariance to signature rotation, ring topology has been adopted, which is equivalent to left-to-right topology and a transition from the last state to the first state is allowed [38]. However, independent of the topology used, HMMs seem to be superior to other signature modeling techniques based on structural descriptions [128], [129] and fuzzy approaches [119], [185]. Some results have also demonstrated that HMM-based systems for offline signature verification can outperform human verifiers [39]. Furthermore, recent approaches use HMM in combination with autoregressive models while the signature is decomposed into pseudostationary segments and represented by a one-dimension spatial stochastic sequence [202]. The effect of interpersonal and intrapersonal variability on HMM has also been investigated [141], as well as the possibility of automatically and dynamically deriving various author-dependent parameters by cross-validation [71].

Support vector machines (SVMs) are another promising statistical approach to signature verification. An SVM is a new classification technique in the field of statistical learning theory and it has been successfully applied in many pattern recognition applications. An SVM can map input vectors to a higher dimensional space in which clusters may be determined by a maximal 
TABLE IV

COMPARISON TECHNIQUES

\begin{tabular}{|c|c|c|c|}
\hline \multicolumn{2}{|c|}{ Technique } & Category & References \\
\hline \multicolumn{2}{|c|}{ Euclidean Distance } & Online / Offline & $\begin{array}{l}\text { R. S. A. Araujo et al [11], G. Dimauro et al. [54, 56, 57], M.A. Ferrer et al. [91], M.A. Khan } \\
\text { et al. [154], S. Ramanujan et al. [273], R. Sabourin et al [288], C. Santos et al. [295], L. Wan } \\
\text { et al. [329] }\end{array}$ \\
\hline \multicolumn{2}{|c|}{ Mahalanobis Distance } & Online / Offline & $\begin{array}{l}\text { B. Fang et al. [85], S. Krawczyk and A. K. Jain [160], R. Martens and L. Claesen [186, 188, } \\
\text { 189], Z.-H. Quan et al. [268], K. Zhang et al. [371] }\end{array}$ \\
\hline \multicolumn{2}{|c|}{ Pattern Matching } & Offline & C.-C. Lien et al. [181], R. Sabourin et al. [283], K. Ueda [318] \\
\hline \multicolumn{2}{|c|}{ Membership functions } & Online & T. Qu et al. [266] \\
\hline \multicolumn{2}{|c|}{ Distance Statistics } & Offline & M. Kalera et al. [145], H. Srinivasan et al. [310] \\
\hline \multicolumn{2}{|c|}{ Dynamic Similarity Measure } & Online & Q. Z. Wu et al. [347] \\
\hline \multirow{11}{*}{$\begin{array}{l}\text { Dynamic } \\
\text { Time } \\
\text { Warping } \\
\text { (DTW) }\end{array}$} & Continuous & Online & $\begin{array}{l}\text { L. Bovino et al. [18], Y.Chen and X.Ding [32], G. Congedo et al. [40], V. Di Lecce et al. } \\
\text { [50, 51], G. Dimauro et al. [53, 55, 59], K. Huang and H. Yan [129], J.P. Leszcyska [177], } \\
\text { M.E. Munich and P. Perona [207, 208, 209], I.Yoshimura and M. Yoshimura [363], } \\
\text { M. Yoshimura et al. [366] }\end{array}$ \\
\hline & Parallel & Online & Y.J. Bae and M.C. Fairhurst [14] \\
\hline & GA-based & Online & M. Wirotius et al. $[337,338]$ \\
\hline & PCA-based & Online & A. Kholmatov and B. Yanikoglu [155], B.Li et al. [180] \\
\hline & MCA-based & Online & B.Li et al. $[180]$ \\
\hline & LR-based & Online & H. Lei et al. [175] \\
\hline & PA-based & Online & M. Wirotius et al. $[337,338]$ \\
\hline & EP-based & Online & H. Feng and C.C. Wah [90] \\
\hline & Random-based & Online & M. Wirotius et al. $[337,338]$ \\
\hline & Stoke-based & Online & B. Wirtz [339] \\
\hline & Asymmetric & Online & R. Martens and L.Claesen $[186,187,189]$ \\
\hline \multicolumn{2}{|c|}{ Dynamic Programming } & Online / Offline & $\begin{array}{l}\text { B. Fang et al. [83, 84], J. K. Guo et al. [114], J. Lee et al. [166], I. Nakanishi et al. [220], } \\
\text { F. Nouboud [230], F. Nouboud and R. Plamondon [231] }\end{array}$ \\
\hline \multicolumn{2}{|c|}{ Correlation } & Online & $\begin{array}{l}\text { J.B.Fasquel, M.Bruynooghe [88], K.K. Lau et al. [163], J.S. Lew [179], M.L. Molina et al. } \\
\text { [204], V. S. Nalwa [224], M. Perizeau and R. Plamondon [241], C.-J. Wen et al. [332] }\end{array}$ \\
\hline \multicolumn{2}{|c|}{ Relaxation Matching } & Offline & K. Huang and H. Yan [128], C.-F. Lin and C.-W. Chen [182] \\
\hline \multicolumn{2}{|c|}{ Bayesian approach } & Offline & D. Muramatsu at al. [212] \\
\hline \multicolumn{2}{|c|}{ Split-and-Merge } & Online & Q.Z. Wu et al. [346] \\
\hline \multicolumn{2}{|c|}{$\begin{array}{l}\text { String / Graph / Tree } \\
\text { Matching }\end{array}$} & Online / Offline & $\begin{array}{l}\text { Y. Chen and X. Ding [31], S. Chen and S. N. Srihari [33, 34, 35], N.-J. Cheng et al. [36], } \\
\text { K. Han and I. K. Sethi [118], A. K. Jain et al [138], I. Pavlidis et al. [243, 244], M. Perizeau } \\
\text { and R. Plamondon [241], X.-H. Xiao and R.W. Dai [349] }\end{array}$ \\
\hline \multicolumn{2}{|c|}{ Structural Description Graph } & Online/Offline & L. Bovino et al. [18], G. Dimauro et al. [56], K. Huang and H.Yan [129] \\
\hline \multicolumn{2}{|c|}{ Displacement Function } & Offline & Y. Mizukami et al. $[199,200]$ \\
\hline \multicolumn{2}{|c|}{ Fuzzy Logic } & Offline & $\begin{array}{l}\text { M. Hanmandlu et al. [120], V. K. Madasu et al. [185], W. S. Wijesoma et al. [335], } \\
\text { K. Zhang et al. [372] }\end{array}$ \\
\hline $\begin{array}{l}\text { Support } \\
\text { (SVM) }\end{array}$ & Vector Machine & Online / Offline & $\begin{array}{l}\text { M.A. Ferrer et al. [91], M. Fuentes et al. [104], E. J.R. Justino et al. [143], A. Kholmatov and } \\
\text { B. Yanikoglu [155], H. Lv et al. [184], S.N. Srihari et al [308] }\end{array}$ \\
\hline \multirow{8}{*}{$\begin{array}{l}\text { Neural } \\
\text { Network } \\
(\mathrm{NN})\end{array}$} & Bayesian & Online / Offline & H.D.Chang et al. [30], X.-H.Xiao and G. Leedham [351] \\
\hline & $\begin{array}{l}\text { Multi-Layer } \\
\text { Perceptrons } \\
\text { (MLP) }\end{array}$ & Online / Offline & $\begin{array}{l}\text { A. I. Al-Shoshan [7], R. Bajaj and S. Chaudhury [15], H. Baltzakis and N. Papamarkos [17], } \\
\text { H. Cardot et al. [26, 27], L.P. Cordella et al. [44, 45], E. A. Fadhel and P. Bhattacharyya } \\
\text { [75], M. Fuentes et al. [104], K.Huang et al [123, 124, 125, 126], L. L. Lee [168], W.-S. Lee } \\
\text { et al. [172], C. Sansone and M. Vento [294], C. Santos et al. [295], Q.-Z. Wu et al. [343, } \\
\text { 344], X.-H. Xiao and G. Leedham [350] }\end{array}$ \\
\hline & Time-Delay & Online / Offline & J. Bromely et al. [22], L. L. Lee [167] \\
\hline & ARTMAP & Online / Offline & N.A. Murshed et al. $[215,216,217,199]$ \\
\hline & $\begin{array}{l}\text { Backpropagation } \\
\text { Network (BPN) }\end{array}$ & Online / Offline & $\begin{array}{l}\text { S. Armand et al. [13], R. Bajaj and S. Chaudhury [15], A.M. Darwish and G.A. Auda [47], } \\
\text { J.P.Drouhard et al. [66, 67, 68], D.Z. Letjman and S.E. George [176], N.A. Murshed et al. } \\
\text { [218], R. Sabourin and J.P. Drouhard [282] }\end{array}$ \\
\hline & $\begin{array}{l}\text { Self-organizing } \\
\text { Map }\end{array}$ & Online / Offline & $\begin{array}{l}\text { A. Abu-Rezq and A.S. Tolba [1, 2], H. Cardot et al. [26, 27], A.S. Tolba [317], T. Wessels } \\
\text { and C.W. Omlin [333] }\end{array}$ \\
\hline & Fuzzy Nets & Online / Offline & $\begin{array}{l}\text { K. Franke et al. [102], C. Quek and R.W.Zhou [270], S. Watanabe et al. [330, 331], } \\
\text { Y. Xuhua et al. [353, 354] }\end{array}$ \\
\hline & $\begin{array}{l}\text { Radial } \quad \text { Basis } \\
\text { Functions (RBF) }\end{array}$ & Online / Offline & $\begin{array}{l}\text { S. Armand et al. [13], H. Baltzakis and N. Papamarkos [17], C. Gruber et al. [109], } \\
\text { M.L. Molina et al [203], N. F. O'Brien and S. C. Gustafson [232], M. Tanaka et al. [316] }\end{array}$ \\
\hline \multirow[t]{3}{*}{$\begin{array}{l}\text { Hidden } \\
\text { Markov } \\
\text { Models } \\
(\text { HMM) }\end{array}$} & $\begin{array}{l}\text { Left-to-right } \\
\text { topology }\end{array}$ & Online / Offline & $\begin{array}{l}\text { J.G.A. Dolfing et al. [63], A. El-Yacoubi et al. [71], M.A. Ferrer et al. [91], J. Fierrez-Aguilar } \\
\text { et al. [94, 96, 97], M. Fuentes et al. [104], J. J. Igarza et al [130, 131], E.J.R. Justino et al. } \\
\text { [141, 142, 143], R.S. Kashi et al. [146, 147], D.Muramatsu and T.Matsumoto, [213, 214], J. } \\
\text { Ortega-Garcia et al. [238], S.K. Ramanujan et al. [273], G.Rigoll and A. Kosmala [277], } \\
\text { M.M.Shafiei and H.R. Rabiee [299], B. Van et al. [321], T. Wessels and C.W. Omlin [333], } \\
\text { L. Yang et al. [357], H.S. Yoon et al. [362], M. Zou et al. [379] }\end{array}$ \\
\hline & Ergodic topology & Online / Offline & Z. -H. Quan and K.-H. Liu [269], T. Wessels and C.W. Omlin [333] \\
\hline & Ring topology & Offline & J. Coetzer et al. [38] \\
\hline
\end{tabular}




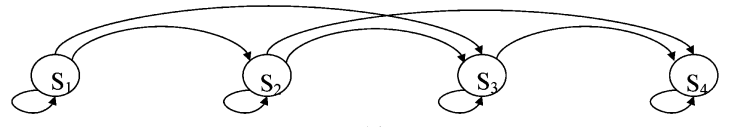

(a)

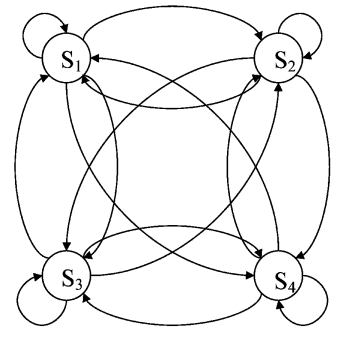

(b)

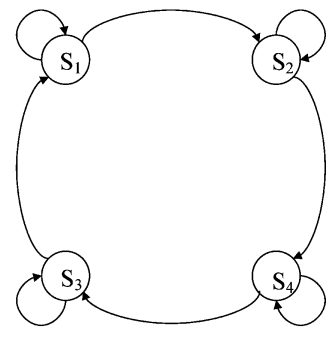

(c)
Fig. 6. HMM topologies. (a) Left-to-right. (b) Ergodic. (c) Ring.

separating hyperplane [25]. SVMs have been used successfully in both offline [91], [143], [184] and online [104], [155] signature verification.

Structural approaches mainly concern string, graph, and tree matching techniques and are generally used in combination with other techniques. For instance, string matching [31], [349] is used not only for signature verification but also for signature identification purposes, via advanced local associative indexing [118]. In other cases, the structural description graph is used to verify the structural organization of a questioned signature [18], [56], [129], as Fig. 7 illustrates.

In recent years, multiexpert (ME) approaches have been investigated to improve signature verification performance. For this purpose, serial [55], [161], [294], [371], parallel [59], [265], or hybrid strategies [44], [45] have been used and well-defined techniques for reliability estimation have been adopted [43]. Among the others, hybrid combination strategies seem to be particularly suited for signature verification since they attempt to achieve the performance advantages of serial approaches in fast rejecting very poor forgeries while retaining the reliability of parallel combination schemes [44], [45].

Since an ME verification system should combine decisions from complementary signature verifiers, sets of verifiers based on global and local strategies [92], [95] and feature sets [123], [125], parameter features and function features [260], static and dynamic features [50], [51] have been used. Several decision combination schemes have been implemented, ranging from majority voting [4], [50], [51], [59], [274] to Borda count [12], from simple and weighted averaging [18] to Dempster-Shafer evidence theory [12] and NNs [15], [17], [26]. The boosting algorithm has been used to train and integrate different classifiers, for both verification of online [122] and offline [329] signatures.

In addition, ME approaches have been used for stroke-based signature verification in which the verification of a signature is performed by the analysis of its elements. Stroke-based signature verification can lead to lower error rates compared to global approaches, since a large amount of personal information is conveyed in specific parts of the signature and cannot be detected when the signature is viewed as a whole [8], [21], [54]-[57], [59], [126], [164], [278], [298]. Furthermore, the verification at stroke level can be performed by DTW [41], [50], [51], [55], also considering multiple function features for stroke representation (like position, velocity, and acceleration) in order to verify both the shape and dynamics of each part of the signature [18].

Along with the matching techniques, attention has been given to knowledge-base development also in relation to learning strategies [308], [310], [311] and signature modeling techniques [248], [308]. In particular, special attention has been given to writer-dependent learning strategies using only genuine specimens [156], [215], [216], [217], [328]. In this case, a first approach uses a single prototype of genuine signatures for each writer, and several techniques have been proposed for the development of the optimal average prototype for a signer, including shape and dynamic feature combination [298], time- and position-based averaging [340], or selecting the genuine specimen with the smallest average difference, when compared to the other true signatures available [156]. After the prototype has been determined, the decision threshold is generally defined on the basis of the difference values that can be determined from the genuine signatures [156]. A second approach uses a set of genuine signatures for reference. In this case, a crucial problem concerns the selection of the optimal subset of reference signatures, among the specimens available. When static signature verification is considered, the validity of the reference model has been evaluated according to specific quality criteria, as for instance, intraclass variability that should be as low as possible [3], [78], [79]. In dynamic signature verification, the selection of the best subset of reference signatures has been performed on the basis of the analysis of variance within samples [112] or by considering the stability regions in the signatures, determined by a well-defined analysis of local stability [40], [51]. The selection of the best subset of reference signatures can be avoided at the cost of using multiple models for signature verification [148], [197], [198]. Furthermore, knowledge-base development involves the problem of having a lack of sufficient reference data to characterize a given signature class, as is generally the case of many practical applications. Thus, specific research has been devoted to feature modeling [158], [279], also using regularization techniques that estimate the statistical significance of small-size training sets [85], [86], [276]. Other approaches propose the generation of additional training samples from the existing ones by convolutions [48], elastic matching [85], [86], and perturbations [126].

Finally, promising research has recently been devoted to the investigation of different type, complexity, and stability of signatures. These aspects have great theoretical and practical relevance since they highlight the large difference between humans and machines in perceiving, processing, and verifying signatures, while providing fundamental information for developing the next generation systems, with high adaptive capabilities. For instance, short signatures could convey less information than long signatures, resulting in less accurate verification results [20]. Similarly, people with common names could be more likely to share similar signatures with other individuals-at least concerning shape characteristics. In both cases, the system should be able to adapt itself to the characteristics of the enrolled individuals [278].

The complexity of a signature has been quantified by estimating the difficulty for its imitation, obtained as the result of the estimated difficulty in perceiving, preparing, and executing each stroke of the signature itself [20]. 


\begin{tabular}{|c|c|c|c|c|c|c|c|c|c|c|}
\hline & \multirow[t]{2}{*}{ Authentic Signatures } & \multicolumn{9}{|c|}{ Fundamental Components } \\
\hline & & $\mathbf{a}$ & b & c & $\mathbf{d}$ & e & f & $\mathbf{g}$ & $\mathbf{h}$ & $\mathbf{i}$ \\
\hline$S^{1}$ & 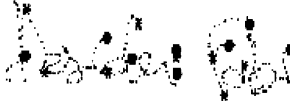 & 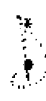 & $\vartheta_{6}$ & $\cdots$ & : & 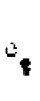 & & $\rightarrow$ & 4 & 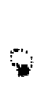 \\
\hline $\mathbf{S}^{2}$ & 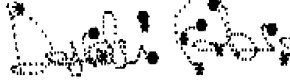 & & & \multicolumn{2}{|c|}{$\mathrm{H}$} & t & & $-*$ & 3 & 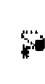 \\
\hline $\mathbf{S}^{3}$ & 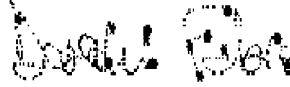 & & & & $\omega_{\infty}^{\infty}$ & * & & $* \bullet$ & क्ष & 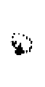 \\
\hline
\end{tabular}

(a)

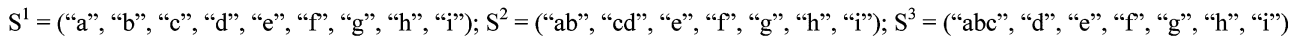

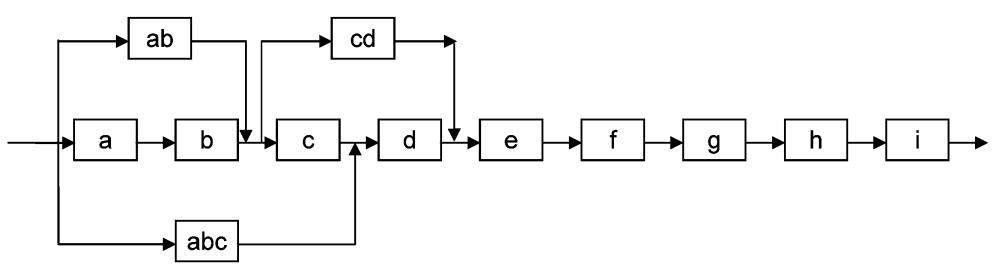

(b)

Fig. 7. Structural description of signatures. (a) Description of authentic signatures by components. (b) Structural description graph.

Concerning signature stability, a local stability function can be obtained by using DTW to match a genuine signature against other authentic specimens [42], [53], [129]. Each matching is used to identify the direct matching points (DMPs), which are unambiguously matched points of the genuine signature. Thus, a DMP can indicate the presence of a small stable region of the signature, since no significant distortion has been locally detected. More formally, let $T:\left(T_{1}, T_{2}, \ldots, T_{N_{T}}\right)$ be an authentic signature and $R^{i}:\left(R_{1}^{i}, R_{2}^{i}, \ldots, R_{N_{R_{i}}}^{i}\right), \quad i=1$, $2, \ldots, n$ be a set of $n$ additional genuine specimens. For each couple $\left(T, R^{i}\right), i=1,2, \ldots, n$, the optimal warping function $W^{*}\left(T, R^{i}\right)$ can be determined by means of DTW. From $W^{*}(T$, $R^{i}$ ), the DMP of $T$ with respect to $R^{i}$ are identified as the points of $T$ that have a one-to-one coupling with a point of $R^{i}$. In other words, let $T_{p}$ be a point of $T$ coupled with $R_{q}^{i}$ of $R^{i} ; T_{p}$ is DMP of $T$ with respect to $R^{i}$ if and only if:

1) $\forall \underline{p}=1, \ldots, N_{T}, \underline{p} \neq p$, it results that $T_{\underline{p}}$ is not coupled with $R_{q}^{i}$;

2) $\forall \underline{q}=1, \ldots, N_{R i}, \underline{q} \neq q$, it results that $R_{q}^{i}$ is not coupled with $T_{p}$.

A DMP indicates the existence of a small part of the signature $T$ that is roughly similar to the corresponding part of the signature $R^{i}$, in the domain specified by the distance used for the DTW. Therefore, for each sample of $T$, a score is introduced according to its type of coupling with respect to the points of $R^{i}$ [42], [53]: $\operatorname{Score}^{i}\left(T_{p}\right)=1$, if $T_{p}$ is a DMP; $\operatorname{Score}^{i}\left(T_{p}\right)=0$, otherwise. The local stability function of $T$ is defined as $I\left(T_{p}\right)=1 / n \sum_{i=1}^{n} \operatorname{Score}^{i}\left(T_{p}\right), p=1,2, \ldots, N_{T}$; hence, $I\left(T_{p}\right)$ $\in[0,1], p=1,2, \ldots, n$. Fig. 8 schematically shows a simple example in which the local stability of a short sequence $T$ is evaluated by considering the corresponding sequences $S^{i}, i=$ $1,2,3$.
Following this procedure, Fig. 9 shows the analysis of stability for an entire test signature [see Fig. 9(a)] and the identification of low- and high-stability regions. More precisely, from the consideration that the value of local stability can vary in the range $[0,1]$, low-stability regions are identified as those in which the value of local stability is lower than 0.5 , whereas the high-stability regions are identified as those in which the value of local stability is greater than or equal to 0.5 [see Fig. 9(b)].

Furthermore, when the analysis of local stability is used to measure short-term modifications-which depend on the psychological condition of the writer and on the writing conditions-it allows the selection of the best subset of reference signatures [40], [51] and the most effective feature functions for verification aims [51] while providing useful information to weight the verification decision obtained at the stroke level, according to the local stability analysis [53], [129]. Long-term modifications depend on the alteration of the physical writing system of the signer (arm and hand, etc.) as well as on the modification of the motor program in his/her brain. When these modifications are evaluated, useful information can be achieved for updating the reference signature model by including additional information from other new signatures, as they become available [278].

Other types of approaches estimate the stability of a set of common features and the physical characteristics of signatures which they are most related to, in order to obtain global information on signature repeatability that can be used to improve the verification systems [110], [111], [150]. In general, these approaches have shown that there is a set of features that remain stable over long periods, while there are other features that change significantly in time, as a function of signer age. This is the case of features 


\begin{tabular}{|c|c|c|}
\hline 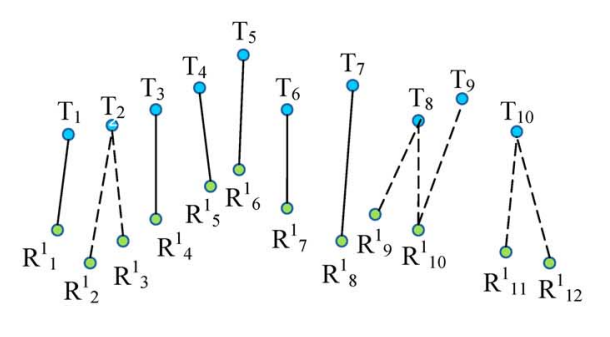 & 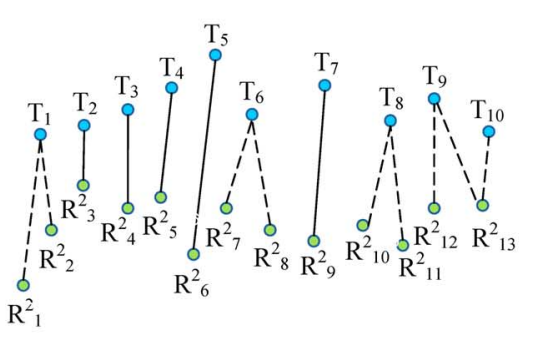 & 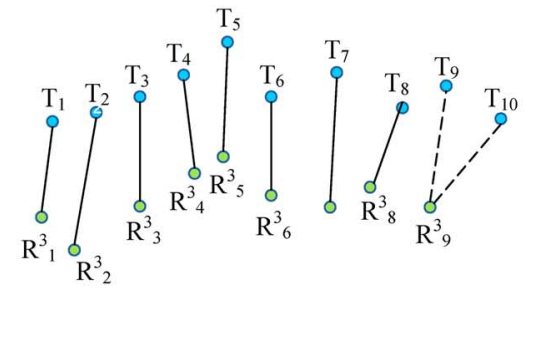 \\
\hline $\begin{array}{c}W^{*}\left(T, S^{1}\right)= \\
\left(T_{1}, R_{1}^{1}\right),\left(T_{2}, R_{2}^{1}\right),\left(T_{2}, R^{1}{ }_{3}\right),\left(T_{3}, R^{1}{ }_{4}\right),\left(T_{4}, R_{5}^{1}\right),\left(T_{5}, R_{6}^{1}\right),\left(T_{6}, R^{1}{ }_{7}\right), \\
\left(T_{7}, R_{8}^{1}\right),\left(T_{8}, R_{9}^{1}\right),\left(T_{8}, R_{10}^{1}\right),\left(T_{9}, R^{1}{ }_{10}\right),\left(T_{9}, R^{1}{ }_{10}\right),\left(T_{10}, R^{1}{ }_{11}\right),\left(T_{10}, R^{1}{ }_{12}\right)\end{array}$ & $\begin{array}{c}\mathrm{W}^{*}\left(\mathrm{~T}, \mathrm{~S}^{1}\right)= \\
\left(\mathrm{T}_{1}, \mathrm{R}^{2}\right),\left(\mathrm{T}_{1}, \mathrm{R}_{2}^{2}\right),\left(\mathrm{T}_{2}, \mathrm{R}_{3}^{2}\right),\left(\mathrm{T}_{4}, \mathrm{R}_{5}^{2}\right),\left(\mathrm{T}_{4}, \mathrm{R}_{5}^{2}\right),\left(\mathrm{T}_{5}, \mathrm{R}_{6}^{2}\right),\left(\mathrm{T}_{6},\right. \\
\left.\mathrm{R}_{7}^{2}\right),\left(\mathrm{T}_{6}, \mathrm{R}_{8}^{2}\right),\left(\mathrm{T}_{7}, \mathrm{R}^{2}{ }_{9}\right),\left(\mathrm{T}_{8}, \mathrm{R}^{2}{ }_{10}\right),\left(\mathrm{T}_{8}, \mathrm{R}^{2}{ }_{11}\right),\left(\mathrm{T}_{9}, \mathrm{R}^{2}{ }_{12}\right),\left(\mathrm{T}_{9},\right. \\
\left.\mathrm{R}_{13}^{2}\right),\left(\mathrm{T}_{10}, \mathrm{R}_{13}^{2}\right)\end{array}$ & 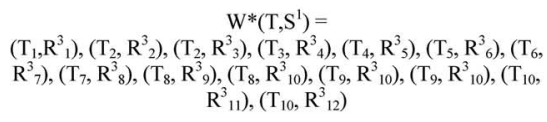 \\
\hline $\begin{array}{c}\mathrm{DMP}=\left\{\mathrm{T}_{1}, \mathrm{~T}_{3}, \mathrm{~T}_{4}, \mathrm{~T}_{5}, \mathrm{~T}_{6}, \mathrm{~T}_{7}\right\} \\
\text { (Direct Matching : continuous line) }\end{array}$ & $\begin{array}{c}\mathrm{DMP}=\left\{\mathrm{T}_{2}, \mathrm{~T}_{3}, \mathrm{~T}_{4}, \mathrm{~T}_{5}, \mathrm{~T}_{7}\right\} \\
\text { (Direct Matching : continuous line) }\end{array}$ & $\begin{array}{c}\text { DMP }=\left\{T_{1}, T_{2}, T_{3}, T_{4}, T_{5}, T_{6}, T_{7}, T_{8}\right\} \\
\text { (Direct Matching: continuous line) }\end{array}$ \\
\hline
\end{tabular}

(a)

\begin{tabular}{|c|c|c|c|c|c|c|c|c|c|c|}
\hline & \multicolumn{10}{|c|}{ Scores } \\
\hline & $\mathbf{T}_{\mathbf{1}}$ & $\mathbf{T}_{\mathbf{2}}$ & $\mathbf{T}_{\mathbf{3}}$ & $\mathbf{T}_{\mathbf{4}}$ & $\mathbf{T}_{\mathbf{5}}$ & $\mathbf{T}_{\mathbf{6}}$ & $\mathbf{T}_{\mathbf{7}}$ & $\mathbf{T}_{\mathbf{8}}$ & $\mathbf{T}_{\mathbf{9}}$ & $\mathbf{T}_{\mathbf{1 0}}$ \\
\hline Score $^{\mathbf{1}}(\cdot)$ & 1 & 0 & 1 & 1 & 1 & 1 & 1 & 0 & 0 & 0 \\
\hline Score $^{\mathbf{2}}(\cdot)$ & 0 & 1 & 1 & 1 & 1 & 0 & 1 & 0 & 0 & 0 \\
\hline Score $^{\mathbf{3}}(\cdot)$ & 1 & 1 & 1 & 1 & 1 & 1 & 1 & 1 & 0 & 0 \\
\hline Local Stability Value & $\mathbf{0 . 6 7}$ & $\mathbf{0 . 6 7}$ & $\mathbf{1}$ & $\mathbf{1}$ & $\mathbf{1}$ & $\mathbf{0 . 6 7}$ & $\mathbf{1}$ & $\mathbf{0 . 3 3}$ & $\mathbf{0}$ & $\mathbf{0}$ \\
\hline
\end{tabular}

(d) (c)

Fig. 8. Evaluating the local stability. (a) $T$ versus $S^{1}$ matching and DMPs. (b) $T$ versus $S^{2}$ matching and DMPs. (c) $T$ versus $S^{3}$ matching and DMPs. (d) Computing the local stability.

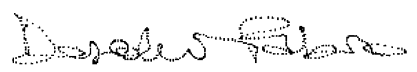

(a)

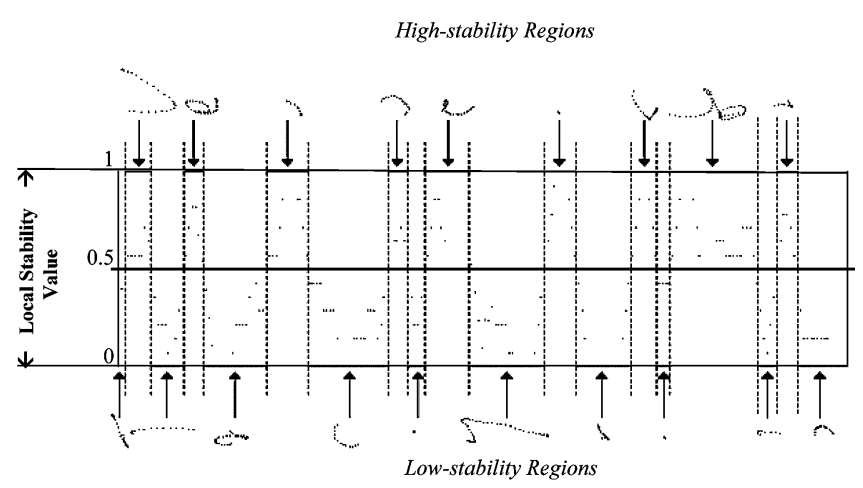

(b)

Fig. 9. Analysis of local stability. (a) Test signature. (b) Low- and highstability regions.

related to total execution time, velocity, and acceleration [110]. Since intersession variability is one of the most important causes of the deterioration of verification performances, specific parameter-updating approaches have been considered [150].

The enormous differences in the signatures of people from different countries have also required the development of specifically designed solutions. For instance, occidental-style

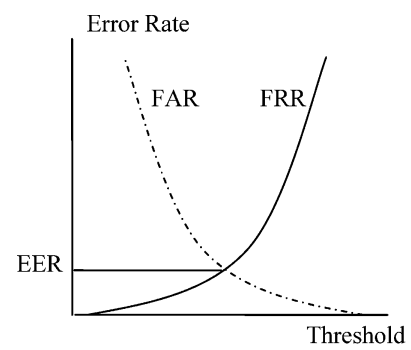

(a)

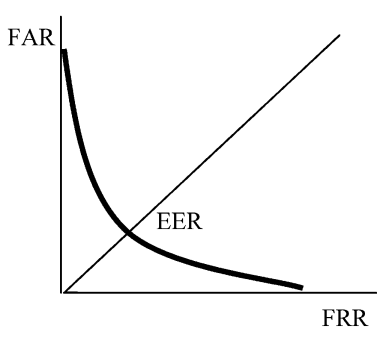

(b)
Fig. 10. Performance measures. (a) FAR and FRR. (b) ROC graph.

signatures generally consist of signs that could form concatenated text combined with pictorial strokes. In some countries, the habit is to sign with a readable written name whereas in other countries, signatures are not always legible. Many more differences can be expected when considering signatures written by people from non-Western countries. For this purpose, specific approaches have been proposed in the literature for Chinese [30], [36], [163], [182]-[184], [349] and Japanese [318], [364], [365], [367] signatures, which can consist of independent symbols, as well as Arabian/Persian [28], [29], [47], [134] signatures, which are cursive sketches usually independent of the person's name. In general, as the need for cross-cultural applications increases, it is becoming more and more important to evaluate both the extent to which personal background affects signature characteristics and the accuracy of the verification process. For this purpose, a set of metadata, sometimes also called "soft biometrics," is considered. Metadata concern 
various aspects of a writer background, such as nationality, script language, age, gender, handedness, etc. Some metadata can be estimated by statistically analyzing human handwriting, thus it is possible to adapt signature verification algorithms to the metadata context in order to improve verification performances [140], [297], [326], [342].

\section{Performance Evaluation}

Automatic signature verification can produce two types of errors: Type I errors concern the false rejections of genuine signatures [false rejection rate (FRR)]; Type II errors concern the false acceptance of forged signatures [false acceptance rate (FAR)]. Therefore, the performance of a signature verification system is generally estimated in terms of FRR and FAR [165], [248], [258]. Depending on the applications, a tradeoff between the two error types must be defined since any reduction of FAR increases FRR, and vice versa. In addition, the equal error rate (EER), which is defined as the system error rate when FRR = FAR, is widely considered to be a measure of the overall error of a system [see Fig. 10(a)] [341]. In other cases, the total error rate $\varepsilon_{t}$, which is defined as $\varepsilon_{t}=\left(\left(\right.\right.$ FRR $\left.\cdot P\left(\omega_{1}\right)\right)+($ FAR . $\left.P\left(\omega_{2}\right)\right)$-where $P\left(\omega_{1}\right)$ and $P\left(\omega_{2}\right)$ are the a priori probabilities of classes of genuine signatures $\left(\omega_{1}\right)$ and forgeries $\left(\omega_{2}\right)$, is used [281]- [283]. The receiver operating characteristic (ROC) curve analysis is also applied to FRR versus FAR evaluation since it shows the ability of a system to discriminate genuine signatures from forged ones [see Fig. 10(b)] [309], [311].

Unfortunately, the existence of skilled forgeries for a given signature is not certain, nor is the possibility of collecting good quality forgery samples for the test [201], [248]. Since signature forgeries are the results of a behavioral activity, they depend strongly on the type and amount of information provided to forger, as well as his/her training and effort [16]. Thus, the FAR evaluation is difficult and generally imprecise [259], [377]. The traditional method of handling this problem consists of considering different classes of forgeries [248]: random forgeries, in which the forger uses his own signature instead of the signature to be tested; simple forgeries, in which the forger makes no attempt to simulate or trace a genuine signature; and freehand or skilled forgeries, in which the forger tries and practices imitating as closely as possible the static and dynamic information of a genuine signature. Another attempt for grading of forgery quality considers the following four categories: [377]: accidental forgeries are those which use arbitrary nonauthentic writing samples against some other reference; blind attackers are when the forger only has a textual knowledge about the writing content; low-force forgeries occur when the forger is in possession of an offline representation of the signature image; and brut-force attackers are when the forger also has the opportunity to observe the dynamics of the writing process.

Tables V and VI summarize the characteristics of some of the most interesting signature verification systems presented in the literature for offline and online signatures, respectively. For each system, some additional information is briefly described in the following. A more detailed description can be found in the literature.

In Table V, Abu-Rezq and Tolba [2] used a neural approach for signature verification based on moment invariant features and projection-based features. Bajaj and Chaudhury [15] used different types of global features: projection based (horizontal and vertical projection) and contour based (upper and lower envelope). Classification was performed by feedforward NN classifiers whereas the classification decisions were combined by a simple-layer feedforward NN (ADALINE). The system of Baltzakis and Papamarkos [17] performed signature verification through global, grid, and texture features. In this case, the classification stage consisted of a two-stage neural scheme, based on RBF. The hybrid ME scheme proposed by Cordella et al. [44] was based on two stage cascaded classifiers. It used contour-based features at the first stage and gray-level features at the second, whereas classification was performed by MLP at each stage. In the multiresolution approach of Deng et al. [49], curvature data were decomposed into signals using wavelet transforms. A statistical measurement was used to systematically decide which closed contours, and the associated frequency data, of a writer are most stable and discriminating. Based on these data, the optimal threshold value, which controls the accuracy of the feature extraction process, was calculated. Projection-based, slant-based, and geometric-based features and Granlund descriptors (derived by Fourier transform) were used in the ME system of Dimauro et al. [59]. This system combined a wholistic approach based on a Euclidean distance classifier, a structural-based approach, and an NN-based approach, using an ARTMAP NN. The results from the three approaches were combined by a voting strategy. Drouhard et al. [68] used the directional probability density function (pdf) as a global shape factor and a BPN classifier for signature verification. Some experimental evidence demonstrated that BPN could give almost the same performance as a $k$-nearest neighbor classifier and was definitely superior to a threshold classifier. In the approach of ElYacoubi et al. [71], pixel density was considered to model offline signatures by HMM-LR. For each writer considered in the enrolment phase, the signer-dependent thresholds were dynamically and automatically derived. Wavelets were used by Fadhel and Bhattacharyya [76] for both data reduction and feature selection. The system proposed used global (wavelet based), statistical, and geometrical features and performed signature verification by a feedforward NN. Fang et al. [84] used vertical projectionbased features and DTW for signature matching. Fang and Tang [85] considered a set of peripheral features and a Mahalanobisdistance-based threshold classifier. They proposed two methods to face the sparse data problem in offline signature verification. The first one artificially generated additional training samples from the existing training set by an elastic matching technique. The second approach applied regularization technique to the sample covariance matrix. The experimental results showed that both techniques can significantly improve the verification performance. Geometric-based features extracted from contour and stroke analysis were used by Ferrer et al. [91]. Euclidean distance classifier, SVM, and HMM-LR were also considered for the verification of both random and simple forgeries. The experimental results indicated HMM superiority with respect to SVM and Euclidean distance classifiers. Huang and Yan [126] presented a system based on geometric features extracted under different scales. The overall match rating was generated by combining the decisions achieved at each scale, by an MLP. The statistical models of Huang and Yan [128] were constructed for pixel distribution and structural description. Both geometric 
TABLE V

PERFORMANCES: OFFLINE SYSTEMS

\begin{tabular}{|c|c|c|c|c|}
\hline Authors & Main features & Database & Approach & Results \\
\hline $\begin{array}{l}\text { A. N. Abu-Rezq and A. S. } \\
\text { Tolba [2] }\end{array}$ & $\begin{array}{l}\text { X-Y correlations, Projection- } \\
\text { based, Moment-based }\end{array}$ & \begin{tabular}{|l} 
Training) $100(\mathrm{G})(10(\mathrm{G}) \times 10(\mathrm{~A}))$ \\
Test) $60(\mathrm{G})(6(\mathrm{G}) \times 10(\mathrm{~A})$
\end{tabular} & $\mathrm{NN}$ & FRR: $3 \%$ (FAR : not estimated) \\
\hline $\begin{array}{l}\text { R. Bajaj and S. Chaudhury } \\
{[15]}\end{array}$ & $\begin{array}{l}\text { Projection based, Contour based } \\
\text { (envelope) }\end{array}$ & Test) $150(\mathrm{G}), 100(\mathrm{~F})$ & NN & FRR: $1 \%$, FAR: $3 \%$ \\
\hline $\begin{array}{l}\text { H. Baltzakis and N. } \\
\text { Papamarkos [17] }\end{array}$ & $\begin{array}{l}\text { Geometric-based, projection- } \\
\text { based, slant-based,grid-based, } \\
\text { texture-based }\end{array}$ & $\begin{array}{l}\text { Training) } 1500(\mathrm{~S})(\text { from } 115(\mathrm{~A})) \\
\text { Test) } 500(\mathrm{~S})\end{array}$ & NN (RBF) & FRR: $3 \%$, FAR: $9,81 \%$ \\
\hline L. P. Cordella et al. [44] & $\begin{array}{l}\text { Contour-based (projections of } \\
\text { the outline of the signature) } \\
\text { gray-level intensity-based }\end{array}$ & FD) $1960(\mathrm{~S})(20(\mathrm{G}), 20(\mathrm{~F})) \times 49(\mathrm{~A}))$ & $\begin{array}{l}\text { NN (MLP) (ME by Cascaded } \\
\text { Multiple Experts) }\end{array}$ & $\begin{array}{l}\text { FRR: } 2,04 \% \text {, FAR: } 0,01 \% \text { (RD), } \\
4,29 \% \text { (SP), 19,80 (SK) }\end{array}$ \\
\hline P. S Deng et al. [49] & Wavelet transform & $\begin{array}{l}\text { Training) } 500(\mathrm{G})(\text { from } 50(\mathrm{~A})) \\
\text { Test) } 500(\mathrm{G}), 2500(\mathrm{~F})\end{array}$ & DTW & $\begin{array}{l}\text { FRR: } 5,60 \% \text {,FAR: } 10,98 \% \text { (English } \\
\text { signatures) } \\
\text { FRR: } 6,00 \% \text {, FAR: } 7,80 \% \text { (Chinese } \\
\text { signatures) }\end{array}$ \\
\hline G. Dimauro et al. [59] & $\begin{array}{l}\text { Projection-based, Slant-based, } \\
\text { Geometric-based, Fourier } \\
\text { Transform (Granlund } \\
\text { descriptor) }\end{array}$ & $\begin{array}{l}\text { Training) } 225(\mathrm{G})(25(\mathrm{G}) \times 9(\mathrm{~A})) \\
\text { Test) } 450(\mathrm{G})(50(\mathrm{G}) \times 9(\mathrm{~A})), 450(\mathrm{RF}) \\
(50(\mathrm{RF}) \times 9(\mathrm{~A})), 90(\mathrm{SK})(10(\mathrm{SK}) \times 9(\mathrm{~A}))\end{array}$ & $\begin{array}{l}\text { Euclidean Distance, NN (ME } \\
\text { by Majority Vote) }\end{array}$ & $\begin{array}{l}\text { FRR: } 2 \% \text {, FAR: } 0,5 \% \text { (RF), } 3.9 \% \\
\text { (SK) } \\
\text { (with 22\% Rejection Rate) }\end{array}$ \\
\hline J.-P. Drouhard et al. [68] & Direction-based & \begin{tabular}{|l} 
Training) $400(\mathrm{~S})$ \\
Test) $400(\mathrm{~S})$
\end{tabular} & $\mathrm{NN}(\mathrm{BPN})$ & $\varepsilon_{\mathrm{t}}: 3,22 \%$ (with $\mathrm{P}\left(\omega_{1}\right)=\mathrm{P}\left(\omega_{2}\right)=0.5$ ) \\
\hline A.El Yacoubi et al. [71] & Grid-based (density of pixels) & $\begin{array}{l}\text { Training) } 1600 \text { (S) (from 40(A)) } \\
\text { Test) } 2400(\mathrm{~S})(\text { from } 60(\mathrm{~A}))\end{array}$ & HMM (Cross validation) & $\begin{array}{l}\text { FRR: } 0,75 \% \text {, FAR: } 0,18 \% \text { (on } \\
\text { training datasets) } \\
\text { FRR: } 1,17 \% \text {, FAR: } 0,64 \% \text { (on test } \\
\text { datasets) }\end{array}$ \\
\hline $\begin{array}{l}\text { E.A. Fadhel and P. } \\
\text { Bhattacharyya [76] }\end{array}$ & $\begin{array}{l}\text { Global (Wavelet-based), } \\
\text { statistical and geometrical }\end{array}$ & FD) $300(\mathrm{~S})($ from $31(\mathrm{~A}))$ & $\mathrm{NN}$ & FRR: $6,2 \%$, FAR: $5,5 \%$ \\
\hline B. Fang et al. [84] & Projection-based & $\begin{array}{l}\text { FD) } 1320(\mathrm{G})(\text { from } 55(\mathrm{~A})) \text {, } \\
1320(\mathrm{~F})(\text { from } 55(\mathrm{~A}))\end{array}$ & DTW & FRR: $22,1 \%$, FAR: $23,5 \%$ \\
\hline $\begin{array}{l}\text { B. Fang and Y.Y. Tang } \\
\text { [85] }\end{array}$ & Peripheral-based & Test) $1320(\mathrm{G}), 1320(\mathrm{~F})$ & Mahalanobis distance & EER: $11,4 \%$ \\
\hline M.A. Ferrer et al. [91] & Geometric-based & $\begin{array}{l}\text { FD) } 3840(\mathrm{G})(24(\mathrm{G}) \times 160(\mathrm{~A})), 4800(\mathrm{~F}) \\
(30(\mathrm{~F}) \times 160(\mathrm{~A}))\end{array}$ & $\begin{array}{l}\text { 1) Euclidean Distance, } \\
\text { 2) SVM, } \\
\text { 3) HMM }\end{array}$ & $\begin{array}{l}\text { 1) FRR: } 5.61 \% \text {, }(16.39 \%, \text { FAR: } \\
\text { 4.96\% }(15.50 \%) \text { on RF (SF) } \\
\text { 2) FRR: } 3.23 \%,(15.41 \%) \text { FAR: } \\
\text { 2.65\% }(13.12 \%) \text { on RF (SF) } \\
\text { 3) FRR: } 2.2 \%,(14.1 \%) \text { FAR: } 3.3 \% \\
(12.6 \%) \text { on RF (SF) }\end{array}$ \\
\hline K. Huang and H. Yan [126] & Geometric based, grid-based & Test) $504(\mathrm{G}), 3024(\mathrm{~F})$ & \begin{tabular}{|l|l} 
NN \\
\end{tabular} & FRR: $11,1 \%$, FAR: $11,8 \%$ \\
\hline K. Huang and H. Yan [128] & $\begin{array}{l}\text { Geometric-based, Direction } \\
\text { based }\end{array}$ & $\begin{array}{l}\text { Training) } 424(\mathrm{G}) \\
\text { Test) } 848(\mathrm{G}), 7632(\mathrm{~F})\end{array}$ & $\begin{array}{l}\mathrm{NN}, \text { Structural Matching (ME } \\
\text { by Relaxation match.) }\end{array}$ & FRR: $6,3 \%$, FAR: $8,2 \%$ \\
\hline E. J. R. Justino et al. [144] & Graphometric-based & $\begin{array}{l}\text { FD1) } 1600(\mathrm{~S})(40(\mathrm{~S}) \times 40(\mathrm{~A})) \\
\text { FD2) } 2400(\mathrm{~S})(40(\mathrm{~S}) \times 60(\mathrm{~A}))\end{array}$ & HMM (Cross validation) & $\begin{array}{l}\text { FRR: } 0.75 \% \text {, FAR: } 0.22 \%(\text { FD1 }) \\
\text { FRR: } 1 \% \text {, FAR: } 0.77 \%(\text { FD2 })\end{array}$ \\
\hline V. K. Madasu et al. [185] & $\begin{array}{l}\text { Grid-based (normalized vector } \\
\text { angle) }\end{array}$ & $\begin{array}{l}\text { Training) } 255(\mathrm{G})(17(\mathrm{G}) \times 5(\mathrm{~A})) \\
\text { Test) } 85(\mathrm{SF}), 85(\mathrm{RF}), 85(\mathrm{SK})\end{array}$ & Fuzzy logic modeling & FRR: $0 \%$, FAR: $3,5 \%$ \\
\hline Y. Mizukami et al. [199] & Position & FD) $400(\mathrm{~S})(200(\mathrm{G}), 200(\mathrm{~F}))$ & Displacement function & EER: $24,9 \%$ \\
\hline N. A. Murshed et al. [215] & Grid-based & FD) $200(\mathrm{~S})(40(\mathrm{~S}) \times 5(\mathrm{~A}))$ & \begin{tabular}{|l|l} 
NN (ARTMAP) \\
\end{tabular} & FRR: $7,27 \%$, FAR: $11 \%$ \\
\hline $\begin{array}{l}\text { V.E.Ramesh and } \\
\text { M.Narasimha Murty [274] }\end{array}$ & $\begin{array}{l}\text { Geometric-based, Moment- } \\
\text { based, Contour-based } \\
\text { (envelope), wavelet transform }\end{array}$ & $\begin{array}{l}\text { Training) 225(G) ((15(G) x15(A), } \\
\text { 195(F)(13(F) x15(A)) } \\
\text { Test) 75(G) }(5(\mathrm{G}) \times 15(\mathrm{~A})) \\
150(\mathrm{~F})(10(\mathrm{~F}) \times 15(\mathrm{~A}))\end{array}$ & $\begin{array}{l}\text { Confidence intervals, Minmax, } \\
\text { N-dim boundary, NN, Hybrid } \\
\text { approach }\end{array}$ & FRR: $10 \%$, FAR: $2 \%(\mathrm{SP})$ \\
\hline R. Sabourin et al. [281] & Shadow code-based & Test) $800(\mathrm{~S})(40(\mathrm{~S}) \times 20(\mathrm{~A}))$ & $\begin{array}{l}\text { Case a) } \mathrm{kNN} \text { classifier } \\
\text { Case b) min distance classifier }\end{array}$ & $\begin{array}{l}\text { (Case a) } \varepsilon_{\mathrm{t}}: 0,01 \%(\mathrm{k}=1) \text { (with } \\
\left.\mathrm{P}\left(\omega_{1}\right)=\mathrm{P}\left(\omega_{2}\right)=0.5\right) \\
\left(\text { Case b) } \varepsilon_{\mathrm{t}}: 0,87 \%(\mathrm{~N}=4) \text { (with }\right. \\
\left.\mathrm{P}\left(\omega_{1}\right)=\mathrm{P}\left(\omega_{2}\right)=0.5\right)\end{array}$ \\
\hline $\begin{array}{l}\text { R. Sabourin and J.-P } \\
\text { Drouhard [282] }\end{array}$ & $\begin{array}{l}\text { Direction based (Probability } \\
\text { Density Function - PDF) }\end{array}$ & $\begin{array}{l}\text { Training) } 400(\mathrm{~S}) \\
\text { Test) } 400(\mathrm{~S})\end{array}$ & $\mathrm{NN}$ & $\varepsilon_{\mathrm{t}}: 4,07 \%$ (with $\left.\mathrm{P}\left(\omega_{1}\right)=\mathrm{P}\left(\omega_{2}\right)=0.5\right)$ \\
\hline R. Sabourin et al. [283] & Shape Matrices & FD) $800(\mathrm{~S})($ from 20(A)) & Pattern Matching & $\varepsilon_{\mathrm{t}}: 0,84 \%$ \\
\hline C. Santos et al. [295] & Graphometric based & Test) $300(\mathrm{G}), 600(\mathrm{~F})$ & $\begin{array}{l}\text { Euclidean distance }+\mathrm{NN} \\
\text { (MLP) }\end{array}$ & $\begin{array}{l}\text { FRR: } 10,33 \% \\
\text { FAR:4,41\% (RD), } 1,67 \% \text { (SP), } \\
15,67 \% \text { (sim. forgeries) }\end{array}$ \\
\hline K. Ueda [318] & Pattern Image & Test) $1000(\mathrm{G}), 1000(\mathrm{~F})$ & Pattern Matching & EER: $9,1 \%$ \\
\hline $\begin{array}{l}\text { X.-H. Xiao and G. } \\
\text { Leedham [350] }\end{array}$ & Direction based, grid based & $\begin{array}{l}\text { Training) Genuine samples only (Case 1), } \\
\text { Genuine samples + artificial forgeries } \\
\text { (Case 2) } \\
\text { Test) } 350(\mathrm{G}), 158 \text { (SK), 230(RF) }\end{array}$ & NN (MLP) & $\begin{array}{l}\text { FRR: } 10.6 \%, \text { FAR: } 38.9 \%(\mathrm{SK}) \\
\text { (Case } 1) \\
\text { FRR: } 9.2 \% \text {, FAR: } 17 \% \text { (SK) (Case } \\
\text { 2) }\end{array}$ \\
\hline
\end{tabular}

features and directional frontier features were considered for signature description. The statistical verification algorithm used the geometric features and an MLP for signature verification. For questionable signatures where the pixel feature judgment was inconclusive, a structural matching algorithm was applied, using directional frontier features. Justino et al. [144] used HMM-LR with a density-based static feature and a pseudodynamic feature, based on axial slant. In the fuzzy-modeling approach proposed by Madasu et al. [185], a well-defined fuzzification function with structural parameters was used for signature verification. In this case, the signature image was partitioned into a fixed number of subimages by a grid-based approach and a normalized 
vector angle was considered as a feature, for each subimage. A Euclidean-distance-based functional approach was proposed by Mizukami et al. [199] for offline signature verification. A questioned signature was compared with a corresponding authentic one by evaluating the minimum of the functional. The signature was then accepted only if the measured dissimilarity was below a well-defined threshold. In the approach of Murshed et al. [215], the signature was first centered and successively divided into $m$ regions, through the use of an identity grid. In the verification stage, the grid-based information was fed to $m$ fuzzy ARTMAP networks, each of which was responsible for one region in the signature. A majority voting rule was used to provide a verification response for the whole signature. Ramesh and Narasimha Murty [274] used four different types of pattern representation schemes based on geometric features, moment-based representations, envelope characteristics, and wavelet features. The final decision on signature authenticity was achieved by combining the outputs of the four subsystems, according to a genetic approach. A $k$-nearest neighbor classifier and a minimum distance classifier were used by Sabourin et al. [281] for offline signature verification based on extended-shadow coding. Sabourin et al. used a feedforward NN classifier and the directional pdf, for random forgery detection [282]; whereas they used a similarity measure with shape matrices as a mixed shape factor for offline signature verification [283]. Santos et al. used MLP to verify offline signatures described by graphometric-based features. Pattern matching was investigated by Ueda [318] for offline signature verification. For this purpose, signature strokes were first thinned and then blurred by a fixed point-spread function. An MLP classifier was used by Xiao and Leedham [350] with both direction-based and grid features. A selective attention mechanism was proposed to deal with the intraclass variability between genuine signatures and the difficulty of collecting forgeries. For this purpose, the MLP classifier was forced to pay special attention to local stable parts of the signature by weighting their corresponding node responses through a feedback mechanism.

In Table VI, a stroke-oriented description of signatures well suited for an ME approach was discussed by Bovino et al. [18]. Each stroke was analyzed in the domain of position, velocity, and acceleration. Successively, a two-level scheme for decision combination was used. For each stroke, at the first level softand hard-combination rules were used to combine decisions from different representation domains. At the second level, simple and weighted averaging was used to combine decisions from different parts of the signature. Di Lecce et al. [50] performed signature verification by combining three experts. The first expert uses shape-based features and performed signature verification by a global analysis. The second and third expert used speed-based features and adopted a regional analysis. The combination of expert decisions was performed by a majority voting strategy. Igarza et al. [130] used a left-to-right HMM for online signature verification and verified its superiority with respect to ergodic HMMs. The superiority of PCA and MCA for online signature verification with respect to DTW and Euclidean-based verification was also investigated by Igarza et al. [131]. Jain et al. [138] used a set of local parameters - describing both spatial and temporal information. In the verification process, the test signature was compared to all signatures in the reference set. Three methods to combine the individual dissimilarity values into one value were investigated: the minimum of all dissimilarity values, the average of all dissimilarity values, and the maximum of all dissimilarity values. Furthermore, common and personalized (signer dependent) thresholds were also considered. The best results were achieved by considering the minimum of all dissimilarity values and the personalized threshold values. The online signature verification system proposed by Kashi et al. [146] used a Fourier-transform-based normalization technique and both global and local features for signature modeling. The global features captured spatial and temporal information of the signature whereas local features, extracted by a left-to-right HMM, captured the dynamics of the signature production process. The verification result was achieved by the combination of the information derived by global and local features. Lee et al. [166] performed signature segmentation by a DP technique based on geometric extrema. Segment matching was performed by global features and a DP approach. BPN integrating the global features approach and the DP matching results was used for signature verification. The scheme proposed by Morita et al. [205] used position, pressure, and inclination functions, whereas DTW was considered to compute a distance between the template and input signature, in the verification phase. Templates were generated from several authentic signatures of individuals, in order to improve verification performances. Maramatsu and Matsumoto [213] used HMM-LR incorporating signature trajectories for online signature verification. In the approach proposed by Nakanishi et al. [220], position signals of the online signature were decomposed into subband signals by using the discrete wavelet transform (DWT). Individual features were extracted as high-frequency signals in subbands. The total decision for verification was carried out by averaging the verification results achieved at each subband. Ortega-Garcia et al. [238] presented an investigation of HMMLR modeling capabilities of the signing process, based on a set of 24 function features (eight basic function features and their first and second derivatives). In the system of Shafiei and Rabiee [299], each signature was segmented using its perceptually important points. For each segment, four dynamic and three static parameters were extracted, which are scale and displacement invariant. HMM was used for signature verification. Wessels and Omlin [333] combined a Kohonen self-organizing feature map and a HMM. Both left-to-right and ergodic models were considered. Wijesoma et al. [335] considered two feature sets. The first set consisted of ten shape-related features while the second set consisted of 14 dynamics-related features. GAs were used to determine the optimal personalized features for each subject whereas verification decision was achieved by fuzzy logic. Fourier analysis was used by Wu et al. [347] for online signature verification. In particular, cepstrum coefficients were extracted and used for verification, according to a dynamic similarity measure. Geometric- and curvature-based features were used for the online signature verification discussed by Xuhua et al. [354]. Successively, a GA was used to select discriminative features and a fuzzy logic approach was applied for signature verification. Yang et al. [357] used directional features along with several HMM topologies for signature modeling. The results demonstrated that HMM-LR is superior to other topologies in capturing the individual features of the signatures and at the 
TABLE VI

PERFORMANCES: ONLINE SySTEMS

\begin{tabular}{|c|c|c|c|c|}
\hline Authors & Main features & Database & Approach & Results \\
\hline L. Bovino et al. [18] & Position, Velocity, Acceleration & \begin{tabular}{|l|} 
Training) $45(\mathrm{G})(3(\mathrm{G}) \times 15(\mathrm{~A}))$ \\
Test) $750(\mathrm{G})(50(\mathrm{G}) \times 15(\mathrm{~A})), 750(\mathrm{~F})(50(\mathrm{~F}) \times 15(\mathrm{~A}))$
\end{tabular} & $\begin{array}{l}\text { DTW (ME by } \\
\text { simple averaging) }\end{array}$ & EER: $0,4 \%$ \\
\hline V. Di Lecce et al. [50] & $\begin{array}{l}\text { Shape-based features } \\
\text { (segmentation dependent), } \\
\text { Velocity }\end{array}$ & $\begin{array}{l}\text { Training } 45(\mathrm{G})(3(\mathrm{G}) \times 15(\mathrm{~A})) \\
\text { Test) } 750(\mathrm{G})(50(\mathrm{G}) \times 15(\mathrm{~A})), 750(\mathrm{~F})(50(\mathrm{~F}) \times 15(\mathrm{~A}))\end{array}$ & $\begin{array}{l}\text { DTW (ME by } \\
\text { majority voting) }\end{array}$ & FRR: $3,2 \%$, FAR: $0.55 \%$ \\
\hline K. Huang and H. Yan [129] & Velocity, Pressure & FD) $4600(\mathrm{~S})$ & DTW & EER: $4 \%$ \\
\hline J. J. Igarza et al. [130] & Direction of pen movement, ... & FD) $3750(\mathrm{G})(25(\mathrm{G}) \times 150(\mathrm{~A})), 3750(\mathrm{~F})$ & HMM & EER: $9,253 \%$ \\
\hline A. K. Jain et al. [138] & Velocity, Curvature based. & FD) 1232 (S) (from $102(\mathrm{~A}))$ & String matching & $\begin{array}{l}\text { FRR: } 3,3 \% \text {, FAR: } 2,7 \% \\
\text { (common threshoold) } \\
\text { FRR: } 2,8 \% \text {, FAR: } 1,6 \% \text { (writer } \\
\text { dependent threshold) }\end{array}$ \\
\hline R. S. Kashi et al. [146] & $\begin{array}{l}\text { Total signature time duration, } \\
\text { X-Y (speed) correlation, RMS } \\
\text { speed, Moment-based, } \\
\text { direction-based, etc. }\end{array}$ & Test) $542(\mathrm{G}), 325(\mathrm{~F})$ & HMM & EER: $2,5 \%$ \\
\hline J. Lee et al. [166] & $\begin{array}{l}\text { Position (geometric extrema), } \\
\text { AVE velocity, number of pen- } \\
\text { ups, time duration of neg. /pos. } \\
\text { velocity, total signing time, } \\
\text { direction-based, ... }\end{array}$ & FD) 6790 (S) (from 271(A)) & $\mathrm{NN}+\mathrm{DP}$ & EER: $0.98 \%$ \\
\hline B. Li et al. [180] & Position, Velocity & $\begin{array}{l}\text { Training) } 405(\mathrm{G})(5(\mathrm{G}) \times 81(\mathrm{~A})) \\
\text { Test) } 405(\mathrm{G})(5(\mathrm{G}) \times 81(\mathrm{~A})), 405(\mathrm{~F})(5(\mathrm{~F}) \times 81(\mathrm{~A}))\end{array}$ & PCA, MCA & EER: $5,00 \%$ \\
\hline H. Morita et al. [205] & $\begin{array}{l}\text { Position, Pressure, Pen } \\
\text { Inclination }\end{array}$ & $\begin{array}{l}\text { Training) } 205(\mathrm{~S}) \\
\text { Test) } 861(\mathrm{G}), 1921(\mathrm{~F})\end{array}$ & DTW & EER: $3 \%$ \\
\hline $\begin{array}{l}\text { D. Muramatsu and } \\
\text { T. Matsumoto [213] }\end{array}$ & Direction of pen movements & $\begin{array}{l}\text { Training) } 165(\mathrm{G}) \\
\text { Test) } 1683(\mathrm{G}), 3170(\mathrm{SK}) \\
\end{array}$ & HMM & EER: $2,78 \%$ \\
\hline I. Nakanishi et al. [220] & Wavelet Transform. & $\begin{array}{l}\text { Training) } 20(\mathrm{G}) \text { from }(4(\mathrm{~A})) \\
\text { Test) } 98(\mathrm{G})(\text { from } 4(\mathrm{~A})), 200(\mathrm{~F})(\text { from } 5(\mathrm{~A}))\end{array}$ & $\begin{array}{l}\text { Dynamic } \\
\text { Programming }\end{array}$ & EER: $4 \%$ \\
\hline J. Ortega-Garcia et al. [238] & $\begin{array}{l}\text { Position, Velocity, Pressure, } \\
\text { Pen Inclination (Azimuth), } \\
\text { Direction of Pen Movement, ... }\end{array}$ & $\begin{array}{l}\text { Training) 300(G) (from 50(A)) } \\
\text { Test) (450 (G) (from 50(A)), } 750 \text { (SK) (from 50(A)) }\end{array}$ & HMM & $\begin{array}{l}\text { EER: } 1,21 \% \text { (global threshold) } \\
\text { EER: } 0,35 \% \text { (user-specific } \\
\text { threshold) }\end{array}$ \\
\hline T. Qu et al. [266] & $\begin{array}{l}\text { Total signature time, } \\
\text { AVE/RMS speed, pressure, } \\
\text { direction-based, number of pen- } \\
\text { ups/pen downs, ... } \\
\end{array}$ & Test) $60(\mathrm{G}), 60(\mathrm{~F})$ & $\begin{array}{l}\text { Membership } \\
\text { function }\end{array}$ & FRR: $6,67 \%$, FAR: $1,67 \%$ \\
\hline $\begin{array}{l}\text { M. M. Shafiei and H. R. } \\
\text { Rabiee [299] }\end{array}$ & $\begin{array}{l}\text { AVE Speed, acceleration, } \\
\text { pressure, Direction of Pen } \\
\text { movement,... }\end{array}$ & FD) 622 (G) (from 69(A)), 1010 (SK) & HMM & FRR: $12 \%$, FAR: $4 \%$ \\
\hline $\begin{array}{l}\text { T. Wessels and C.W. Omlin } \\
\text { [333] }\end{array}$ & $\begin{array}{l}\text { Position, Pressure, Direction of } \\
\text { pen movements, Pen } \\
\text { inclination. }\end{array}$ & $\begin{array}{l}\text { Training) } 750(\mathrm{G})(15(\mathrm{G}) \times 50(\mathrm{~A})) \\
\text { Test) } 750(\mathrm{G})(15(\mathrm{G}) \times 50(\mathrm{~A}))\end{array}$ & HMM & FAR: $13 \%$ \\
\hline W. S. Wijesoma et al. [335] & $\begin{array}{l}\text { RMS / MAX speed, } \\
\text { acceleration, Time duration of } \\
\text { Positive /Negative Velocity, } \\
\text { Pen-down time ratio, Direction- } \\
\text { based, ... }\end{array}$ & \begin{tabular}{|l} 
Training) 410(G) (10(G) x 41(A)) \\
Test) $820(\mathrm{G})(20(\mathrm{G}) \times 41(\mathrm{~A})), 410(\mathrm{~F})($ from $6(\mathrm{~A}))$
\end{tabular} & Fuzzy Logic & EER: $4,82 \%$ \\
\hline Q. Z. Wu et al. [347] & $\begin{array}{l}\text { Fourier transform (cepstrum } \\
\text { coefficients) }\end{array}$ & \begin{tabular}{|l|} 
Training) $270(\mathrm{G})($ from $27(\mathrm{~A}))$ \\
Test) $560(\mathrm{G})($ from $27(\mathrm{~A})), 650(\mathrm{~F})$
\end{tabular} & $\begin{array}{l}\text { Dynamic similarity } \\
\text { measure }\end{array}$ & FRR: $1,4 \%$, FAR: $2,8 \%$ \\
\hline Y. Xuhua et al. [354] & $\begin{array}{l}\text { Geometric-based, Curvature- } \\
\text { based,,... }\end{array}$ & $\begin{array}{l}\text { Training) } 45(\mathrm{G})(45(\mathrm{G}) \times 1(\mathrm{~A})), 45(\mathrm{~F})(\text { from } 19(\mathrm{~A})) \\
\text { Test) } 75(\mathrm{G})(75(\mathrm{G}) \times 1(\mathrm{~A})), 90(\mathrm{~F})(\text { from } 19(\mathrm{~A}))\end{array}$ & Fuzzy Logic & FRR: $8,5 \%$, FAR: $1,8 \%$ \\
\hline L. Yang et al. [357] & Direction of Pen movements & FD) $496(\mathrm{~S})$ (from $31(\mathrm{~A})$ & HMM & FRR: $1,75 \%$, FAR: $4,44 \%$ \\
\hline $\begin{array}{l}\text { D.-Y. Yeung et al. [360] }\left(1^{\text {st }}\right. \\
\text { Int. Signature Verification } \\
\text { Competition })\end{array}$ & $\begin{array}{l}\text { Task 1: Position; } \\
\text { Task 2: Position, Pen } \\
\text { Inclination (azimuth), } \\
\text { Pressure,... }\end{array}$ & $\begin{array}{l}\text { Training) } 800(\mathrm{G})(20(\mathrm{G}) \times 40(\mathrm{~A})), 800(\mathrm{SK})(20(\mathrm{SK}) \times 40(\mathrm{~A})) \\
\text { Test 1) } 600(\mathrm{G})(10(\mathrm{G}) \times 60(\mathrm{~A})), 1200(\mathrm{SK})(20(\mathrm{SK}) \times 60(\mathrm{~A})) \\
\text { Test 2) } 600(\mathrm{G})(10(\mathrm{G}) \times 60(\mathrm{~A})), 1200(\mathrm{RF})(20(\mathrm{RF}) \times 60(\mathrm{~A}))\end{array}$ & & $\begin{array}{l}\text { (Test 1) EER: 2,84\% (Task 1), } \\
\text { EER: } 2,89 \% \text { (Task 2) } \\
\text { (Test 2) EER: 2,79\% (Task 1), } \\
\text { EER: } 2,51 \% \text { (Task 2) } \\
\end{array}$ \\
\hline H.S. Yoon et al. [362] & Position & $\begin{array}{l}\text { Training) } 1500(\mathrm{~S})((15(\mathrm{~S}) \times 100(\mathrm{~A})) \\
\text { Test) } 500(\mathrm{~S})(5(\mathrm{~S}) \times 100(\mathrm{~A}))\end{array}$ & HMM & EER: $2,2 \%$ \\
\hline K. Zhang et al. [371] & $\begin{array}{l}\text { Geometric-based, Curvature- } \\
\text { based }\end{array}$ & FD) $306(\mathrm{G}), 302(\mathrm{~F})$ & \begin{tabular}{|l|} 
Mahalanobis \\
distance, Euclidean \\
Distance,DTW
\end{tabular} & FRR: $5,8 \%$, FAR: $0 \%$ \\
\hline M. Zou et al. [379] & $\begin{array}{l}\text { Speed, Pressure, Direction- } \\
\text { based, Fourier transform }\end{array}$ & FD) $1000(\mathrm{G}), 10000(\mathrm{~F})$ & $\begin{array}{l}\text { Membership } \\
\text { function }\end{array}$ & FRR: $11,30 \%$, FAR: $2,00 \%$ \\
\hline
\end{tabular}

Full Database (FD), Signature (S), Genuine Signatures (G), Forgeries (F), Random Forgeries (RF), Simple Forgeries (SF), Skilled Forgeries (SK), Number of Authors (A)

same time accepting variability in signing. Yeung et al. [360] reported the results of the First International Signature Verification Competitions (SVC2004), to which teams from all over the world participated. In particular, SVC2004 considered two separate signature verification tasks using two different signature databases. The signature data for the first task contained position information only, which was well suited for online signature verification on small pan-based input devices such as PDA. The signature data for the second task contained position, pen inclination, and pressure information that were well suited 
for applications based on digitizing tablets. A polar coordinate system was considered for signature representation by Yoon et al. [362] in order to reduce normalization error and computing time. Signature modeling and verification was performed by HMMs that demonstrated their ability to capture the local characteristics in the time-sequence data and their flexibility to model signature variability. The system presented by Zhang et al. [371] used global, local, and function features. The first verification stage implemented a parameter-based method, in which the Mahalanobis distance was used as a dissimilarity measure between the signatures. The second verification stage involved corner extraction and corner matching. It also performed signature segmentation. The third verification stage used an elastic matching algorithm establishing a point-to-point correspondence between the compared signatures. By combining the three different types of verification, a high security level was reached. Zou et al. [379] used local shape analysis for online signature verification. More precisely, Fast Fourier Transform (FTT) was used to derive spectral and tremor features from well-defined segments of the signature. A weighted distance was finally considered to combine the similarity values derived from different feature sets.

The results in Tables V and VI are encouraging. Concerning offline systems, Table $\mathrm{V}$ shows that $k$-nearest neighbor classifier [281] and pattern matching techniques [283] provided good results when datasets of small to medium size were considered (for instance, datasets with a total number of signatures for training and testing less than 1000). When larger datasets were used, the best results were achieved with HMM, using both gridbased [71] and graphometric-based [144] features. Conversely, as Table VI shows, experimental results achieved with datasets of small to medium [146] and large [238] size demonstrated the superiority of HMM for online signature verification. Similar results were also achieved by means of DTW in combination with ME approaches [18], when several functions were used as features. Anyway, it should be pointed out that, although several results are very positive, system performances were generally overestimated since they were obtained from laboratory tests, which usually took into consideration very controlled writing conditions and poor forgeries produced by researchers [341].

Furthermore, the approaches proposed in the literature cannot be easily compared due to the lack of large, public signature databases and widely accepted protocols for experimental tests [65], [73], [89], [247], [341]. Indeed, there have been only a limited number of very large-size public experiments to date [107], [257]. Furthermore, it is worth noting that the development of a benchmark signature database is a time-consuming and expensive process. It involves not only scientific and technical issues, like those related to the statistical relevance of the population of individuals involved as well as the acquisition devices and protocols, but also legal aspects related to data privacy and intellectual property rights [89]. On the other hand, since the development of benchmark databases is rightly recognized as a key aspect for the success and diffusion of signature-based verification systems, specific efforts have recently been made to develop both unimodal benchmark databases (i.e., that contain only a single biometric trait) and multimodal ones (i.e., that contain two or more biometric traits from the same individuals). Some of the most important examples are the MCYT [239] and MYIDEA [69] signature databases, which contain both online and offline data; the BIOMET [106], Philips [63], and SVC2004 [360] databases of online signatures; the GPDS [91] database of offline signatures; and the Caltech [207]-[209], [211] database obtained by using cameras.

In this sense, the results obtained during the signature verification competition realized in 2004 (SVC2004) are a precise reference for advancements in the field, since they were obtained by using common benchmark databases and testing protocols [360]. Furthermore, the results demonstrate that signature verification systems can be considered as not particularly less accurate than other biometric systems, like those based on face and fingerprint [326]. Indeed, the objective of SVC2004 was to allow researchers and practitioners to evaluate the performance of different online signature verification systems systematically, not only for error rates of difficult tasks (based on pen tablet without visual feedback, synthetic signatures, dynamics of the signatures to imitate provided to forgers, etc.), but also for other parameters, like system cost, verification cost, processing speed, security of data, number of training samples required, and so on. In fact, the feasibility of a particular system in relation to a specific operating environment should also be determined by the analysis of all these parameters [78].

\section{DISCUSSION AND CONCLUSION}

Automatic signature verification is a very attractive field of research from both scientific and commercial points of view. In recent years, along with the continuous growth of the Internet and the increasing security requirements for the development of the e-society, the field of automatic signature verification is being considered with renewed interest since it uses a customary personal authentication method that is accepted at both legal and social levels [78], [196], [258]. Furthermore, recent results achieved in international competitions using standard databases and test protocols have revealed that signature verification systems can have an accuracy level similar to those achieved by other biometric systems [326]. Finally, different from physiological biometrics, handwritten signature is an active method that requires the user to perform the explicit act of signing. Thus, automatic signature verification is particularly useful in all applications in which the authentication of both transaction and user is required [259], [326].

Therefore, the number of possible applications for online signature verification is continuously growing along with the development of more and more sophisticated and easy-to-use input devices for online handwriting acquisition. For instance, online signature verification can be a valuable contribution for controlling access security in computer networks, documents, and databases. An example of this application can be seen in health care applications-for medical record access and remote partner verification -in distributed working communities, as well as in the areas of passport and driving license applications. Online signature verification has important applications in online banking, monetary transactions, and retail POS. For instance, it can be used to replace the current practice of signing paper credit card receipts. In this case, the verification process can be performed by comparing the live online signature of a user with 
the biometric information of his/her handwritten signature that can be stored in a personal smart card to verify that the person using the card is the rightful owner. Furthermore, online signature verification can support switching paper-based documents to digital documents. For instance, it can enhance administrative procedures for insurance companies by reducing the amount of paper-based documents, generating a higher return on investment [103], [160], [259], [320], [324].

Notwithstanding efforts toward the dematerialization of documents, the need for fast and accurate paper-based document authentication is still growing in our society. Offline signature verification applications mainly concern the authentication of bank checks, contracts, ID personal cards, administrative forms, formal agreements, acknowledgement of services received, etc. [60], [171], [236], [259]. This type of verification is related to paper-based document authentication. Thus, offline signature verification systems can be more limited with respect to online systems.

The net result is that in the near future, along with a wide range of potential applications, a significant annual growth is expected in the worldwide signature verification market [133], [153], [320]. Of course, this trend has been further affected by research results in recent years, which have significantly advanced the state of the art in the field. Nevertheless, in order to strengthen the commercial and social benefits related to automatic signature verification, additional efforts are necessary.

In this paper, the state of the art in automatic signature verification has been presented and the main results have been addressed. Furthermore, some of the most promising directions for research in this field have been highlighted. In the near future, research need not be focused almost exclusively on accuracy improvements, as it has mostly been in the past. Instead, it should address a multitude of issues related to various scenarios of the application themselves.

For instance, as the number of input devices and techniques for handwriting acquisition increases, device interoperability will become an area of greater relevance and need specific investigation. The result of these developments is that signature capture will be feasible in many daily environments by means of fixed and mobile devices, and automatic signature verification will be used in even more applications [5].

Furthermore, in recent years, a number of benchmark databases have been developed in order to comparatively evaluate signature verification systems, and important results have been achieved for the standardization of signature data interchange formats, in order to facilitate system interoperability and integration. Advances in this direction can be expected on the well-suited integration of metadata in large-size databases and the design and implementation of standard frameworks for effective experimental construction and evaluation of signature verification systems under different forgery quality models [16], [113], [327], [377]. In the context of "soft biometrics," the deployment of metadata-based systems for large-scale applications, which can expect both multiethnic and multilingual users, is very important and needs specific consideration [325], [342].

The analysis of individual characteristics of handwriting still remains an interesting research area that encompasses not only those features produced by people with normal abilities but also those generated by people who suffer from disabilities and diseases that may lead to handwriting constraints [259]. For this purpose, investigation of the mechanisms underlying handwriting production and the ink-depository processes is worthy of additional attention, as well as studies on feature selection techniques and signature modeling methods for the adaptability and personalization of the verification processes. Similarly, techniques for the analysis of signature complexity and stability can offer insight into the selection of the most profitable biometric signature data for various kinds of applications, such as cryptography-for cryptographic key generation [103], [320], [319].

In addition, ME systems offer the potential of improving signature verification accuracy by combining different decisions. They can combine decisions obtained through multiple representations and matching algorithms at both local and global levels. Furthermore, ME systems can support a combination of decisions achieved on various biometric traits, also by using adaptive management strategies that are worthy of specific studies [322]. Indeed, to date, the characteristics of unimodal biometrics are not always adequate for large-scale deployment and for security critical applications, independent of which biometric trait is considered [65], [325]. Thus, an ME approach could also be an important area for further research to enable multimodal biometrics [93], [98], [108], [160], [240], which addresses the problem of nonuniversality and is expected to achieve higher performance than unimodal approaches [93], [105].

Finally, the relevance of the results in the legal and regulatory aspects of personal verification by handwritten signature should also be underlined. These findings are a sign of the awareness and attention that governments and institutions at national and international levels are giving to this important field of research. However, it is clear that several issues still remain to be addressed also in this field, such as those concerning privacy and the protection of personal data.

Thus, in the age of the e-society, automatic signature verification can no longer be considered exclusively restricted to academics and research laboratories since the possibility of applying automatic signature verification in a range of applications is becoming a reality. Definitely, further research is necessary to fully investigate and interpret the potential of handwritten signatures, which remain very distinct signs, unequivocally demonstrating the inspiration and complexity of human beings.

\section{REFERENCES}

[1] A. Abu-Rezq and A. S. Tolba, "Cooperative self-organizing maps for signature verification," in Proc. Image Anal. Inf. Fusion (IAIF 1997), H. Pan, M. Brooks, D. McMichael, and G. Newsam, Eds., pp. 391-402.

[2] A. Abu-Rezq and A. S. Tolba, "Cooperative self-organizing maps for consistency checking and signature verification," Digit. Signal Process., vol. 9, pp. 107-119, 1999.

[3] C. Allgrove and M. C. Fairhurst, "Enrolment model stability in static signature verification," in Proc. 7th Int. Workshop Front. Handwriting Recognit. (IWFHR-7), L. R. B. Schomaker, and L. G. Vuurpijl, Eds., Amsterdam, The Netherlands, Sep. 2000, pp. 565-570.

[4] C. Allgrove and M. C. Fairhurst, "Majority voting for improved signature verification," in Proc. Inst. Elect. E Colloq. Vis. Biometrics, London, U.K., 2000, pp. 9-1-9-4.

[5] F. Alonso-Fernandez, J. Fierrez-Aguilar, and J. Ortega-Garcia, "Sensor interoperability and fusion in signature verification: A case study using tablet PC," (Lecture Notes in Computer Science 3781) in Proc. Int. Workshop Biometric Recognit. Syst. (IWBRS). Beijing, China SpringerVerlag, Oct. 2005, pp. 180-187. 
[6] F. Alonso-Fernandez, J. Fierrez-Aguilar, F. Del Valle, and J. OrtegaGarcia, "On-line signature verification using tablet PC," in Proc. 4th Int. Symp. Image Signal Process. Anal. (ISPA 2005), pp. 245-250.

[7] A. I. Al-Shoshan, "Handwritten signature verification using image invariant and dynamic features," in Proc. Int. Conf. Comput. Graphics, Imag. Vis. (CGIV 2006), 2008, pp. 173-176.

[8] M. Ammar, Y. Yoshida, and T. Fukumura, "Structural description and classification of signature images," Patt. Recognit., vol. 23, no. 7, pp. 697-710, 1990.

[9] S. Ando and M. Nakajima, "An active search of local individualities for an offline signature verification," Trans. IEICE, vol. J84-D-II, no. 7, pp. 1339-1350, 2001.

[10] Information Technology-Biometric Data Interchange FormatsSignature/Sign Data, ANSI Standard ANSI INCITS 395-2005.

[11] R. S. A. Araujo, G. D. C. Cavalcanti, and E. C. D. B. C. Filho, "On-line verification for signatures of different sizes," presented at the 10th Int. Workshop Front. Handwriting Recognit. (IWFHR 10), La Baule, France, Oct. 2006.

[12] M. Arif, T. Brouard, and N. Vincent, "A fusion methodology for recognition of offline signatures," in Proc. 4th Int. Workshop Pattern Recognit. Inf. Syst. (PRIS 2004), pp. 35-44.

[13] S. Armand, M. Blumenstein, and V. Muthukkumarasamy, "Offline signature verification based on the modified direction feature," in Proc. 18th Int. Conf. Pattern Recog. (ICPR 2006), Hong Kong, pp. 509-512.

[14] Y. J. Bae and M. C. Fairhurst, "Parallelism in dynamic time warping for automatic signature verification," in Proc. 3rd Int. Conf. Doc. Anal. Recog. (ICDAR-3), IEEE Comput. Soc., Montreal, Canada, Aug. 14-16, 1995 , vol. 1, pp. 426-429.

[15] R. Bajaj and S. Chaudhury, "Signature verification using multiple neural classifiers," Pattern Recognit., vol. 30, no. 1, 1997, pp. 1-7.

[16] L. Ballard, D. Lopresti, and F. Monrose, "Forgery quality and its implication for behavioural biometric security," IEEE Trans. Syst., Man, Cybern. B, Cybern., vol. 37, no. 5, pp. 1107-1118, Oct. 2007.

[17] H. Baltzakis and N. Papamarkos, "A new signature verification technique based on a two-stage neural network classifier," Eng. Appl. Artif. Intell., vol. 14, pp. 95-103, 2001.

[18] L. Bovino, S. Impedovo, G. Pirlo, and L. Sarcinella, "Multi-expert verification of hand-written signatures," in Proc. 7th Int. Conf. Doc. Anal. Recognit. (ICDAR-7), IEEE Comput. Soc., Edinburgh, U.K., Aug. 2003, pp. 932-936.

[19] K. W. Boyer, V. Govindaraju, and N. K. Ratha, Eds., "Special issue on recent advances in biometric systems," IEEE Trans. Syst., Man, Cybern. B, Cybern., vol. 37, no. 5, pp. 1091-1095, Oct. 2007.

[20] J.-J. Brault and R. Plamondon, "A complexity measure of handwritten curves: Modeling of dynamic signature forgery," IEEE Trans. Syst., Man, Cybern., vol. 23, no. 2, pp. 400-413, Mar./Apr. 1993.

[21] J.-J. Brault and R. Plamondon, "Segmenting handwritten signatures at their perceptually important points," IEEE Trans. Pattern Anal. Mach. Intell., vol. 15, no. 9, pp. 953-957, Sep. 1993.

[22] J. Bromley, J. W. Bentz, L. Bottou, I. Guyon, L. Jackel, Y. L. Cun, C. Moore, E. Sackinger, and R. Shah, "Signature verification using a 'Siamese' time delay neural network," Int. J. Pattern Recognit. Artif. Intell. (IJPRAI), vol. 7, no. 4, pp. 669-688, 1993.

[23] M. Bulacu and L. Schomaker, "Text-independent writer identification and verification using textural and allographic features," IEEE Trans. Pattern Anal. Mach. Intell., vol. 29, no. 4, pp. 701-717, Apr. 2007.

[24] H. Bunke, T. Von Siebenhal, T. Yamasaki, and M. Schenkel, "On line handwriting data acqusition using a video camera," in Proc. 5th Int. Conf. Doc. Anal. Recognit. (ICDAR-5), IEEE Comput. Soc., Bangalore, India, Sep. 1999, pp. 573-576.

[25] C. J. C. Burges, "A tutorial on support vector machines for pattern recognition," Data Mining Knowl. Discov., vol. 2, pp. 121-167, 1998.

[26] H. Cardot, M. Revenu, B. Victorri, and M.-J. Revillet, "A static signature verification system based on a cooperating neural networks architecture," Int. J. Pattern Recognit. Artif. Intell. (IJPRAI), vol. 8, no. 3, pp. 679-692, 1994.

[27] H. Cardot, M. Revenu, B. Victorri, and M.-J. Revillet, "An artificial neural networks architectures for handwritten signature authentication," Proc. SPIE, vol. 11, no. 6, pp. 633-644, 1995.

[28] A. Chalechale, G. Naghdy, and A. Mertins, "Signature-based document retrieval," in Proc. IEEE Int. Symp. Signal Process. Inf. Technol. (ISSPIT 2003), Darmstadt, Germany, Dec., pp. 597-600.

[29] A. Chalechale, G. Naghdy, P. Premaratne, and A. Mertins, "Document image analysis and verification using cursive signature," in Proc. IEEE
Int. Conf. Multimedia Expo. (IEEE-ICME 2004), Taipei, Taiwan, Jun., pp. $887-890$.

[30] H. D. Chang, J. F. Wang, and H. M. Suen, "Dynamic handwritten Chinese signature verification," in Proc. 2nd Int. Conf. Doc. Anal. Recognit. (ICDAR-2), Tsukuba, Japan, Oct. 1993, pp. 258-261.

[31] Y. Chen and X. Ding, "On-line signature verification using direction sequence string matching," Proc. SPIE, vol. 4875, pp. 744-749, Jul. 2002.

[32] Y. Chen and X. Ding, "Sequence-matching-based feature extraction with applications to signature verification," Proc. SPIE, vol. 5676, pp. 76-83, Jan. 2005.

[33] S. Chen and S. N. Srihari, "Combining one- and two-dimensional approaches to signature verification," in Proc. SPIE Doc. Recognit. Retrieval XIII, Electron. Imag., K. Taghva, and X . Lin, Eds., San Jose, CA, Jan. 2006, vol. 6067, pp. 606701-1-606701-10.

[34] S. Chen and S. N. Srihari, "A new offline signature verification method based on graph matching," in Proc. Int. Conf. Pattern Recog. (ICPR 2006), Hong Kong, pp. 869-872.

[35] S. Chen and S. N. Srihari, "Use of exterior contours and word shape in offline signature verification," in Proc. Int. Conf. Doc. Anal. Recognit. (ICDAR 2005), Seoul, Korea, pp. 1280-1284.

[36] N.-J. Cheng, C.-J. Wen, H.-F. Yau, T.-S. Liu, K. Liu, K.-C. Cheng, and B.-S. Jeng, "Handwritten Chinese signature verification based on attributed string matching of stroke linkage order," in Proc. 32nd Int. Carnahan Conf. Secur. Technol., Alexandria, VA, Oct. 1998, pp. 238 243.

[37] S. Chi, J. Lee, J. Soh, D. Kim, W. Oh, and C. Kim, "Visualization of dynamic characteristics in two-dimensional time series patterns: An application to online signature verification," in Proc. WISA 2003 (Lecture Notes in Computer Science), vol. 2908, K. Chae and M. Yung, Eds. Berlin, Germany: Springer-Verlag, 2004, pp. 395-409.

[38] J. Coetzer, B. M. Herbst, and J. A. du Preez, "Offline signature verification using the discrete radon transform and a hidden Markov model," EURASIP J. Appl. Signal Process., vol. 2004, no. 4, pp. 559-571, 2004.

[39] J. Coetzer, B. M. Herbst, and J. A. Du Preez, "Offline signature verification: A comparison between human and machine performance," presented at the 10th Int. Workshop Front. Handwriting Recognit. (IWFHR 10), La Baule, France, Oct. 2006.

[40] G. Congedo, G. Dimauro, A. M. Forte, S. Impedovo, and G. Pirlo, "Selecting reference signatures for on-line signature verification," in Proc. 8th Int. Conf. Image Anal. Process. (ICIAP-8) (Lecture Notes in Computer Science), vol. 974, C. Braccini, L. De Floriani, and G. Vernazza, Eds. Berlin, Germany: Springer-Verlag, Sep. 1995, pp. 521-526.

[41] G. Congedo, G. Dimauro, S. Impedovo, and G. Pirlo, "Offline signature verification by fundamental components analysis," in Proc. 7th Int. Conf. Image Anal. Process. (ICIAP-7), Progr. Image Anal. Process. III, S. Impedovo, Ed. Monopoli, Italy: World Scientific, Sep. 1993, pp. 331-337.

[42] G. Congedo, G. Dimauro, S. Impedovo, and G. Pirlo, "A new methodology for the measurement of local stability in dynamical signatures," in Proc. 4th Int. Workshop Front. Handwriting Recognit. (IWFHR-4), Taipei, Taiwan, Dec. 1994, pp. 135-144.

[43] L. P. Cordella, P. Foggia, C. Sansone, F. Tortorella, and M. Vento, "Reliability parameters to improve combination strategies in multi-expert systems," Pattern Anal. Appl., vol. 3, no. 2, pp. 205-214, 1999.

[44] L. P. Cordella, P. Foggia, C. Sansone, F. Tortorella, and M. Vento, "A cascaded multiple expert system for verification," in Proc. 1st Int. Workshop, Multiple Classifier Syst. (MCS-1) (Lecture Notes in Computer Science), vol. 1857, J. Kittler and F. Roli, Eds. Berlin, Germany: Springer-Verlag, Jun. 2000, pp. 330-339.

[45] L. P. Cordella, P. Foggia, C. Sansone, and M. Vento, "Document validation by signature: A serial multi-expert approach," in Proc. 5th Int. Conf. Document Anal. Recognit. (ICDAR-5), IEEE Comput. Soc., Bangalore, India, Sep. 1999, pp. 601-604.

[46] H. D. Crane and J. S. Ostrem, "Automatic signature verification system using a three-axis force-sensitive pen," IEEE Trans. Syst., Man, Cybern., vol. SMC-13, no. 3, pp. 329-337, May/Jun. 1983.

[47] A. M. Darwish and G. A. Auda, "A new composite feature vector for Arabic handwritten signature recognition," in Proc. IEEE Int. Conf. Acoust., Speech, Signal Process. (ICASSP), Apr. 1994, vol. 2, pp. 613-616.

[48] C. de Oliveira, C. A. A. Kaestner, F. Bortolozzi, and R. Sabourin, "Generation of signatures by deformations," in Proc. BSDIA 1997, Curitiba, Brazil, pp. 283-298.

[49] P. S. Deng, H.-Y. M. Liao, C. W. Ho, and H.-R. Tyan, "Wavelet-based offline handwritten signature verification," Comput. Vis. Image Underst. vol. 76, no. 3, pp. 173-190, Dec. 1999

[50] V. Di Lecce, G. Dimauro, A. Guerriero, S. Impedovo, G. Pirlo, and A. Salzo, "A multi-expert system for dynamic signature verification," in Proc. 1st Int. Workshop, Multiple Classifier Syst. (MCS 2000) (Lecture Notes in Computer Science), vol. 1857, J. Kittler and F. Roli, Eds. Berlin, Germany: Springer-Verlag, Jun. 2000, pp. 320-329. 
[51] V. Di Lecce, G. Dimauro, A. Guerriero, S. Impedovo, G. Pirlo, A. Salzo, and L. Sarcinella, "Selection of reference signatures for automatic signature verification," in Proc. 5th Int. Conf. Doc. Anal. Recognit. (ICDAR-5), Bangalore, India, Sep. 20-22, 1999, pp. 597-600.

[52] G. Dimauro, S. Impedovo, M. G. Lucchese, R. Modugno, and G. Pirlo, "Recent advancements in automatic signature verification," in Proc. 9th Int. Workshop Front. Handwriting Recognit. (IWFHR-9), Kichijoji, Japan, Oct. 25-29, 2004, pp. 179-184.

[53] G. Dimauro, S. Impedovo, R. Modugno, G. Pirlo, and L. Sarcinella, "Analysis of stability in hand-written dynamic signatures," in Proc. 8th Int. Workshop Front. Handwriting Recognit. (IWFHR-8), Niagara-onthe-Lake, ON, Canada, Aug. 2002, pp. 259-263.

[54] G. Dimauro, S. Impedovo, and G. Pirlo, "A stroke-oriented approach to signature verification," in From Pixels to Features III-Frontiers in Handwriting Recognition, S. Impedovo and J. C. Simon, Eds. Amsterdam, The Netherlands: Elsevier, 1992, pp. 371-384.

[55] G. Dimauro, S. Impedovo, and G. Pirlo, "On-line signature verification by a dynamic segmentation technique," in Proc. 3rd Int. Workshop Front. Handwriting Recognit. (IWFHR-3), Buffalo, NY, May 1993, pp. 262271.

[56] G. Dimauro, S. Impedovo, and G. Pirlo, "Component-oriented algorithms for signature verification," Int. J. Pattern Recognit. Artif. Intell. (IJPRAI), vol. 8, no. 3, pp. 771-794, 1994.

[57] G. Dimauro, S. Impedovo, and G. Pirlo, "Offline signature verification through fundamental strokes analysis," in Progress in Image Analysis and Processing III, S. Impedovo, Ed. Singapore: World Scientific, 1994, pp. 331-337.

[58] G. Dimauro, S. Impedovo, and G. Pirlo, "Algorithms for automatic signature verification," in Handbook of Character Recognition and Document Image Analysis, H. Bunke and P. S. P. Wang, Eds. Singapore: World Scientific, 1997, pp. 605-621.

[59] G. Dimauro, S. Impedovo, G. Pirlo, and A. Salzo, "A multi-expert signature verification system for bankcheck processing," Int. J. Pattern Recognit. Artif. Intell. (IJPRAI), vol. 11, no. 5, pp. 827-844, 1997 [Automatic Bankcheck Processing (Series in Machine Perception and Artificial Intelligence), vol. 28, S. Impedovo, P. S. P. Wang, and H. Bunke, Eds. Singapore: World Scientific, pp. 365-382].

[60] G. Dimauro, S. Impedovo, G. Pirlo, and A. Salzo, "Automatic bankcheck processing: A new engineered system," Int. J. Pattern Recognit. Artif. Intell., vol. 11, no. 4, pp. 467-504, 1997 [Automatic Bankcheck Processing (Series in Machine Perception and Artificial Intelligence), vol. 28 , S. Impedovo, P. S. P. Wang, and H. Bunke, Eds. Singapore: World Scientific, pp. 5-42].

[61] S. Djeziri, F. Nouboud, and R. Plamondon, "Extraction of signatures from check background based on a filiformity criterion," IEEE Trans. Image Process. (T-IP), vol. 7, no. 10, pp. 1425-1438, Oct. 1998.

[62] D. S. Doermann and A. Rosenfeld, "Recovery of temporal information from static images of handwriting," Int. J. Comput. Vis. (IJCV), vol. 15, pp. 143-164, 1995

[63] J. G. A. Dolfing, E. H. L. Aarts, and J. J. G. M. Van Oosterhout, "Online verification signature with hidden Markov models," in Proc. 14th Int. Conf. Pattern Recog. (ICPR-14), Brisbane, Australia, Aug. 1998, pp. 1309-1312.

[64] R. C. Doria, E. C. B. C. Filho, and E. F. A. Silva, "How distortions in different size signatures influence moment based techniques," in Proc. 6th Int. Conf. Pattern Recog. Inf. Process. (PRIP'01), Minsk, Belarus, May 2001, vol. 1, pp. 219-226.

[65] B. Dorizzi, S. Garcia-Salicetti, and M. A. Mellakh, "Multimodality in BioSecure: Towards an evaluation protocol on virtual multi-modal databases," presented at the 13th Eur. Signal Process. Conf. (EUSIPCO), Antalya, Turkey, Sep. 4-8, 2005.

[66] J.-P. Drouhard, R. Sabourin, and M. Godbout, "Evaluation of a training method and of various rejection criteria for a neural network classifier used for offline signature verification," in Proc. Int. Conf. Neural Netw. (ICNN 1994), Orlando, FL, pp. 4294-4299.

[67] J. P. Drouhard, R. Sabourin, and M. Godbout, "A comparative study of the $\mathrm{k}$ nearest neighbour, threshold and neural network classifiers for handwritten signature verification using an enhanced directional PDF," in Proc. 3rd Int. Conf. Doc. Anal. Recognit. (ICDAR-3), Montreal, QC, Canada, Aug. 1995, vol. 1, pp. 807-810.

[68] J.-P. Drouhard, R. Sabourin, and M. Godbout, "A neural network approach to offline signature verification using directional PDF," Pattern Recognit., vol. 29, no. 3, pp. 415-424, Mar. 1996.

[69] B. Dumas, C. Pugin, J. Hennebert, D. Petrovska-Delacrétaz, A. Humm, F. Evéquoz, R. Ingold, and D. Von Rotz, "MyIdea-Multimodal biometrics database, description of acquisition protocols," in Proc. 3rd COST, Hatfield, U.K., Oct. 2005, pp. 59-62.

[70] A. G. Dyer, B. Found, and D. Rogers, "Visual attention and expertise for forensic signature analysis," J. Forensic Sci., vol. 51, no. 6, pp. 13971404, 2006.

[71] A. El-Yacoubi, E. J. R. Justino, R. Sabourin, and F. Bortolozzi, "Offline signature verification using HMMs and cross-validation," in Proc. 10th Int. Workshop Neural Netw. Signal Process. (NNSP 2000), Sydney, Australia, Dec. 2000, vol. 2, pp. 859-868.

[72] S. J. Elliott, "A comparison of on-line dynamic signature trait variables vis-à-vis mobile computing devices and table-based digitizers," in Proc. Workshop Autom. Identification Adv. Technol., Tarrytown, NY, 2002, pp. 121-125.

[73] S. J. Elliott, "Development of a biometric testing protocol for dynamic signature verification," in Proc. 7th Int. Conf. Control, Autom., Robot. Vis. (ICARCV 2002), vol. I, pp. 782-787.

[74] S. J. Elliott, "Differentiation of signature traits vis-à-vis mobile- and table-based digitizers," ETRI J., vol. 26, no. 6, pp. 641-646, Dec. 2004.

[75] E. A. Fadhel and P. Bhattacharyya, "Ability of neural network for offline signature verification," presented at the Int. Conf. Know. Based Comput. Syst. (KBCS 2000), Mumbai, India, Dec.

[76] E. A. Fadhel and P. Bhattacharyya, "Application of a steerable wavelet transform using neural network for signature verification," Pattern Anal. Appl. J., vol. 2, no. 2, pp. 184-195, Jun. 1999.

[77] M. C. Fairhurst, "Automatic signature verification: Making it work," in Proc. 1st Inst. Elect. Eng. Eur. Workshop Handwriting Anal. Recognit., Brussels, Belgium, Jul. 1994, pp. 3.1-3.7.

[78] M. C. Fairhurst, "Signature verification revisited: Promoting practical exploitation of biometric technology," Inst. Elect. Eng. Electron. Commun. Eng. J. (ECEJ), vol. 9, no. 6, pp. 273-280, Dec. 1997.

[79] M. C. Fairhurst and C. Allgrove, "Enrolment validation in optimisation of practical signature verification procedures," presented at the 5th Int. Workshop Front. Handwriting Recognit. (IWFHR-5), Colchester, U.K., Sep. 1996 [in Progress in Handwriting Recognition, A. C. Downton and S. Impedovo, Eds. Singapore: World Scientific, 1997, pp. 587-592].

[80] M. C. Fairhurst and P. S. Brittan, "An evaluation of parallel strategies for feature vector construction in automatic signature verification systems," Int. J. Pattern Recognit. Artif. Intell. (IJPRAI), vol. 8, no. 3, pp. 661-678, 1994.

[81] M. C. Fairhurst and E. Kaplani, "Perceptual analysis of handwritten signatures for biometric authentication," Inst. Elect. Eng. Proc. Vis., Image Signal Process., vol. 150, no. 6, pp. 389-394, Dec. 2003.

[82] M. C. Fairhust and S. Ng, "Management of access through biometric control: A case study based on automatic signature verification," in Universal Access in the Information Society (UAIS), vol. 1, no. 1. New York: Springer-Verlag, 2001, pp. 31-39.

[83] B. Fang "Tracking of feature and stroke positions for offline signature verification," in Proc. Int. Conf. Image Process. (ICIP), 2002, vol. III, pp. $965-968$.

[84] B. Fang, C. H. Leung, Y. Y. Tang, K. W. Tse, P. C. K. Kwok, and Y. K. Wong, "Offline signature verification by the tracking of feature and stroke positions," Pattern Recognit., vol. 36, no. 1, pp. 91-101, Jan. 2003.

[85] B. Fang and Y. Y. Tang, "Reduction of feature statistics estimation error for small training sample size in offline signature verification," (Lecture Notes in Computer Science 3072), in Proc. 1st Int. Conf. Biometric Authentication (ICBA 2004), D. Zhang and A. K. Jain, Eds. Berlin, Germany: Springer-Verlag, pp. 526-532.

[86] B. Fang and Y. Y. Tang, "Improved class statistics estimation for sparse data problem in offline signature verification," IEEE Trans. Syst., Man Cybern. C, Appl. Rev., vol. 35, no. 3, pp. 276-286, Aug. 2005.

[87] B. Fang, Y. Y. Wang, C. H. Leung, P. C. K. Kwok, K. W. Tse, Y. Y. Tang, and Y. K. Wong, "A smoothness index based approach for offline signature verification," in Proc. 5th Int. Conf. Doc. Anal. Recognit. (ICDAR-5), Bangalore, India, Sep. 1999, pp. 785-791.

[88] J. B. Fasquel and M. Bruynooghe, "A hybrid opto-electronic method for fast offline handwritten signature verification," Int. J. Doc. Anal. Recognit. (IJDAR), vol. 7, no. 1, pp. 56-68, Mar. 2004.

[89] M. Faundez-Zanuy, J. Fierrez-Aguilar, J. Ortega-Garcia, and J. Gonzalez-Rodriguez, "Multimodal biometric databases: An overview," IEEE Aerosp. Electron. Syst. Mag., vol. 21, no. 8, pp. 29-37, Aug. 2006.

[90] H. Feng and C. C. Wah, "Online signature verification using a new extreme points warping technique," Pattern Recognit. Lett., vol. 24, no. 16, pp. 2943-2951, Dec. 2003.

[91] M. A. Ferrer, J. B. Alonso, and C. M. Travieso, "Offline geometric parameters for automatic signature verification using fixed-point arithmetic," IEEE Trans. Pattern Anal. Mach. Intell., vol. 27, no. 6, pp. 993-997, Jun. 2005.

[92] J. Fierrez-Aguilar, N. Alonso-Hermira, G. Moreno-Marquez, and J. Ortega-Garcia, "An offline signature verification system based on fusion of local and global information," (Lecture Notes in Computer Science 3087), in Proc. Eur. Conf. Comput. Vis., Workshop Biometric Authentication (BIOAW), Prague, Czech Republic, May 2004, pp. 295306.

[93] J. Fierrez-Aguilar, D. Garcia-Romero, J. Ortega-Garcia, and J. GonzalezRodriguez, "Exploiting general knowledge in user dependent fusion strategies for multimodal biometric verification," in Proc. IEEE Int. 
Conf. Acoust., Speech Signal Process. (ICASSP), Montreal, QC, Canada, vol. 5, May 2004, pp. 617-620.

[94] J. Fierrez-Aguilar, S. Krawczyk, J. Ortega-Garcia, and A. K. Jain, "Fusion of local and regional approaches for on-line signature verification," presented at the Proc. Int. Workshop Biometric Recognit. Syst. (IWBRS), Beijing, China, Oct. 2005.

[95] J. Fierrez-Aguilar, L. Nanni, J. Lopez-Penalba, J. Ortega-Garcia, and D. Maltoni, "An on-line signature verification system based on fusion of local and global information," (Lecture Notes in Computer Science 3546), in Audio- and Video-Based Biometric Person Authentication (AVBPA). New York: Springer-Verlag, Jul. 2005, pp. 523-532.

[96] J. Fierrez-Aguilar, J. Ortega-Garcia, D. D. Ramos, and J. GonzalezRodriguez, "HMM-based on-line signature verification: Feature extraction and signature modelling," Pattern Recognit. Lett., vol. 28, no. 16, pp. 2325-2334, Dec. 2007.

[97] J. Fierrez-Aguilar, J. Ortega-Garcia, and J. Gonzalez-Rodriguez, "Target dependent score normalization technique and their application to signature verification," IEEE Trans. Syst., Man Cybern. C, Appl. Rev., vol. 35, no. 3, pp. 418-425, Aug. 2005.

[98] J. Fierrez-Aguilar, J. Ortega-Garcia, J. Gonzalez-Rodriguez, and J. Bigun, "Discriminative multimodal biometric authentication based on quality measures," Pattern Recognit., vol. 38, no. 5, pp. 777-779, May 2005.

[99] K. Franke, O. Bünnemeyer, and T. Sy, "Ink texture analysis for writer identification," in Proc. 8th Int. Workshop Front. Handwriting Recognit. (IWFHR-8), Aug. 2002, pp. 268-273.

[100] K. Franke and S. Rose, "Ink-deposition analysis using temporal (online) data," in Proc. 10th Int. Workshop Front. Handwriting Recognit. (IWFHR), La Baule, France, 2006, pp. 447-453.

[101] K. Franke and S. Rose, "Ink deposition model, the relation of writing and ink deposition processes," presented at the 9th International Workshop Front. Handwriting Recognit. (IWFHR-9), Kichijoji, Japan, Oct. 25-29, 2004, pp. 173-178.

[102] K. Franke, Y.-N. Zhang, and M. Köppen, "Static signature verification employing a kosko-neuro-fuzzy approach," (Lecture Notes in Artificial Intelligence 2275), in Proc. AFSS 2002, N. R. Pal and M. Sugeno, Eds. Berlin, Germany: Springer-Verlag, 2002, pp. 185-190.

[103] M. Freire-Santos, J. Fierrez-Aguilar, and J. Ortega-Garcia, "Cryptographic key generation using handwritten signature," Proc. SPIE, vol. 6202 , pp. $62020 \mathrm{~N}-1-62020 \mathrm{~N}-7$, Apr. 2006.

[104] M. Fuentes, S. Garcia-Salicetti, and B. Dorizzi, "On-line signature verification: Fusion of a hidden Markov model and a neural network via a support vector machine," in Proc. 8th Int. Workshop Front. Handwriting Recognit. (IWFHR-8), Niagara-on-the-Lake, ON, Canada, Aug. 2002, pp. 253-258.

[105] S. Garcia-Salicetti, J. Fierrez-Aguilar, F. Alonso-Fernandez, C. Vielhauer, R. Guest, L. Allano, T. D. Trung, B. L. Van, J. Dittmann, B. Dorizzi, J. Ortega-Garcia, J. Gonzalez-Rodriguez, M. B. di Castiglione, and M. Fairhurst, "Biosecure reference systems for on-line signature verification: A study of complementarity," Ann. Telecommun., Special Issue Multimodal Biometrics, vol. 62, no. 1/2, pp. 36-61, 2007.

[106] S. Garcia-Salicetti, C. Beumier, G. Chollet, B. Dorizzi, J. Leroux les Jardins, J. Lunter, Y. Ni, and D. Petrovska-Delacrtaz, "Biomet: A multimodal person authentication database including face, voice, fingerprint, hand and signature modalities," in Lecture Notes in Computer Science. Berlin, Germany: Springer-Verlag, vol. 2688, 2003, pp. 845-853.

[107] M. Gifford and N. Edwards, "Trial of dynamic signature verification for a real-world identification solution," BT Technol. J., vol. 23, no. 2, pp. 259-266, Apr. 2005

[108] J. Gonzalez-Rodriguez, J. Fierrez-Aguilar, D. Ramos-Castro, and J. Ortega-Garcia, "Bayesian analysis of fingerprint, face and signature evidences with automatic biometric systems," Forensic Sci. Int., vol. 155, no. $2 / 3$, pp. 126-140, Dec. 2005.

[109] C. Gruber, M. Coduro, and B. Sick, "Signature verification with dynamic RBF networks and time series motifs," presented at the 10th Int. Workshop Front. Handwriting Recognit. (IWFHR 10), La Baule, France, Oct. 2006.

[110] R. M. Guest, "The repeatability of signatures," in Proc. 9th Int. Workshop Front. Handwriting Recognit. (IWFHR-9), Kichijoji, Japan, Oct. 2004, pp. 492-497.

[111] R. Guest, "Age dependency in handwritten dynamic signature verification systems," Pattern Recognit. Lett., vol. 27, no. 10, pp. 1098-1104, Jul. 2006.

[112] R. Guest and M. Fairhurst, "Sample selection for optimising signature enrolment," presented at the 10th Int. Workshop Front. Handwriting Recognit. (IWFHR 10), La Baule, France, Oct. 2006.

[113] R. Guest, M. Fairhurst, and C. Vielhauer, "Toward a flexible framework for open source software for handwritten signature analysis," in From Data and Information Analysis to Knowledge Engineering. Berlin, Germany: Springer-Verlag, 2005, pp. 622-629.
[114] J. K. Guo, D. S. Doermann, and A. Rosenfeld, "Forgery detection by local correspondence," Int. J. Pattern Recognit. Artif. Intell. (IJPRAI), vol. 15 , no. 4, pp. 579-641, 2001.

[115] D. J. Hamilton, J. Whelan, A. McLaren, I. Macintyre, and A. Tizzard, "Low cost dynamic signature verification system," in Proc. Eur. Convention Secur. Detection, 1995, no. 408, pp. 202-206.

[116] K. Han and I. K. Sethi, "Local structural association for retrieval and recognition of signature images," SPIE, vol. 2420, pp. 125-136 1995.

[117] K. Han and I. K. Sethi, "Signature identification via local association of features," in Proc. 3rd Int. Conf. Doc. Anal. Recognit. (ICDAR-3), IEEE Comput. Soc., Montreal, QC, Canada, Aug. 1995, vol. 1, pp. 187190.

[118] K. Han and I. K. Sethi, "Handwritten signature retrieval and identification," Pattern Recognit. Lett., vol. 17, no. 1, pp. 83-90, Jan. 1996.

[119] M. Hanmandlu, K. R. Murali Mohan, S. Chakraborty, and G. Garg, "Fuzzy modeling based signature verification system," in Proc. 6th Int Conf. Doc. Anal. Recognit. (ICDAR-6), IEEE Comput. Soc., Seattle, WA Sep. 2001, pp. 110-114.

[120] M. Hanmandlu, M. H. M. Yusof, and V. K. Madasu, "Offline signature verification and forgery detection using fuzzy modeling," Pattern Recognit., vol. 38, no. 3, pp. 341-356, Mar. 2005.

[121] N. M. Herbst and C. N. Liu, "Automatic signature verification based on accelerometry," IBM J. Res. Dev, vol. 21, pp. 245-253, 1977.

[122] Y. Hongo, D. Muramatsu, and T. Matsumoto, "AdaBoost-based on-line signature verifier," in Biometric Technology for Human Identification II, A. K. Jain and N. K. Ratha, Eds. Proc. SPIE, vol. 5779, pp. 373-380, Mar. 2005.

[123] K. Huang, J. Wu, and H. Yan, "Offline writer verification utilizing multiple neural networks," Opt. Eng., vol. 36, no. 11, pp. 3127-3133, Nov. 1997.

[124] K. Huang and H. Yan, "On-line signature verification based on dynamic segmentation and global and local matching," Opt. Eng., vol. 34, no. 12 , pp. 3480-3487, Dec. 1995.

[125] K. Huang and H. Yan, "Identifying and verifying handwritten signature images utilizing neural networks," in Proc. ICONIP 1996, Sep. pp. $1400-1404$.

[126] K. Huang and H. Yan "Offline signature verification based on geometric feature extraction and neural network classification," Pattern Recognit. vol. 30, no. 1, pp. 9-17, Jan. 1997

127] K. Huang and H. Yan, "Signature verification using fractal transformation," in Proc. 15th Int. Conf. Pattern Recog. (ICPR-15), Barcelona, Spain, Sep. 2000, vol. 2, pp. 851-854.

[128] K. Huang and H. Yan, "Offline signature verification using structural feature correspondence," Pattern Recognit., vol. 35, no. 11, pp. 24672477, Nov. 2002.

[129] K. Huang and H. Yan, "Stability and style-variation modeling for on-line signature verification," Pattern Recognit., vol. 36, no. 10, pp. 2253-2270, Oct. 2003.

[130] J. J. Igarza, I. Goirizelaia, K. Espinosa, I. Hernáez, R. Méndez, and J. Sánchez, "Online handwritten signature verification using hidden Markov models," (Lecture Notes in Computer Science 2905), in Proc. CIARP 2003, A. Sanfeliu and J. Ruiz-Shulcloper, Eds. Berlin, Germany: Springer-Verlag, pp. 391-399.

[131] J. J. Igarza, L. Gómez, I. Hernáez, and I. Goirizelaia, "Searching for an optimal reference system for on-line signature verification based on (x, y) alignment," (Lecture Notes in Computer Science 3072), in Proc. ICBA 2004, D. Zhang and A. K. Jain, Eds. Berlin, Germany: SpringerVerlag, pp. 519-525.

[132] S. Impedovo, L. Ottaviano, and S. Occhinegro, "Optical character recognition-A survey," Int. J. Pattern Recognit. Artif. Intell. (IJPRAI), vol. 5 , no. $1 / 2$, pp. 1-24, 1991

[133] International Biometric Group, Biometrics Market and Industry Report 2006-2010. New York: IBG Press, 2007.

[134] M. A. Ismail and S. Gad, "Offline arabic signature recognition and verification," Pattern Recognit., vol. 33, pp. 1727-1740, 2000.

[135] Information Technology - Biometric Data Interchange Formats-Part 7: Signature/Sign Time Series Data, ISO Standard ISO/IEC FCD 19794-7, 2006.

[136] Information Technology-Biometric Data Interchange Formats-Part 11: Signature/Sign Processed Dynamic Data, ISO Standard ISO/IEC WD 19794-11, 2007.

[137] A. K. Jain, L. Hong, and S. Pankanti, "Biometric identification," Commun. ACM, vol. 43, no. 2, pp. 91-98, Feb. 2000.

[138] A. K. Jain, F. D. Griess, and S. D. Connell, "On-line signature verification," Pattern Recognit., vol. 35, no. 12, pp. 2963-2972, Dec. 2002.

[139] A. K. Jain, P. Flynn, and A. Ross, Handbook of Biometrics. New York: Springer-Verlag, 2007

[140] A. K. Jain, S. C. Dass, and K. Nandakumar "Can soft biometric traits assist user recognition?," in Proc. SPIE, vol. 5404, Biometric Technol. Human Identification, Orlando, FL, Apr. 2004, pp. 561-572. 
[141] E. J. R. Justino, F. Bortolozzi, and R. Sabourin, "The interpersonal and intrapersonal variability influences on offline signature verification using HMM," in Proc. XV Brazilian Symp. Comput. Graph. Image Process. (SIBGRAPI-XV), Fortaleza, Brazil, Oct. 2002, pp. 197202.

[142] E. J. R. Justino, F. Bortolozzi, and R. Sabourin, "An offline signature verification method based on SVM classifier and graphometric features," in Proc. 5th Int. Conf. Adv. Pattern Recog. (ICAPR-5), Kolkata, India, Dec. 2003, pp. 134-141.

[143] E. J. R. Justino, F. Bortolozzi, and R. Sabourin, "A comparison of SVM and HMM classifiers in the offline signature verification," Pattern Recognit. Lett., vol. 26, pp. 1377-1385, 2005.

[144] E. J. R. Justino, A. El Yacoubi, F. Bortolozzi, and R. Sabourin, "An offline signature verification system using HMM and graphometric features," in Proc. 4th Int. Workshop Doc. Anal. Syst. (DAS 2000), Rio de Janeiro, Brazil, Dec., pp. 211-222.

[145] M. K. Kalera, S. Srihari, and A. Xu, "Offline signature verification and identification using distance statistics," Int. J. Pattern Recognit. Artif. Intell. (IJPRAI), vol. 18, no. 6, pp. 1339-1360, 2004.

[146] R. S. Kashi, J. Hu, W. L. Nelson, and W. Turin, "On-line handwritten signature verification using hidden Markov model features," in Proc. 4th Int. Conf. Doc. Anal. Recognit. (ICDAR-4), Ulm, Germany, Aug. 1997, vol. 1 , pp. 253-257.

[147] R. S. Kashi, J. Hu, W. L. Nelson, and W. L. Turin, "A hidden Markov model approach to online handwritten signature verification," Int. J. Doc. Anal. Recognit. (IJDAR), vol. 1, no. 2, pp. 102-109, 1998.

[148] R. S. Kashi and W. L. Nelson, "Signature verification: Benefits of multiple tries," in Proc. 8th Int. Workshop Front. Handwriting Recognit. (IWFHR-8), Niagara-on-the-Lake, ON, Canada, Aug. 2002, pp. 424427.

[149] R. S. Kashi, W. Turin, and W. L. Nelson, "On-line handwritten signature verification using stroke direction coding," Opt. Eng., vol. 35, no. 9, pp. 2526-2533, Sep. 1996.

[150] Y. Kato, D. Muramatsu, and T. Matsumoto, “A sequential Monte Carlo algorithm for adaptation to intersession variability in on-line signature verification," presented at the 10th Int. Workshop Front. Handwriting Recognit. (IWFHR 10), La Baule, France, Oct. 2006.

[151] M. Kawamoto, T. Hamamoto, and S. Hangai, "Improvement of on-line signature verification system robust to intersession variability," (Lecture Notes in Computer Science 2359), in Biometric Authentication, M. Tistarelli, J. Bigun, and A. K. Jain, Eds. Berlin, Germany: SpringerVerlag, 2002, pp. 168-175.

[152] H. Ketabdar, J. Richiardi, and Drygajba, "Global feature selection for on-line signature verification," in Proc. Conf. Int. Graphonomics Soc. (IGS 2005), Salerno, Italy, Jun. 26-29, 2005, pp. 59-63.

[153] I. Khan, "The dynamics of signature verification," Biometric Watch, vol. 4, no. 7, Sep. 2006. Available at: http://vega.icu.ac.kr/ autoid/ bbs/tb.php/notice/1

[154] M. K. Khan, M. A. Khan, M. A. U. Khan, and I. Ahmad, "On-line signature verification by exploiting inter-feature dependencies," in Proc. 18th Int. Conf. Pattern Recog. (ICPR 2006), Aug., pp. 796-799.

[155] A. Kholmatov and B. Yanikoglu, "Identity authentication using improved online signature verification method," Pattern Recognit. Lett., vol. 26, pp. 2400-2408, Nov. 2005.

[156] J. H. Kim, J. R. Yu, and S. H. Kim, "Learning of prototypes and decision boundaries for a verification problem having only positive samples," Pattern Recognit. Lett., vol. 17, pp. 691-697, 1996.

[157] S. H. Kim, M. S. Park, and J. Kim, "Applying personalized weights to a feature set for on-line signature verification," in Proc. 3rd Int. Conf. Doc. Anal. Recognit. (ICDAR-3), Montreal, QC, Canada, Aug. 1995, vol. 1, pp. $882-885$

[158] G. V. Kiran, R. S. Kunte, and S. Samuel, "On-line signature verification system using probablistic feature modeling," in Proc. 6th Int. Symp. Signal Process. Appl., Kuala Lampur, Malaysia, 2001, vol. 1, pp. 355358.

[159] Y. Komiya, T. Ohishi, and T. Matsumoto, "A pen input on-line signature verifier integrating position, pressure and inclination trajectories," IEICE Trans. Inf. Syst., vol. E84-D, no. 7, pp. 833-838, Jul. 2001.

[160] S. Krawczyk and A. K. Jain, "Securing electronic medical records using biometric authentication," in Proc. Audio-Video-Based Biometric Person Authentication (AVBPA) 2005, Rye Brook, NY, Jul., pp. 1110-1119.

[161] H. Kwon, E. Ha, and H. Hwang, "Online signature verification based on dynamic feature segmentation and 3-step matching," (Lecture Notes in Computer Science 2690), in Proc. IDEAL 2003, J. Liu et al., Eds. Berlin, Germany: Springer-Verlag, pp. 1062-1065.

[162] H. Y. Kwon, E. Y. Ha, and H. Y. Hwang, "Segmentation based on dynamic features for on-line signature verification," presented at the Int. 12th Turkish Symp. Artif. Intell. Neural Netw. (TAINN), Çanakkale, Turkey, 2003.

[163] K. K. Lau, P. C. Yuen, and Y. Y. Tang, "A new function-based online signature verification method," in Proc. 6th Int. Workshop Front
Handwriting Recognit. (IWFHR-6), Taejon, Korea, 1998, pp. 449454.

[164] K. K. Lau, P. C. Yuen, and Y. Y. Tang, "Stroke extraction and stroke sequence estimation on signatures," in Proc. 16th Int. Conf. Pattern Recog. (ICPR 2002), Quebec, QC, Canada, Aug. 2002, vol. 3, pp. 119 122.

[165] F. Leclerc and R. Plamondon, "Automatic signature verification: The state of the art-1989-1993," Int. J. Pattern Recognit. Artif. Intell. (IJPRAI), vol. 8, no. 3, pp. 643-660, Jun. 1994 [Series in: MPAI, R. Plamondon, Ed. Singapore: World Scientific, 1994, pp. 3-20].

[166] J. Lee, H.-S. Yoon, J. Soh, B. T. Chun, and Y. K. Chung, "Using geometric extrema for segment-to-segment characteristics comparison in online signature verification," Pattern Recognit., vol. 37, no. 1, pp. 93-103, Jan. 2004

[167] L. L. Lee, "Neural approaches for human signature verification," in Proc. 3rd Int. Conf. Doc. Anal. Recognit. (ICDAR-3), IEEE Comput. Soc., Montréal, Canada, Aug. 1995, vol. 1, pp. 1055-1058.

[168] L. L. Lee, "On two-pattern classification and feature selection using neural networks," Int. Conf. Acoust., Speech, Signal Process. (ICASSP '94), Apr., vol. 2, pp. 617-620.

[169] L. L. Lee and T. Berger, "Reliable on-line human signature verification systems for point-of-sales applications," in Proc. 12th IAPR Int. Conf. Pattern Recog. (ICPR), Jerusalem, Israel, 1994, vol. 2, pp. 19-23.

[170] L. L. Lee, T. Berger, and E. Aviczer, "Reliable on-line human signature verification systems," IEEE Trans. Pattern Anal. Mach. Intell. (T-PAMI), vol. 18, no. 6, pp. 643-647, Jun. 1996.

[171] L. L. Lee, M. G. Lizarraga, N. R. Gomes, and A. L. Koerich, "A prototype for Brazilian bankcheck recognition," Int. J. Pattern Recognit. Artif. Intell. (IJPRAI), vol. 11, no. 4, pp. 549-569, 1997 [Automatic Bankcheck Processing (Series in Machine Perception and Artificial Intelligence), vol. 28, S. Impedovo, P. S. P. Wang, and H. Bunke, Eds. Singapore: World Scientific, 1997, pp. 87-108].

[172] W.-S. Lee, N. Mohankrishnan, and M. J. Paulik, "Improved segmentation through dynamic time warping for signature verification using a neural network classifier," in Proc. IEEE Int. Conf. Image Process. (ICIP), Chicago, IL, Oct. 1998, vol. 2, pp. 929-933.

[173] H. Lei, S. Palla, and V. Govindaraju, "Mouse based signature verification for internet based transactions," in Proc. SPIE Symp. Electron. Imag. Sci. Technol. Electron. Imag. Vis., SPIE Proc. Series, San Jose, CA, Jan. 2005, vol. 5673, pp. 153-160.

[174] H. Lei and V. Govindaraju, "A comparative study on the consistency of features in on-line signature verification," Pattern Recognit. Lett., vol. 26, pp. 2483-2489, 2005.

[175] H. Lei, S. Palla, and V. Govindaraju, "ER2 : An intuitive similarity measure for on-line signature verification," in Proc. 9th Int. Workshop Front. Handwriting Recognit. (IWFHR-9), Kichijoji, Japan, Oct. 2004, pp. 191195.

[176] D. Z. Lejtman and S. E. George, "On-line handwritten signature verification using wavelets and back-propagation neural networks," in Proc. 6th Int. Conf. Doc. Anal. Recognit. (ICDAR-6), Seattle, WA, Sep. 2001, pp. 992-996.

[177] J. P. Leszczyska, "On-line signature verification using dynamic time warping with positional coordinates," Proc. SPIE, vol. 6347, pp. 6347241-634724-08, Oct. 2006.

[178] J. S. Lew, "Optimal accelerometer layouts for data recovery in signature verification," IBM J. Res. Dev., vol. 24, pp. 496-511, 1980.

[179] J. S. Lew, "An improved regional correlation algorithm for signature verification which permits small changes between handwriting segments," IBM J. Res. Dev., vol. 27, no. 2, pp. 181-185, Mar. 1983.

[180] B. Li, K. Wang, and D. Zhang, "On-line signature verification based on PCA (principal component analysis) and MCA (minor component analysis)," (Lecture Notes in Computer Science 3072), in ICBA 2004, D. Zhang, A. K. Jain, Eds. Berlin, Germany: Springer-Verlag, 2004, pp. 540-546.

[181] C.-C. Lien, C.-C. Han, and S.-M. Lin, "Personal authentication in video surveillance systems using an on-line signature verification approach," in Biometric Technol. Human Identification II, A. K. Jain and N. K. Ratha, Eds., Proc. SPIE, vol. 5779, pp. 354-362, Mar. 2005

[182] C.-F. Lin and C.-W. Chen, "A new approach to the verification of Chinese signatures with variant orientations and scales using relaxation and statespace search methods," Pattern Recognit., vol. 31, no. 6, pp. 665-674, 1998.

[183] C.-L. Liu, R.-W. Dai, and Y.-J. Liu, "Extracting individual features from moments for Chinese writer identification," in Proc. 3rd Int. Conf. Doc. Anal. Recognit., IEEE Comput. Soc., Montréal, QC, Canada, Aug. 1995, vol. 1, pp. 438-441.

[184] H. Lv, W. Wang, C. Wang, and Q. Zhuo, "Offline Chinese signature verification based on support vector machines," Pattern Recognit. Lett., vol. 26, pp. 2390-2399, 2005.

[185] V. K. Madasu, M. Hafizuddin, M. Yusof, M. Hanmandlu, and K. Kubik, "Offline signature verification and forgery detection system based 
on fuzzy modeling," (Lecture Notes in Artificial Intelligence 2903), in AI 2003, T. D. Gedeon and L. C. C. Fung, Eds. Berlin, Germany: SpringerVerlag, 2003, pp. 1003-1013.

[186] R. Martens and L. Claesen, "On-line signature verification by dynamic time-warping," in Proc. 13th Int. Conf. Pattern Recog. (ICPR96), Vienna, Austria, 1996, pp. 38-42.

[187] R. Martens and L. Claesen, "Dynamic programming optimisation for on-line signature verification," in Proc. 4th Int. Conf. Doc. Anal. Recognit. (ICDAR-4), IEEE Comput. Soc., Ulm, Germany, Aug. 1997, vol. 2, pp. 653-656.

[188] R. Martens and L. Claesen, "On-line signature verification: Discrimination emphasised," in Proc. 4th Int. Conf. Doc. Anal. Recognit. (ICDAR4), IEEE Comput. Soc., Ulm, Germany, Aug. 1997, vol. 2, pp. 657660.

[189] R. Martens and L. Claesen, "Incorporating local consistency information into the online signature verification process," Int. J. Doc. Anal. Recognit. (IJDAR), vol. 1, no. 2, pp. 110-115, 1998.

[190] R. Martens and L. Claesen, "Utilizing baum-welch for on-line signature verification," in Proc. 6th Int. Workshop Front. Handwriting Recognit. (IWFHR-6), Taejon, Korea, 1998, pp. 389-397.

[191] J. C. Martinez-Romo and R. A. Silva, "Optimal prototype functions of features for online signature verification," Int. J. Pattern Recognit. Artif. Intell. (IJPRAI), vol. 18, no. 7, pp. 1189-1206, 2004.

[192] T. Matsuura and S. Yamamoto, "Signature verification using distribution of angular direction of pen-point movement," in Proc. 6th Int. Workshop Front. Handwriting Recognit. (IWFHR-6), Taejon, Korea, 1998, pp. 537545.

[193] T. Matsuura and T. S. Yu, "On-line signature verification by IIR system," presented at the 5th Int. Workshop on Front. Handwriting Recognition (IWFHR-5). Colchester, U.K., Sep. 1996, [Progress in Handwriting Recognition, A. C. Downton and S. Impedovo, Eds. Singapore: World Scientific, 1997, pp. 413-416].

[194] D. K. McCormack, B. M. Brown, and J. F. Pedersen, "Neural network signature verification using Haar wavelet and Fourier transforms," Proc. SPIE, vol. 2064, pp. 14-25, Aug. 1993.

[195] D. K. McCormack and J. F. Pedersen, "Handwritten static signature verification performed using wavelet transforms and neural networks," Proc. SPIE, vol. 3391, pp. 577-586, Mar. 1998.

[196] B. Miller, "Vital signs of identity," IEEE Spectr., vol. 31, no. 2, pp. 22 30, Feb. 1994.

[197] M. Ma and W. S. Wijesoma, "Automatic online signature verification based on multiple models," in Proc. IEEE/IAFE/INFORMS Conf. Comput. Intell. Finan. Eng., 2000, pp. 30-33.

[198] M. Ma, W. S. Wijesoma, and E. Sung, "An automatic on-line signature verification system based on three models," in Proc. Can. Conf. Elect. Comp. Eng., 2000, pp. 890-894.

[199] Y. Mizukami, M. Yoshimura, H. Miike, and I. Yoshimura, "An offline signature verification system using an extracted displacement function," in Proc. 5th Int. Conf. Doc. Anal. Recognit. (ICDAR-5), Bangalore, India, Sep. 1999, vol. 1, pp. 757-760.

[200] Y. Mizukami, K. Tadamura, M. Yoshimura, and I. Yoshimura, "Statistical displacement analysis for handwriting verification," in Lecture Notes in Computer Science, vol. 3617. New York: Springer-Verlag, 2005, pp. 1174-1181.

[201] N. Mohankrishnan, W.-S. Lee, and M. J. Paulik, "A performance evaluation of a new signature verification algorithm using realistic forgeries," in Proc. Int. Conf. Image Process. (ICIP), 1999, pp. 575-579.

[202] N. Mohankrishnan, M. J. Paulik, and M. Khalil, "On-line signature verification using a nonstationary autoregressive model representation," in Proc. IEEE Int. Symp. Circuits Syst., Chicago, IL, 1993, pp. 23032306.

[203] M. L. Molina, N. A. Arias, and O. Gualdron, "Verification of the authenticity of handwritten signature using structure neural-network-type OCON," Proc. SPIE, vol. 5622, pp. 218-223, Oct. 2004.

[204] M. L. Molina, N. A. Arias, and J. Meneses, "Verification of handwritten signature using three-dimensional correlation," Proc. SPIE, vol. 4829, pp. 200-201, Nov. 2003.

[205] H. Morita, D. Sakamoto, T. Ohishi, Y. Komiya, and T. Matsumoto, "Online signature verifier incorporating pen position, pen pressure, and pen inclination trajectories," (Lecture Notes in Computer Science 2091), in AVBPA 2001, J. Bigun and F. Smeraldi, Eds. Berlin, Germany: SpringerVerlag, 2001, pp. 318-323.

[206] S. Mozaffari, K. Faez, and F. Faradji, "One-dimensional fractal coder for online signature recognition," in Proc. 18th Int. Conf. Pattern Recog. (ICPR'06), Aug. 2006, pp. 857-860.

[207] M. E. Munich, P. Perona, "Camera-based ID verification by signature tracking," (Lecture Notes in Computer Science 1406), in 5th European Conference on Computer Vision (ECCV), vol. 1, H. Burkhardt and B. Neumann, Eds. Berlin, Germany: Springer-Verlag, 1998, pp. $782-796$.

[208] M. E. Munich and P. Perona, "Continuous dynamic time warping for translation-invariant curve alignment with applications to signature verification," in Proc. 7th Int. Conf. Comput. Vis., Corfu, Greece, Sep. 1999, vol. 1, pp. 108-115.

[209] M. E. Munich and P. Perona, "Visual signature verification using affine arc-length," in Proc. IEEE CS Conf. Comput. Vis. Pattern Recog., 1999, pp. $180-186$.

[210] M. E. Munich and P. Perona, "Visual input for pen-based computers," IEEE Trans. Pattern Anal. Mach. Intell. (T-PAMI), vol. 24, no. 3, pp. 313328, Mar. 2002

[211] M.E. Munich and P. Perona, "Visual identification by signature tracking," IEEE Trans. Pattern Anal. Mach. Intell. (T-PAMI), vol. 25, no. 2, pp. 200217, Feb. 2003

[212] D. Muramatsu, M. Kondo, M. Sasaki, S. Tachibana, and T. Matsumoto, "A Markov chain Monte Carlo algorithm for Bayesian dynamic signature verification," IEEE Trans. Inf. Forensics Secur., vol. 1, no. 1, pp. 22-34, Mar. 2006.

[213] D. Muramatsu and T. Matsumoto, "An HMM on-line signature verification algorithm," (Lecture Notes in Computer Science 2688), in AVBPA 2003, J. Kittler and M. S. Nixon, Eds. Berlin, Germany: Springer-Verlag, 2003, pp. 233-241.

[214] D. Muramatsu and T. Matsumoto, "An HMM on-line signature verifier incorporating signature trajectories," in Proc. 7th Int. Conf. Doc. Anal. Recognit. (ICDAR -7), IEEE Comput. Soc., Edinburgh, U.K., Aug. 2003, pp. $438-442$.

[215] N. A. Murshed, F. Bortolozzi, and R. Sabourin, "Offline signature verification using fuzzy ARTMAP neural network," in Proc. IEEE Int. Conf. Neural Netw., Perth, Australia, Nov./Dec.1995, pp. 2179-2184.

[216] N. A. Murshed, F. Bortolozzi, and R. Sabourin, "Offline signature verification, without a priori knowledge of class $\omega 2$. A new approach," in Proc. 3rd Int. Conf. Doc. Anal. Recognit. (ICDAR-3), Montréal, Canada, Aug. 1995, vol. 1, pp. 191-196.

[217] N. A. Murshed, F. Bortolozzi, and R. Sabourin, "Offline signature verification without requiring random forgeries for training," in Proc. 3rd Int. Comput. Sci. Conf., Hong Kong, Dec. 1995, pp. 107-115.

[218] N. A. Murshed, R. Sabourin, and F. Bortolozzi, "A cognitive approach to offline signature verification," Int. J. Pattern Recognit. Artif. Intell. (IJPRAI), vol. 11, no. 5, pp. 801-825, 1997 [Automatic Bankcheck Processing (Series in Machine Perception and Artificial Intelligence), vol. 28, S. Impedovo, P. S. P. Wang, and H. Bunke, Eds. Singapore: World Scientific, 1997, pp. 339-363].

[219] S. Nabeshima, S. Yamamoto, K. Agusa, and T. Taguchi, "MemoPen: A new input device," in Proc. Int. Conf. Human Factors Comput. Syst. (CHI), 1995, pp. 256-257.

[220] I. Nakanishi, N. Nishiguchi, Y. Itoh, and Y. Fukui, "On-line signature verification based on discrete wavelet domain adaptive signal processing," (Lecture Notes in Computer Science 3072), in ICBA 2004, D. Zhang and A. K. Jain, Eds. Berlin, Germany: Springer-Verlag, 2004, pp. 584591.

[221] I. Nakanishi, N. Nishiguchi, Y. Itoh, and Y. Fukui, "On-line signature verification method utilizing feature extraction based on DWT," in Proc. 2003 Symp. Circuits Syst. (ISCAS '03), May, vol. 4, pp. 73-76.

[222] I. Nakanishi, H. Sakamoto, Y. Itoh, and Y. Fukui, "Multi-matcher online signature verification system in DWT domain," in Proc. Int. Conf. Acoust., Speech Signal Process. (ICASSP 2005), Philadelphia, PA, Mar. 2005, vol. 2, pp. 965-968.

[223] I. Nakanishi, H. Sakamoto, Y. Itoh, and Y. Fukui, "DWT domain multimatcher on-line signature verification system," in Proc. 2005 Symp. Circuits Syst. (ISCAS '05), May, vol. 6, pp. 5413-5416.

[224] V. S. Nalwa, "Automatic on-line signature verification," Proc. IEEE, vol. 85 , no. 2, pp. 215-239, Feb. 1997.

[225] S. Nanavati, M. Thieme, and R. Nanavati, Biometrics: Identity Verification in a Networked World. New York: Wiley, 2002, pp. 123-131.

[226] E.-M. Nel, J. A. du Preez, and B. M. Herbst, "Estimating the pen trajectories of static signature using hidden Markov models," IEEE Trans. Pattern Anal. Mach. Intell. (T-PAMI), vol. 27, no. 11, pp. 1733-1746, Nov. 2005.

[227] W. Nelson, W. Turin, and T. Hastie, "Statistical methods for on-line signature verification," Int. J. Pattern Recognit. Artif. Intell. (IJPRAI), vol. 8, no. 3, pp. 749-770, 1994.

[228] W. F. Nemcek and W. C. Lin, "Experimental investigation of automatic signature verification," IEEE Trans. Syst., Man, Cybern., vol. 4, no. 1, pp. 121-126, Jan. 1974.

[229] E. Newham, "Survey: Signature verification technologies," in Signature Verification. Amsterdam, The Netherlands: Elsevier, Apr. 2000, pp. 8 10.

[230] F. Nouboud "Handwritten signature verification: A global approach," in Fundamentals in Handwriting Recognition, S. Impedovo, Ed. Berlin, Germany: Springer-Verlag, 1994, pp. 455-459.

[231] F. Nouboud and R. Plamondon, "Global parameters and curves for offline signature verification," in Proc. 4th Int. Workshop Front. Handwriting Recognit. (IWFHR-4), Taipei, Taiwan, Dec. 1994, pp. 145-155. 
[232] N. F. O'Brien and S. C. Gustafson, "Real-time signature verification using neural network algorithms to process optically extracted features," Proc. SPIE, vol. 2234, pp. 394-401, Jul. 1994.

[233] T. Ohishi, Y. Komiya, and T. Matsumoto, "An on-line pen input signature verification algorithm," in Proc. IEEE ISPACS, 2000, vol. 2, pp. 589-592.

[234] T. Ohishi, Y. Komiya, and T. Matsumoto, "On-line signature verification using pen-position, pen-pressure and pen-inclination trajectories," in Proc. Int. Conf. Pattern Recog. (ICPR 2000), Barcelona, Spain, Sep., vol. 4 , pp. 547-550.

[235] T. Ohishi, Y. Komiya, H. Morita, and T. Matsumoto, "Pen-input online signature verification with position, pressure, inclination trajectories," in Proc. 15th Int. Parallel Distrib. Process. Symp. (IPDPS-15), San Francisco, CA, Apr. 2001, p. 170.

[236] L. Oliveira, E. J. R. Justino, C. O. A. Freitas, and R. Sabourin, "The graphology applied to signature verification," in Proc. 12th Conf. Int. Graphonomics Soc. (IGS2005), Salerno, Italy, Jun. 2005, pp. 286-290.

[237] S. Omata, "Development of the new digital sign pen system using tactile sensor for handwritten recognition," in Proc. Tech. Dig. 18th Sens. Symp. 2001, Kawasaki, Japan, pp. 131-136.

[238] J. Ortega-Garcia, J. Fierrez-Aguilar, J. Martin-Rello, and J. GonzalezRodriguez, "Complete signal modeling and score normalization for function-based dynamic signature verification," (Lecture Notes in Computer Science 2688), in Audio- and Video-Based Biometric Person Authentication, J. Kittler and M. S. Nixon, Eds. Berlin, Germany: Springer-Verlag, 2003, pp. 658-667.

[239] J. Ortega-Garcia, J. Fierrez-Aguilar, D. Simon, J. Gonzalez, M. Faundez, V. Espinosa, A. Satue, I. Hernaez, J.-J. Igarza, C. Vivaracho, D. Escudero, and Q.-I. Moro, "MCYT baseline corpus: A bimodal biometric database," in Inst. Elect. Eng. Proc. Vis., Image Signal Process., Special Issue Biometrics Internet, Dec. 2003, vol. 150, no. 6, pp. 395401.

[240] J. Ortega-Garcia, J. Gonzalez-Rodriguez, A. Simon-Zorita, and S. Cruz-Llanas, "From biometrics technology to applications regarding face, voice, signature and fingerprint recognition systems," in Biometric Solutions for Authentication in a E-World, D. Zhang, Ed. Norwell, MA: Kluwer, Jul. 2002.

[241] M. Parizeau and R. Plamondon, "A comparative analysis of regional correlation, dynamic time warping, and skeletal tree matching for signature verification," IEEE Trans. Pattern Anal. Mach. Intell. (T-PAMI), vol. 12, no. 7, pp. 710-717, Jul. 1990.

[242] T. Pavlidis, Algorithms for Graphics and Image Processing. Berlin, Germany: Springer-Verlag, 1982.

[243] I. Pavlidis, R. Mavuduru, and N. Papanikolopoulos, "Offline recognition of signatures using revolving active deformable models," in Proc. IEEE Int. Conf. Syst., Man, Cybern., 1994. 'Humans, Inf. Technol'., San Antonio, TX, Oct. 2-5, pp. 771-776.

[244] T. Pavlidis, N. P. Papanikolopoulos, and R. Mavuduru, "Signature identification through the use of deformable structures," Signal Process., vol. 71, no. 2, pp. 187-201, Dec. 1998.

[245] J. D. Penagos, N. Prabhakaran, and S. Wunnava, "An efficient scheme for dynamic signature verification," in Proc. IEEE SouthEastcon Conf. 1996, Tampa, FL, pp. 451-457.

[246] V. Pervoichine and G. Leedham, "Extraction and analysis of forensic document examiner features used for writer identification," Pattern Recognit., vol. 40, pp. 1004-1013, 2007.

[247] P. J. Philips, A. Martin, C. L. Wilson, and M. Przybocki, "An introduction evaluating biometric systems," Computer, vol. 33, no. 2, pp. 56-63, Feb. 2000.

[248] G. Pirlo, "Algorithms for signature verification," in Proc. NATO-ASI Series Fundamentals in Handwriting Recognition, S. Impedovo, Ed. Berlin, Germany: Springer-Verlag, 1994, pp. 433-454.

[249] R. Plamondon, "A model-based dynamic signature verification system," in Proc. NATO-ASI Series Fundamentals in Handwriting Recognition, S. Impedovo, Ed. Berlin, Germany: Springer-Verlag, 1994, pp. 417434.

[250] R. Plamondon, Ed., Progress in Automatic Signature Verification. Singapore: World Scientific, 1994.

[251] R. Plamondon, Eds., "Special issue on automatic signature verification," Int. J. Pattern Recognit. Artif. Intell. (IJPRAI), vol. 8, no. 3, pp. 641-811, Jun. 1994.

[252] R. Plamondon, "The design of an on-line signature verification system: From theory to practice," Int. J. Pattern Recognit. Artif. Intell. (IJPRAI) (Special Issue on Automatic Signature Verification), R. Plamondon, Ed., pp. 155-171 [Progress in Automatic Signature Verification, vol. 8, no. 3, Singapore: World Scientific, 1994, pp. 795-811].

[253] R. Plamondon, "A kinematic theory of rapid human movements: Part I. Movement representation and generation," Biol. Cybern., vol. 72, no. 4, pp. 295-307, 1995.

[254] R. Plamondon, "A kinematic theory of rapid human movements: Part II: Movement time and control," Biol. Cybern., vol. 72, no. 4, pp. 309-320, 1995.
[255] R. Plamondon, "The origin of $2 / 3$ power law," in Proc. 8th Conf. Int. Graphonomics Soc., 1997, pp. 17-20.

[256] R. Plamondon, "A kinematic theory of rapid human movements: Part III: Kinetic outcomes," Biol. Cybern., Jan. 1997.

[257] R. Plamondon, W. Guerfali, and M. Lalonde, "Automatic signature verification: A report on a large-scale public experiment," in Proc. 9th Biennial Conf. Int. Graphonomics Soc., Singapore, 1999, pp. 9-13.

[258] R. Plamondon and G. Lorette, "Automatic signature verification and writer identification-The state of the art," Pattern Recognit., vol. 22, no. 2, pp. 107-131, Jan. 1989.

[259] R. Plamondon and S. N. Srihari, "On-line and offline handwriting recognition: A comprehensive survey," IEEE Trans. Pattern Anal. Mach. Intell., vol. 22, no. 1, pp. 63-84, Jan. 2000.

[260] R. Plamondon, P. Yergeau, and J. J. Brault, "A multi-level signature verification system," in From Pixels to Features III-Frontiers in Handwriting Recognition, S. Impedovo and J. C. Simon, Eds. Amsterdam, The Netherlands: Elsevier, 1992, pp. 363-370.

[261] B. Plimmer, J. Grundy, J. Hosking, and R. Priest, "Inking in the IDE: Experiences with pen-based design and annotation," in Proc. Vis. Lang. Human-Centric Comput., VL/HCC'06, pp. 111-115.

[262] S. Prabhakar, J. Kittler, D. Maltoni, L. O'Gorman, and T. Tan, Eds. "Special issue on biometrics: Progress and directions," IEEE Trans. Pattern Anal. Mach. Intell., vol. 29, no. 4, pp. 513-516, Apr. 2007.

[263] Y. Qi and B. R. Hunt, "Verification of handwritten signature images by multi-resolution wavelet analysis," in Proc. Int. Conf. Pattern Recog. (ICPR), 1993, pp. 6-10.

[264] Y. Qi and B. R. Hunt, "Signature verification using global and grid features," Pattern Recognit., vol. 27, no. 12, pp. 1621-1629, Dec. 1994.

[265] Y. Qi and B. R. Hunt, "A multiresolution approach to computer verification of handwritten signatures," IEEE Trans. Image Process., vol. 4 , no. 6, pp. 870-874, Jun. 1995.

[266] T. Qu, A. El Saddik, and A. Adler, "Dynamic signature verification system using stroke based features," in Proc. IEEE Int. Workshop Haptic, Audio Vis. Environ. Appl. (HAVE2003), Ottawa, ON, Canada, Sep., pp. 83-88.

[267] T. Qu, A. El Saddik, and A. Adler, "A stroke based algorithm for dynamic signature verification," in Proc. Can. Conf. Electr. Comput. Eng., May 2004, vol. 1, pp. 461-464.

[268] Z.-H. Quan, D.-S. Huang, X.-L. Xia, M. R. Lyu, and T.-M. Lok, "Spectrum analysis based on windows with variable widths for online signature verification," in Proc 18th Int. Conf. Pattern Recog. (ICPR 2006), Hong Kong, Aug., pp. 1122-1125.

[269] Z.-H. Quan and K.-H. Liu, "Online signature verification based on the hybrid HMM/ANN model," Int. J. Comput. Sci. Netw. Secur. (IJCSNS), vol. 7, no. 3, pp. 313-321, Mar. 2007.

[270] C. Quek and R. W. Zhou, "Antiforgery: A novel pseudo-outer product based fuzzy neural network driven signature verification system," Pattern Recognit. Lett., vol. 23, no. 14, pp. 1795-1816, Dec. 2002.

[271] L. R. Rabiner and B. H. Juang, "An introduction to hidden Markov models," IEEE ASSP Mag., vol. 3, no. 1, pp. 4-16, Jun. 1986.

[272] L. R. Rabiner and S. E. Levinson, "Isolated and connected word recognition. Theory and selected applications," IEEE Trans. Commun., vol. 29, no. 5, pp. 621-659, May 1981.

[273] S. K. Ramanujan, R. S. Kashi, W. Turin, and W. L. Nelson, "On-line handwritten signature verification using stroke direction coding," Opt. Eng. J., vol. 35, no. 9, pp. 2526-2533, 1996.

[274] V. E. Ramesh and M. N. Murty, "Offline signature verification using genetically optimized weighted features," Pattern Recognit., vol. 32, no. 2, pp. 217-233, Feb. 1999.

[275] T. H. Rhee, S. J. Cho, and J. H. Kim, "On-line signature verification using model-guided segmentation and discriminative feature selection for skilled forgeries," in Proc. 6th Int. Conf. Doc. Anal. Recognit. (ICDAR-6), Seattle, WA, Sep. 2001, pp. 645-649.

[276] J. Richiardi, H. Ketabdar, and A. Drygajlo, "Local and global feature selection for on-line signature verification," in Proc. 8th Int. Conf. Doc. Anal. Recognit. (ICDAR-8), Seoul, Korea, Aug. 2005, vol. 2, pp. 625629.

[277] G. Rigoll and A. Kosmala, "A systematic comparison between online and offline methods for signature verification with hidden Markov models," in Proc. 14th Int. Conf. Pattern Recog. (ICPR-14), Brisbane, Australia, Aug. 1998, vol. 2, pp. 1755-1757.

[278] L. Rragami, M. Gifford, and N. Edwards, "FEATURE, DSV-Questions remain...," Biometric Technol. Today, vol. 11, no. 11, p.7, Nov./Dec. 2003.

[279] G. Russel, J. Hu, A. Biem, A. Heilper, and D. Markman, "Dynamic signature verification using discriminative training," in Proc. 8th Int. Conf. Doc. Anal. Recognit. (ICDAR-8), Seoul, Korea, Aug. 2005, vol. 2, pp. $1260-1264$.

[280] R. Sabourin, "Offline signature verification: Recent advances and perspectives," in Proc. BSDIA 1997, Curitiba, Brazil, Nov., pp. 84-98. 
[281] R. Sabourin, M. Cheriet, and G. Genest, "An extended-shadow-code based approach for offline signature verification," in Proc. 2nd Int. Conf. Doc. Anal. Recognit. (ICDAR-2), Tsukuba Science City, Japan, Oct. 1993, pp. 1-5.

[282] R. Sabourin and J.-P. Drouhard, "Offline signature verification using directional PDF and neural networks," in Proc. 11th Int. Conf. Pattern Recog., Conf. B: Pattern Recog. Methodol. Syst., The Hague, The Netherlands, Aug./Sep. 1992, vol. 2, pp. 321-325.

[283] R. Sabourin, J.-P. Drouhard, and E. S. Wah, "Shape matrices as a mixed shape factor for offline signature verification," in Proc. 4th Int. Conf. Doc. Anal. Recognit. (ICDAR-4), IEEE Comput. Soc., Ulm, Germany, Aug. 1997, vol. 2, pp. 661-665.

[284] R. Sabourin and G. Genest, "An extended-shadow-code based approach for offline signature verification: Part-I-Evaluation of the bar mask definition," in Proc. 12th Int. Conf. Pattern Recog. (ICPR-12), Jerusalem, Israel, Oct. 1994, vol. 2, pp. 450-453.

[285] R. Sabourin and G. Genest, "An extended-shadow-code based approach for offline signature verification: Part-II-Evaluation of several multiclassifier combination strategies," in Proc. 3rd Int. Conf. Doc. Anal. Recognit. (ICDAR-3), IEEE Comput. Soc., Montréal, QC, Canada, Aug. 1995, vol. 1, pp. 197-201.

[286] R. Sabourin, G. Genest, and F. Preteux, "Pattern spectrum as a local shape factor for offline signature verification," in Proc. 13th Int. Conf. Pattern Recog. (ICPR), Vienna, Austria, Aug. 1996, vol. 3, pp. 43-48.

[287] R. Sabourin and R. Plamondon, "Preprocessing of handwritten signature from image gradient analysis," in Proc. 8th Int. Conf. on Pattern Recognit. (ICPR), Paris, 1986, pp. 576-579.

[288] R. Sabourin, G. Genest, and F. J. Prêteux, "Offline signature verification by local granulometric size distributions," IEEE Trans. Pattern Anal. Mach. Intell., vol. 19, no. 9, pp. 976-988, Sep. 1997.

[289] R. Sabourin and R. Plamondon, "Segmentation of handwritten signature images using the statistics of directional data," in Proc. 9th ICPR, Rome, Italy, Nov. 1988, pp. 282-285.

[290] R. Sabourin, R. Plamondon, and L. Beaumier, "Structural interpretation of handwritten signature images" Int. J. Pattern Recognit. Artif. Intell. (IJPRAI). (Special issue on automatic signature verification), R. Plamondon, Ed., pp. 69-108 [Progress in Automatic Signature Verification, vol. 8, no. 3. Singapore: World Scientific, 1994, pp. 709-748].

[291] R. Sabourin, R. Plamondon, and G. Lorette, "Offline identification with handwritten signature images: Survey and perspectives," in Structural Document Image Analysis, H. Baird, H. Bunke, and K. Yamamoto, Eds. New York: Springer-Verlag, 1992, pp. 219-234.

[292] D. Sakamoto, M. Kondo, H. Morita, D. Muramatsu, M. Sasaki, and T. Matsumoto, "Dynamic biometric person authentication using pen signature trajectories," in Proc. 9th Int. Conf. Neural Inf. Process., 2002, vol. 4, pp. 2078-2082.

[293] D. Sakamoto, T. Ohishi, Y. Komiya, H. Morita, and T. Matsumoto, "Online signature verification algorithm incorporating pen position, pen pressure and pen inclination trajectories," in Proc. IEEE ICASSP 2001, vol. 2, pp. 993-996.

[294] C. Sansone and M. Vento, "Signature verification: Increasing performance by a multi-stage system," Pattern Anal. Appl., vol. 3, no. 2, pp. 169-181, 2000.

[295] C. Santos, E. J. R. Justino, F. Bortolozzi, and R. Sabourin, "An offline signature verification method based on the questioned document expert's approach and a neural network classifier," in Proc. 9th Int. Workshop Front. Handwriting Recognit. (IWFHR-9), Kichijoji, Japan, Oct. 2004, pp. 498-502.

[296] Y. Sato and K. Kogure, "On-line signature verification based on shape, motion, and handwriting pressure," in Proc. 6th Int. Conf. Pattern Recog. (ICPR-6), Munich, Germany, Oct. 1982, vol. 2, pp. 823-826.

[297] T. Scheidat, F. Wolf, and C. Vielhauer, "Analyzing handwriting biometrics in metadata context," Proc. SPIE, vol. 6072, pp. 182-193, 2006.

[298] C. Schmidt and K.-F. Kraiss, "Establishment of personalized templates for automatic signature verification," in Proc. 4th Int. Conf. Doc.t Anal. Recognit. (ICDAR-4), IEEE Comput. Soc., Ulm, Germany, Aug. 1997, vol. 1, pp. 263-267.

[299] M. M. Shafiei and H. R. Rabiee, "A new on-line signature verification algorithm using variable length segmentation and hidden Markov models," in Proc. 7th Int. Conf. Doc. Anal. Recognit. (ICDAR-7), IEEE Comput. Soc., Edinburgh, U.K., Aug. 2003, vol. 1, pp. 443-446.

[300] H. Shimizu, S. Kiyono, T. Motoki, and W. Gao, "An electrical pen for signature verification using a two-dimensional optical angle sensor," Sens. Actuators, vol. 111, pp. 216-221, 2004

[301] M. Shridhar, G. Houle, R. Bakker, and F. Kimura, "Real-time featurebased automatic signature verification," presented at the 10th Int. Workshop Front. Handwriting Recognit. (IWFHR 10), La Baule, France, Oct. 2006.

[302] C. Simon, E. Levrat, R. Sabourin, and J. Bremont, "A fuzzy perception for offline handwritten signature verification," presented at the BSDIA 1997, Curitiba, Brazil, Nov.
[303] J. Sita, B. Found, and D. Rogers, "Forensic handwriting examiners' expertise for signature comparison," J. Forensic Sci., vol. 47, pp. 11171124,2002

[304] J. C. Sita, D. Rogers, and B. Found, "Spatial comparison of questioned to specimen signatures using matrix analysis software," in Proc. 11th Conf. Int. Graphonomics Soc., Scottsdale, AZ, 2003, pp. 299-303.

[305] S. N. Srihari, S.-H. Cha, H. Arora, and S. Lee, "Individuality of handwriting," J. Forensic Sci., vol. 47, no. 4, pp. 1-17, Jul. 2002.

[306] S. N. Srihari, C. Huang, H. Srinivasan, and V. Shah, "Biometric and forensic aspects of digital document processing," in Digital Document Processing, B. B. Chaudhuri, Ed. New York: Springer-Verlag, 2007.

[307] S. N. Srihari, S. Shetty, S. Chen, H. Srinivasan, C. Huang, G. Agam, and O. Frieder, "Document image retrieval using signatures as queries," in Proc. 2nd IEEE Conf. Doc. Image Anal. Libr., Lyon, France, Apr. 27-28, 2006, pp. 198-203.

[308] S. N. Srihari, A. Xu, and M. K. Kalera, "Learning strategies and classification methods for offline signature verification," in Proc. 9th Int Workshop Front. Handwriting Recognit. (IWFHR-9), Kichijoji, Japan, Oct. 25-29, 2004, pp. 161-166.

[309] H. Srinivasan, M. Beal, and S. N. Srihari, "Machine learning approaches for person identification and verification," in Proc. SPIE Conf. Homeland Secur., Orlando, FL, Mar. 28-Apr. 1, 2005, pp. 574-586.

[310] H. Srinivasan, S. N. Srihari, and M. Beal, "Signature verification using Kolmogorov-Smirnov statistics," Int. Graphonomics Soc. Conf., Salerno, Italy, Jun. 2005, pp. 574-586.

[311] H. Srinivasan, S. N. Srihari, and M. Beal, "Machine learning for signature verification," (Springer Lecture Notes in Computer Science 4338), in Proc. 5th Indian Conf. Vis., Graph. Image Process. (ICVGIP), Madurai, India, Dec. 2006, pp. 761-775.

[312] J. Sternby, "On-line signature verification by explicit solution to the point correspondence problem," (Lecture Notes in Computer Science 3072) in ICBA 2004, D. Zhang and A. K. Jain, Eds. Berlin, Germany: Springer-Verlag, 2004, pp. 569-576.

[313] A. F. Syukri, E. Okamoto, and M. Mambo, "A user identification system using signature written with mouse," in (Lecture Notes in Computer Science 1438) in ACISP'98, C. Boyd and E. Dawson, Eds. Berlin, Germany: Springer-Verlag, 1998, pp. 403-414

[314] H. Taguchi, K. Kiriyama, E. Tanaka, and K. Fujii, "On-line recognition of handwritten signatures by feature extraction of the pen movements," IEICE Trans., vol. 71, no. 5, pp. 830-840, 1988

[315] K. Tanabe, M. Yoshihara, H. Kameya, S. Mori, S. Omata, and T. Ito, "Automatic signature verification based on the dynamic feature of pressure," in Proc. 6th Int. Conf. Doc. Anal. Recognit. (ICDAR-6), Seattle, WA, Sep. 2001, pp. 1045-1049.

[316] M. Tanaka, Y. Ishino, H. Shimada, T. Inoue, and A. Bargiela, "Determination of decision boundaries for online signature verification," in Kes 2003, (Lecture Notes in Artificial Intelligence 2773), V. Palade, R. J. Howlett, and L. C. Jain, Eds Berlin, Germany: Springer-Verlag, 2003, pp. 401-407.

[317] A. S. Tolba, "GloveSignature: A virtual-reality-based system for dynamic signature verification," Digit. Signal Process., vol. 9, no. 4, pp. 241-266, Oct. 1999.

[318] K. Ueda, "Investigation of offline Japanese signature verification using a pattern matching," in Proc. 7th Int. Conf. Doc. Anal. Recognit. (ICDAR-7), IEEE Comput. Soc., Edinburgh, U.K., Aug. 2003, vol. 2, pp. $951-955$.

[319] U. Uludag, S. Pankanti, S. Prabhakar, and A. K. Jain, "Biometric cryptosystems: Issues and challenges," Proc. IEEE, vol. 92, no. 6, pp. 948960, Jun. 2004

[320] O. Urèche and R. Plamondon, "Document transport, transfer, and exchange, security and commercial aspects," in Proc. ICDAR 1999 Bangalore, India, Sep., pp. 585-588.

[321] S. Garcia-Salicetti and B. Dorizzi, "On using the Viterbi path along with HMM likelihood information for online signature verification," IEEE Trans. Syst., Man, Cybern. B, vol. 37, no. 5, pp. 1237-1247, Oct. 2007.

[322] K. Veeramacheneni, L. A. Osadciw, and P. K. Varshney, "An adaptive multimodal biometric management algorithm," IEEE Trans. Syst., Man, Cybern. C, vol. 35, no. 3, pp. 344-356, Aug. 2005.

[323] A. Vergara da Silva and D. Santana deFreitas, "Wavelet-based compared to function-based on-line signature verification," in Proc. XV Brazilian Symp. Comput. Graph. Image Process. (SIBGRAPI -XV), Fortaleza, Brazil, Oct. 2002, p. 218.

[324] C. Vielhauer and L. C. Ferri, "Applications of a hologram watermarking protocol: Aging-aware biometric signature verification and time validity check with personal documents," Proc. SPIE, vol. 5020, pp. 240-248, Jun. 2003.

[325] C. Vielhauer and J. Dittmann, Biometrics for User Authentication: Encyclopedia of Multimedia, B. Furth, Ed. Berlin, Germany.

[326] C. Vielhauer, "A behavioural biometrics," Public Service Rev.: Eur. Union, vol. 20, no. 9, pp. 113-115, 2005. 
[327] A. Wahl, J. Hennebert, A. Humm, and R. Ingold "Generation and evaluation of brute-force signature forgeries," in Proc. Workshop Multimedia Content Representation, Classification Secur. (MRCS 2006), Istanbul, Turkey, Sep. 2006, pp. 2-9.

[328] L. Wan, Z. Lin, and R.-C. Zhao, "Offline signature verification incorporating the prior model," in Proc. Int. Conf. Mach. Learn. Cybern. (ICMLC2003), Xi' an, China, Nov., pp. 1602-1606.

[329] L. Wan, Z. Lin, and R.-C. Zhao, "Signature verification using integrated classifiers," presented at the 4th Chinese Conf. Biometric Recogn. (Sinobiometrics 2003), Beijing, China, Dec. 7-8.

[330] S. Watanabe, T. Furuhashi, K. Obata, and Y. Uchikawa, "A study on feature extraction using a fuzzy net for offline signature recognition," in Proc. Int. Joint Conf. Neural Netw., 1993, pp. 2857-2858.

[331] S. Watanabe, T. Furuhashi, K. Obata, and Y. Uchikawa, "An offline signature recognition using a fuzzy net," Trans. Inst. Elect. Eng. Japan, vol. 114-D, no. 6, pp. 674-679, 1994.

[332] C. J. Wen, M. W. Chang, B. S. Jeng, and H. F. Yau, "Signature verification based on distortion measure and spectral correlation," Proc. SPIE, vol. 2564, pp. 252-260, Aug. 1995.

[333] T. Wessels and C. W. Omlin, "A hybrid system for signature verification," in Proc. Int. Joint Conf. Neural Netw. (IJCNN 2000), Como, Italy, Jul., vol. 5, pp. 509-514.

[334] W. S. Wijesoma, M. Mingming, and E. Sung, "Selecting optimal personalized features for on-line signature verification using GA," in Proc. IEEE Int. Conf. Syst., Man, Cybern., 2000, vol. 4, pp. 2740 2745.

[335] W. S. Wijesoma, M. Mingming, and K. W. Yue, "On-line signature verification using a computational intelligence approach," (Lecture Notes in Computer Science), in Fuzzy Days 2001, vol. 2206, B. Reusch, Ed. Berlin, Germany: Springer-Verlag, 2001, pp. 699-711.

[336] W. S. Wijesoma, K. W. Yue, K. L. Chien, and T. K. Chow, "Online handwritten signature verification for electronic commerce over the internet," (Lecture Notes in Artificial Intelligence 2198),WI 2001. N. Zhong et al. Eds. Berlin, Germany: Springer-Verlag, 2001, pp. 227-236.

[337] M. Wirotius, J.-Y. Ramel, and N. Vincent, "Selection of points for on-line signature comparison," in Proc. 9th Int. Workshop Front. Handwriting Recognit. (IWFHR-9), Kichijoji, Japan, Oct. 2004, pp. 503-508.

[338] M. Wirotius, J.-Y. Ramel, and N. Vincent, "Comparison of point selection for characterizing on-line signature," in Biometric Technology for Human Identification II, Proc. SPIE, vol. 5779, A. K. Jain and N. K. Ratha, Eds., Mar. 2005, pp. 307-313

[339] B. Wirtz, "Stroke-based time warping for signature verification," in Proc. 3rd Int. Conf. Doc. Anal. Recognit. (ICDAR-3), Montreal, QC, Canada, Aug. 1995, vol. 1, pp. 179-182.

[340] B. Wirtz, "Average prototypes for stroke-based signature verification," in Proc. 4th Int. Conf. Doc. Anal. Recognit. (ICDAR-4), Ulm, Germany, Aug. 1997, vol. 1, pp. 268-272.

[341] B. Wirtz, "Technical evaluation of biometric systems," presented at the ACCU 1998, Hong Kong.

[342] F. Wolf, T. K. Basu, P. K. Dutta, C. Vielhauer, A. Oermann, and B. Yegnanarayana, "A cross-cultural evaluation framework for behavioral biometric user authentication," in Data and Information Analysis to Knowledge Engineering. New York: Springer-Verlag, 2005, pp. 654-661.

[343] Q.-Z. Wu, I.-C. Jou, B.-S. Jeng, N.-J. Cheng, S.-S. Huang, P.-Y. Ting, D.-M. Shieh, and C.-J. Wen, "On-line signature verification using neural networks," in Proc. Int. Symp. Artif. Neural Netw., Taiwan, China, Dec. 1994, pp. 478-482.

[344] Q.-Z. Wu, I.-C. Jou, B.-S. Jeng, N.-J. Cheng, S.-S. Huang, P.-Y. Ting, D.-M. Shieh, and C.-J. Wen, "On the distortion measurement of online signature verification," in Proc. 4th Int. Workshop Front. Handwriting Recognit. (IWFHR-4), Taipei, Taiwan, Dec. 1994, pp. 347353.

[345] Q.-Z. Wu, I.-C. Jou, and S.-Y. Lee, "Online signature verification using LPC cepstrum and neural networks," IEEE Trans. Syst., Man, Cybern. B: Cybern., vol. 27, no. 1, pp. 148-153, Feb. 1997.

[346] Q.-Z. Wu, S.-Y. Lee, and I.-C. Jou, "On-line signature verification based on split-and-merge matching mechanism," Pattern Recognit. Lett., vol. 18, no. 7, pp. 665-673, Jul. 1997.

[347] Q.-Z. Wu, S.-Y. Lee, and I.-C. Jou, "On-line signature verification based on logarithmic spectrum," Pattern Recognit., vol. 31, no. 12, pp. 18651871, Dec. 1998.

[348] Q. Xiao, "Technology review-Biometrics-technology, application, challenge, and computational intelligence solutions," IEEE Comput. Intell. Mag., vol. 2, no. 2, pp. 5-25, May 2007.

[349] X.-H. Xiao and R.-W. Dai, "On-line Chinese signature verification by matching dynamic and structural features with a quasi-relaxation approach," presented at the 5th Int. Workshop Front. Handwriting Recognit. (IWFHR-5), Colchester, U.K., Sep. 1996 [Progress in Handwriting Recognition, A. C. Downton and S. Impedovo, Eds. Singapore: World Scientific, 1997, pp. 353-356]
[350] X.-H. Xiao and G. Leedham, "Signature verification by neural networks with selective attention," Appl. Intell., vol. 11, pp. 213-223, 1999.

[351] X.-H. Xiao and G. Leedham, "Signature verification using a modified Bayesian network," Pattern Recognit., vol. 35, no. 5, pp. 983-995, May 2002.

[352] Y. Xuhua, T. Furuhashi, K. Obata, and Y. Uchikawa, "A study on signature verification using a new approach to generic based machine learning," in Proc. IEEE Int. Conf. Syst., Man, Cybern., Intell. Syst. 21st Century, 1995, vol. 5, pp. 4383-4386.

[353] Y. Xuhua, T. Furuhashi, K. Obata, and Y. Uchikawa, "Constructing a high performance signature verification system using a GA method," in Proc 2nd New Zealand Two-Stream Int. Conf. Artif. Neural Netw. Expert Syst. (ANNES '95), Dunedin, New Zealand, Nov. 20-23, 1995, pp. 170173.

[354] Y. Xuhua, T. Furuhashi, K. Obata, and Y. Uchikawa, "Selection of features for signature verification using the genetic algorithm," Comput. Ind. Eng., vol. 30, no. 4, pp. 1037-1045, 1996.

[355] T. Yamasaki and T. Hattori, "A new data tablet system for handwriting characters and drawing based on image processing," in Proc. Int. Conf. Syst., Man, Cybern., 1996, pp. 428-431.

[356] Z. Yang and C.-C. J. Kuo, "Automatic signature verification based on the wavelet descriptor," Proc. SPIE, vol. 3460, pp. 618-629, Oct 1998.

[357] L. Yang, B. K. Widjaja, and R. Prasad, "Application of hidden Markov models for signature verification," Pattern Recognit., vol. 28, no. 2, pp. 161-170, Feb. 1995.

[358] X. Ye, W. Hou, and W. Feng, "Offline handwritten signature verification with inflections features," in Proc. IEEE Int. Conf. Mechatron. Autom., Jul. 29-Aug. 1, 2005, pp. 787-792.

[359] O. A. Yedekcoglu, M. B. Akban, and Y. H. Lim, "Offline signature verification with thickened templates," in Proc. 5th Int. Conf. Adv. Commun. Control (COMCON 5), Crete, Greece, 1995, pp. 131-142.

[360] D.-Y. Yeung, H. Chang, Y. Xiong, S. George, R. Kashi, T. Matsumoto, and G. Rigoll, "SVC2004: First international signature verification competition," (Lecture Notes in Computer Science 3072), in ICBA 2004, D. Zhang and A. K. Jain, Eds. Berlin, Germany: Springer-Verlag, 2004, pp. 16-22.

[361] J. Yi, C. Lee, and J. Kim, "Online signature verification using temporal shift estimated by the phase of Gabor filter," IEEE Trans. Signal Process., vol. 53, no. 2, pp. 776-783, Feb. 2005

[362] H. S. Yoon, J. Y. Lee, and H. S. Yang, "An on-line signature verification system using hidden Markov model in polar space," in Proc. 8th Int. Workshop Front. Handwriting Recognit. (IWFHR-8), Ontario, Canada, Aug. 2002, pp. 329-333.

[363] I. Yoshimura and M. Yoshimura, "On-line signature verification incorporating the direction of pen movement-An experimental examination of the effectiveness," in From Pixels to Features III-Frontiers in Handwriting Recognition, S. Impedovo and J. C. Simon, Eds. North-Holland, The Netherlands: Elsevier Publishing, 1992, pp. 353-362.

[364] I. Yoshimura and M. Yoshimura, "Offline verification of Japanese signature after elimination of background patterns," Int. J. Pattern Recognit. Artif. Intell. (IJPRAI), vol. 8, no. 3, pp. 693-708, 1994.

[365] I. Yoshimura, M. Yoshimura, and T. Tsukamoto, "Investigation of an automatic verification system for Japanese countersignatures on traver's cheques," in Proc. 7th Int. Biennial Conf. Int. Graphonomics Soc. (IGS-7), 1995, pp. 86-87.

[366] M. Yoshimura, Y. Kato, S.-I. Matsuda, and I. Yoshimura, "On-line signature verification incorporating the direction of pen movement," IEICE Trans., vol. E-74, no. 7, pp. 2083-2092, Jul. 1991.

[367] M. Yoshimura and I. Yoshimura, "Investigation of a verification system for Japanese countersignatures on traveler's checks," Trans. IEICE, vol. J80-D-II, no. 7, pp. 1764-1773, 1997.

[368] K. Yu, Y. Wang, and T. Tan, "Writer identification using dynamic features," (Lecture Notes in Computer Science 3072) in Proc. Ist Int. Conf. Biometric Authentication (ICBA 2004), Hong Kong, China, D. Zhang and A. K. Jain, Eds., pp. 512-518.

[369] K. W. Yue and W. S. Wijesoma, "Improved segmentation and segment association for on-line signature verification," in Proc. IEEE Int. Conf. Syst., Man, Cybern., 2000, vol. 4, pp. 2752-2756.

[370] D. Zhang, J. P. Campbell, D. Maltoni, and R. M. Bolle, Eds., "Special issue on biometric systems," IEEE Trans. Syst., Man Cybern. C, vol. 35, no. 3, pp. 273-275, Aug. 2005

[371] K. Zhang, E. Nyssen, and H. Sahli, "A multi-stage online signature verification system," Pattern Anal. Appl., vol. 5, pp. 288-295, 2002.

[372] K. Zhang, I. Pratikakis, J. Cornelis, and E. Nyssen, "Using landmarks to establish a point-to-point correspondence between signatures," Pattern Anal. Appl., vol. 3, no. 1, pp. 69-75, 2000.

[373] P. Zhao, A. Higashi, and Y. Sato, "On-line signature verification by adaptively weighted DP matching," IEICE Trans. Inf. Syst., vol. E79-D, no. 5, pp. 535-541, May 1996. 
[374] A. Zhukov, M. Vaqquez, and Garcia-Beneytez, "Magnetoelastic sensor for signature identification based on mechanomagnetic effect in amorphous wires," J. Phys., vol. 4, no. 8, pp. 763-766, 1998.

[375] A. Zimmer and L. L. Ling, "A hybrid on/off line handwritten signature verification system," in Proc. 7th Int. Conf. Doc. Anal. Recognit. (ICDAR-7), Edinburgh, U.K., Aug. 2003, vol. 1, pp. 424-428.

[376] A. Zimmer and L. L. Ling, "A window-based hybrid signature verification system," (Lecture Notes in Computer Science 3072), in ICBA 2004, D. Zhang and A. K. Jain, Eds. Berlin, Germany: Springer-Verlag, 2004, pp. 562-568.

[377] F. Zoebisch and C. Vielhauer, "A test tool to support brut-force online and offline signature forgery tests on mobile devices," in Proc. IEEE Int. Conf. Multimedia Expo 2003 (ICME), Baltimore, MD, vol. 3, pp. 225228.

[378] E. N. Zois, A. A. Nassiopoulos, and V. Anastassopuolos, "Signature verification based on line directionality," in Proc. IEEE Workshop Signal Process. Syst. Design Implementation, Nov. 2-4, 2005, pp. 343-346.

[379] M. Zou, J. Tong, C. Liu, and Z. Lou, "On-line signature verification using local shape analysis," in Proc. 7th Int. Conf. Doc. Anal. Recognit. (ICDAR-7), vol. 1, Edinburgh, U.K., Aug. 2003, pp. 314-318.

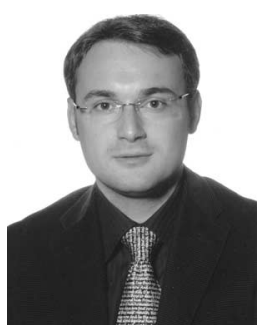

Donato Impedovo received the B.Eng. degree (cum laude) in information engineering in 2005 from the Polytechnic of Bari, Bari, Italy, where he is currently working toward the Ph.D. degree in engineering information.

He was with the Italian Interuniversity Consortium of Computer Science. He is a member of the Centro "Rete Puglia," Università degli Studi di Bari, Bari. His current research interests include pattern recognition and e-learning.

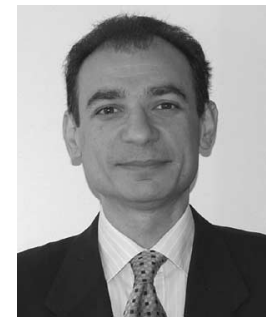

Giuseppe Pirlo (M'08) received the Comput. Sci. degree (cum laude) from the University of Bari, Bari, Italy, in 1986.

He is engaged in research in the field of pattern recognition and image analysis. Since 1991, he has been an Assistant Professor in the Department of Computer Science, University of Bari, where he is currently an Associate Professor. He is also with the Centro "Rete Puglia," Università degli Studi di Bari, Bari. His current research interests include areas of pattern recognition, image analysis, intelligent systems, computer arithmetic, communication, and multimedia technologies. $\mathrm{He}$ has developed several scientific projects and is the author or coauthor of over 100 published papers in the field of document analysis and processing, handwriting recognition, automatic signature verification, parallel architectures for computing, communication, and multimedia technologies for collaborative work and distance learning.

Prof. Pirlo is a member of the International Association for Pattern Recognition TC11 (Technical Committee on "Reading Systems"). In 1988, he received a fellowship from the International Business Machines Corporation. 